\title{
ELEMENTO ÓPTICO DIFRATIVO DE LUZ BRANCA GERADO POR COMPUTADOR
}

Cristhiane Gonçalves

Dissertação de mestrado apresentada à

Escola de Engenharia de São Carlos da

Universidade de São Paulo, como parte

dos requisitos para obtenção do título de

mestre em Engenharia Elétrica, na área

de Telecomunicações.

ORIENTADOR: Prof. Dr. Luiz

Gonçalves Neto

São Carlos

2007 
Dedicatória

“À minha mãe, minha primeira e grande professora”. 
Agradecimentos

Ao professor Dr. Luiz Gonçalves Neto, pela orientação e amizade durante a elaboração deste trabalho.

À Coordenadoria de Aperfeiçoamento de Pessoal de Nível Superior, CAPES, pela bolsa de estudos concedida.

A todos os colegas, professores e funcionários do Departamento de Engenharia Elétrica da EESC/USP pela colaboração e amizade.

Ao Dr. José Carlos Pizolato Junior, pelo apoio e auxílio durante a execução deste trabalho.

A meus pais, José Carlos e Rosely, aos quais agradeço pela compreensão, paciência e apoio oferecido para a conclusão de meus estudos. 


\section{SUMÁRIO}

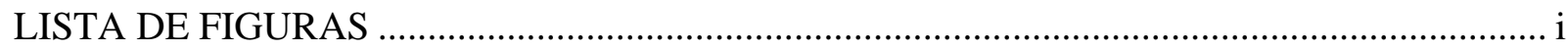

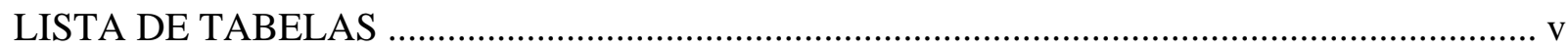

LISTA DE ABREVIATURAS E SIGLAS …...................................................................... vi

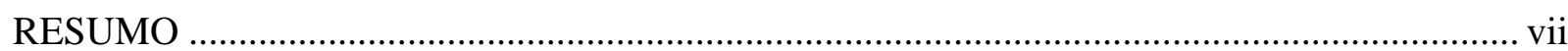

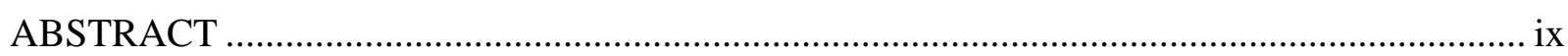

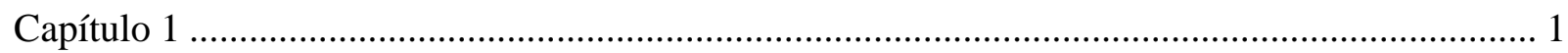

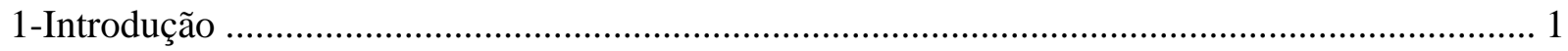

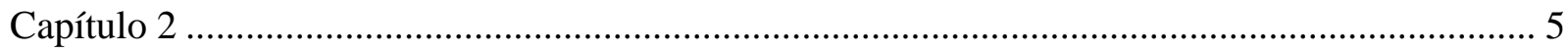

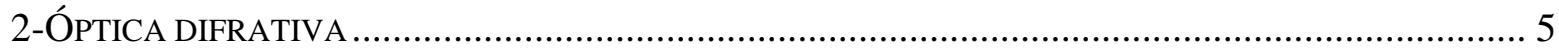

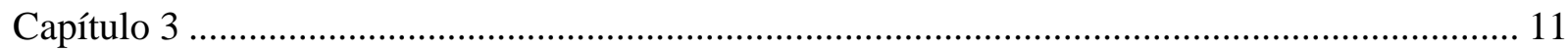

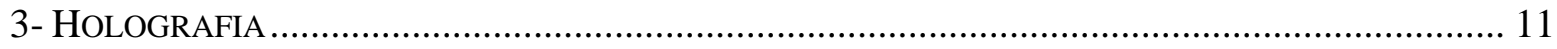

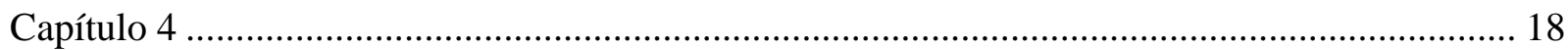

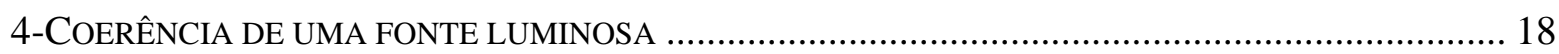

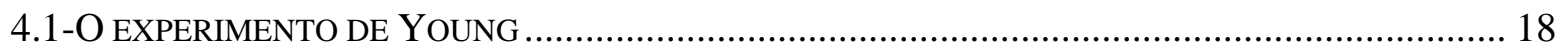

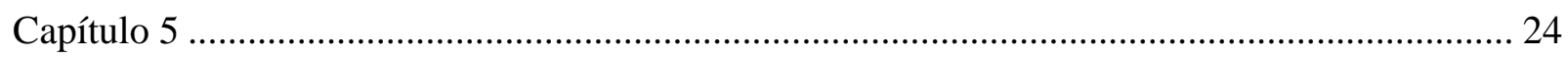

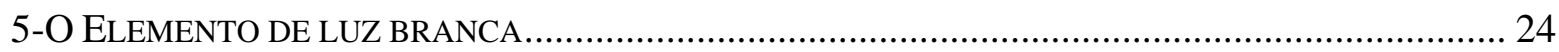

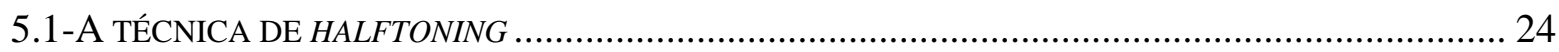

5.2-PROCESSO DE CODIFICAÇÃO DO ELEMENTO DE LUZ BRANCA .............................................. 26

5.3-SIMULAÇÃO E FUNCIONAMENTO DO ELEMENTO DE LUZ BRANCA …....................................... 27

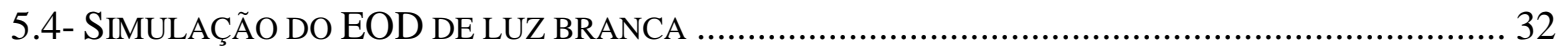

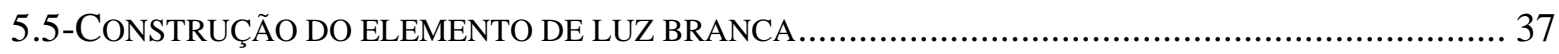

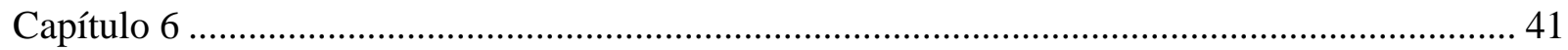




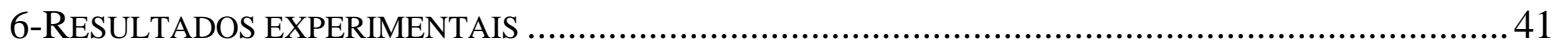

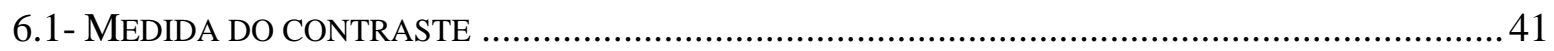

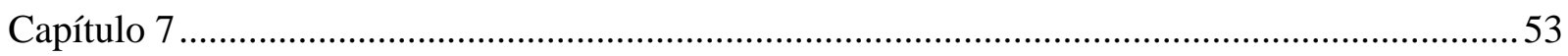

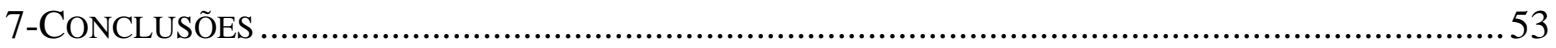

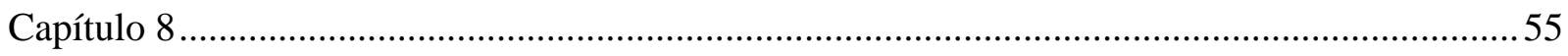

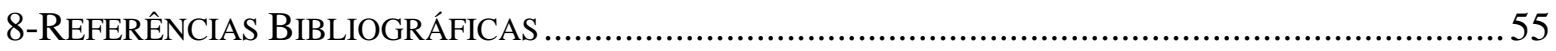

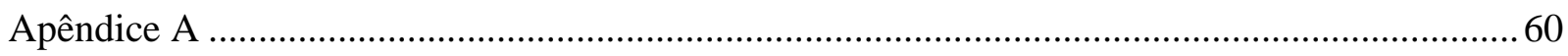

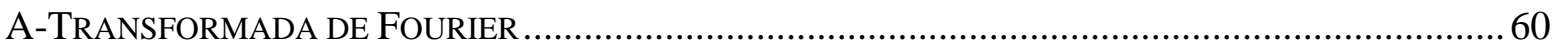

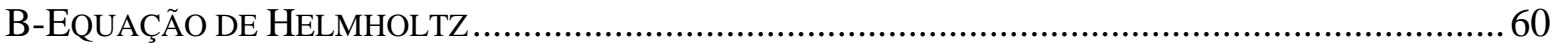

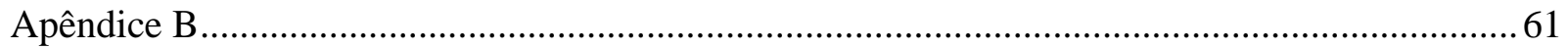

RESPOSTA IMPULSIONAL, FUNÇÃO TRANSFERÊNCIA, E SISTEMAS LINEARES INVARIANTES...........61

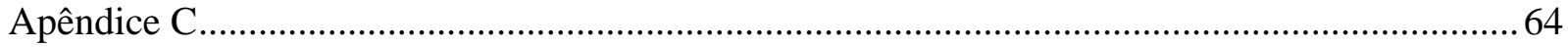

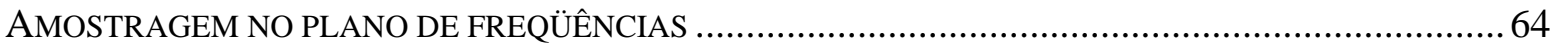

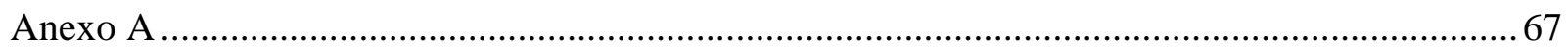

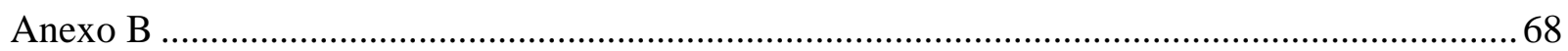




\section{LISTA DE FIGURAS}

FIGURA 1- Princípio de Huygens-Fresnel [33], onde cada ponto de uma frente de onda incidente age como uma nova fonte de onda esférica, cuja interferência construtiva ou destrutiva de cada onda esférica por sua vez nos dá uma nova frente de onda.

FIGURA 2-Obtenção de uma distribuição de luz desejada utilizando-se um Elemento Óptico Difrativo para a modulação de uma frente de luz incidente.

FIGURA 3- Os EODs podem ser classificados em três grupos [34]: (a) espaço-livre para espaço-livre; (b) onda-guiada para onda-guiada; e (c) onda-guiada para espaço-livre (ou espaço-livre para onda-guiada).

FIGURA 4- (a)Holograma rainbow convencional, (b) cédula monetária de 20 reais, emitida pelo Banco do Brasil, utilizando um holograma rainbow como elemento de identificação; e (c) detalhe do holograma impresso na cédula de 20 reais.No holograma, são vistas duas imagens do mico-leão-dourado e da inscrição "20".

FIGURA 5- Comparação entre a Holografia Clássica e a Holografia Computacional.

FIGURA 6- Reconstrução óptica de um EOD iluminado por uma onda plana monocromática coerente. (A) Reconstrução de um holograma de Fourier (difração de Fraunhofer) utilizando-se uma lente de Fourier; (B) Reconstrução de um holograma de Fresnel (difração de Fresnel), obtido pela propagação da luz de $g\left(x^{\prime}, y^{\prime}\right)$ pela distância $d[20]$. 
FIGURA 7-Diagrama esquemático do método iterativo da transformada de Fourier (Iterative Fourier Transform Algorithm - IFTA) para o cálculos de hologramas em regime de modulação de fase ou de amplitude, com a reconstrução em intensidade [42].

FIGURA 8-Janela de reconstrução, localizada no centro do plano de reconstrução, utilizada para melhorar a reconstrução do holograma. Fora da região $g_{r}$ de dimensões $A \times B$, a fase e a amplitude da distribuição $g(x, y)$ pode variar livremente [42].

FIGURA 9-Difração da luz por duas fendas, produzindo máximos e mínimos de intensidade luminosa, observados como franjas de interferência claras e escuras. 18

FIGURA 10-Diferença de caminhos entre dois feixes de luz que incidem na parte inferior e superior da fenda, em destaque.

FIGURA 11-Relação entre a distância entre dois pontos espacialmente coerentes emergindo de uma fonte luminosa de diâmetro $\rho$, de comprimento de onda $\bar{\lambda}$, a uma distância $\mathrm{R}$ de propagação.

FIGURA 12(a)- Imagem original de Lenna 128x128 pixels;(b) Imagem obtida a partir da imagem original

FIGURA 13- Técnica de halftoning aplicada a uma imagem com 17 níveis de cinza................. 25

FIGURA 14-Projeto do EOD para uma informação binária ...................................................... 26

FIGURA 15-Diagrama do algoritmo para o cálculo da propagação da luz modulada pelos ........ 27

FIGURA 16-(a)pixel tipo I e (b)sua respectiva intensidade de propagação.................................. 28

FIGURA 17- (a)Pixel tipo II e (b) intensidade de propagação do pixel tipo II........................... 28

FIGURA 18-(a) Modelo proposto para o pixel tipo I ; (b) sua representação como função rect $(x)$ e (c) sua transformada de Fourier, $\sin c(s)$ 
FIGURA 19- Modelo para o pixel tipo II e (b) sua representação como função $-\frac{1}{2} \prod\left(x+\frac{1}{2}\right)+\frac{1}{2} \prod\left(x-\frac{1}{2}\right) ; \quad$ e $\quad$ (c)sua transformada de Fourier, $-i \sin c(s) \sin c(\pi \mathrm{s})$

FIGURA 20- Diagrama de blocos do algoritmo para cálculo da resposta impulsional dospixels tipo I.

FIGURA 21- Diagrama de blocos do algoritmo para cálculo da resposta impulsional dos pixels tipo II

FIGURA 22- Reconstrução simulada para o holograma gerado a partir da figura Lenna para uma distância do plano do holograma ao plano de reconstrução de (a) $0 \mathrm{~cm}$ e (b) $2 \mathrm{~cm}$......

FIGURA 23- Figuras utilizadas no algoritmo para gerar o holograma de luz branca: (a) Lenna; (b) tigre, (c) periquito; (d) gato.

FIGURA 24- Reconstrução simulada para o holograma gerado a partir das figuras (a)Lenna, (b) tigre, (c) periquito e (d) gato, para uma distância do plano do holograma ao plano de reconstrução de $2 \mathrm{~cm}$. Estas figuras são as mesmas utilizadas para a fabricação do elemento de luz branca.

FIGURA 25- Visão esquemática da seqüência do processo de fabricação do EOD no modo transmissão. Devido ao baixo custo de fabricação foi utilizada uma máscara que consiste de um filme transparente tipo fotolito. O padrão a ser transferido foi impresso no filme transparente por uma plotter com máxima definição $15 \mu \mathrm{m}$ ( AGFA AVANTRA 30e 2400 dpi ). Nenhuma máscara gerada por feixe de elétrons é necessária. 
iv

FIGURA 26- Montagem do holograma de luz branca realizada no laboratório de óptica do departamento de engenharia elétrica da EESC-USP. No plano posterior, observa-se o anteparo, onde a imagem é projetada.

FIGURA 27- Lâmpada dicróica halógena $12 \mathrm{~V}, 50 \mathrm{~W}, \bar{\lambda}=633 \mathrm{~nm}$, da marca OSRAM, utilizada para obtenção da reconstrução óptica do elemento de luz branca.

FIGURA 28-Montagem experimental para cálculo do grau de coerência realizada através de três metodologias: difração por uma fenda dupla, difração através de uma grade de difração e difração através do elemento de luz branca.

FIGURA 29- Reconstruções ópticas geradas a partir do elemento de luz branca "Lenna" utilizando: (a) lâmpada dicróica somente; e lâmpada dicróica com filtros (b) vermelho; (c) verde e (d) azul.

FIGURA 30- Reconstruções ópticas geradas a partir do elemento de luz branca "gato" utilizando: (a) lâmpada dicróica somente; e lâmpada dicróica com filtros (b) vermelho; (c) verde e (d) azul. 48

FIGURA 31- Reconstruções ópticas geradas a partir do elemento de luz branca "tigre" utilizando: (a) lâmpada dicróica somente; e lâmpada dicróica com filtros (b) vermelho; (c) verde e (d) azul. 49

FIGURA 32- Reconstruções ópticas geradas a partir do elemento de luz branca "periquito" utilizando: (a) lâmpada dicróica somente; e lâmpada dicróica com filtros (b) vermelho; (c) verde e (d) azul. 


\section{LISTA DE TABELAS}

TABELA I. Contrastes determinados através da difração por uma grade de difração obtido com a fonte de luz branca separadamente e com filtros vermelho, verde e azul 43

TABELA II. Contrastes determinados através da difração por uma fenda dupla obtido com a fonte de luz branca separadamente e com filtros vermelho, verde e azul. .44

TABELA III.(a) Contrastes determinados através da difração pelo elemento de luz branca Lenna obtidos com a fonte de luz branca separadamente e com filtros vermelho, verde e azul. 44

TABELA III.(b) Contrastes determinados através da difração pelo elemento de luz branca gato obtidos com a fonte de luz branca separadamente e com filtros vermelho, verde e azul. .45

TABELA III.(c) Contrastes determinados através da difração pelo elemento de luz branca tigre obtidos com a fonte de luz branca separadamente e com filtros vermelho, verde e azul. .45

TABELA III.(d) Contrastes determinados através da difração pelo elemento de luz branca periquito obtidos com a fonte de luz branca separadamente e com filtros vermelho, verde e azul. .46 
vi

LISTA DE ABREVIATURAS E SIGLAS

CAPES - Coordenadoria de Aperfeiçoamento de Pessoal de Nível Superior

EESC - Escola de Engenharia de São Carlos

EOD - Elemento Óptico Difrativo

FFT - Fast Fourier Transform

FT- Fourier Transform

IFTA - Iterative Fourier Transform Algorithm

USP-Universidade de São Paulo

POLI- Escola Politécnica da USP 


\section{RESUMO}

\section{Palavras-chave: hologramas gerados por computador, luz branca, halftoning.}

Hologramas podem ser produzidos utilizando-se técnicas tradicionais de holografia ou podem ser gerados também por computador, conhecidos como hologramas gerados por computador(HGCs). A maioria destes hologramas opera usando luz monocromática. Por outro lado, os hologramas podem também operar com luz branca. Estes elementos de luz branca são usados em diversas aplicações, como segurança, para verificar a autenticidade dos cartões de crédito e outros documentos, porque seus processos de fabricação são difíceis e caros de serem reproduzidos. Entretanto, os hologramas de luz branca convencionais operam baseados na reflexão da luz, e apresentam alguns efeitos indesejáveis, como distorções cromáticas, como o efeito rainbow.

Neste trabalho foi proposto um elemento óptico difrativo de luz branca gerado por computador. O elemento é calculado baseado na técnica de halftoning e na coerência espacial parcial de uma fonte de luz branca estendida. Os elementos da fase são produzidos através de técnicas de fabricação bem estabelecidas de circuitos integrados, e as simulações óticas são apresentadas. Não há necessidade de métodos iterativos.

Os resultados das reconstruções ópticas e simuladas deste elemento de luz branca são muito semelhantes e produzem imagens nítidas, não sendo observadas distorções cromáticas.

O elemento de luz branca ainda não foi descrito na literatura, e algumas de suas aplicações podem ser um correlator óptico ou arte holográfica. 
viii

Este trabalho foi realizado no laboratório de óptica do departamento da engenharia elétrica do EESC, e financiado por CAPES (Coordenadoria de Aperfeiçoamento de Pessoal de Nível Superior). 


\section{ABSTRACT}

\section{Keywords: Computer -generated holograms, white light, halftoning.}

Holograms can be produced using traditional holography techniques or may be also generated by computer, wich are known as $\mathrm{CGHs(Computer-generated} \mathrm{holograms).} \mathrm{Most}$ of these holograms operate using monochromatic light. On the other hand, holograms can also operate with white light. These white light holograms are used in several applications, such as security, to verify the autencity of credit cards end other documents, because their fabrication processes are dificult to reproduce and are expensive. However, convencional white light holograms operate based on reflection of light, and present some undesirable effects, like chromatic distortions, such as rainbow effect.

In this work it was proposed a computer-generated phase optical difractive element designed to operate under white light illumination. The element is calculated based on the halftoning technique and in the partial spatial coherence of a white light extended source. Phase elements are manufactured using well-established integrated circuits fabrication techniques and optical simulations are shown. No iterative methods are necessary.

Simulated and optical reconstructions results are very similar and produce good clear images, and no chromatic distortions are observed.

The white light element was not yet described on literature, and some of its applications may be an optical correlator or holographic art.

This work was carried at the laboratory of optics of the department of electrical engineering of the EESC, and supported by CAPES (Coordenadoria de Aperfeiçoamento de Pessoal de Nível Superior). 


\section{Capítulo 1}

\section{1-Introdução}

A técnica de holografia clássica foi proposta por Gabor [1], em 1948, ao observar que uma frente de onda de referência em coerência com a luz difratada ou espalhada por um objeto permite que as informações de amplitude e de fase das ondas difratadas sejam gravadas. Esta mesma técnica foi utilizada por Denisyuk [2] e Benton [3] utilizando iluminação não-coerente na fabricação de hologramas. Denisyuk combinou as técnicas de holografia convencional de Gabor e de fotografia colorida para a produção de hologramas que poderiam ser vistos através de uma iluminação não-coerente de um bulbo incandescente. Já os hologramas de Benton, também conhecidos como hologramas rainbow, empregavam a iluminação não-coerente de uma luz branca para visualizar o holograma. Estes hologramas minimizavam o efeito de distorções cromáticas, porém ocorria perda de informação gravada em uma dimensão.

Após a descoberta do laser nos anos 60, trabalhos de holografia convencional que utilizavam como fonte de iluminação coerente de um laser foram divulgados [4-6]. Além dos métodos holográficos convencionais, vários outros foram propostos para o cálculo de hologramas gerados por computador ( HGCs ), entre eles o algoritmo iterativo da transformada de Fourier (Iterative Fourier Transform Algorithm - IFTA), introduzido na holografia digital por Gerchberg \& Saxton [7] e por Hirsh et al. [8]; o desvio de fase de Brown \& Lohmann [9-11]; o holograma binário sintético em amplitude de Lee [12]; a pesquisa binária direta, de Seldowitz et al. [13]; o holograma com modulação de densidade de pulso de Hanck \& Bryngdahl [14] e a quantização iterativa de hologramas de amplitude digital de Wyrowski [15].

O IFTA foi posteriormente modificado por Wyrowski [15-17], que implementou neste algoritmo o conceito de liberdade de fase durante as iterações para o cálculo de hologramas com 
modulação em níveis discretos. Infelizmente, este método numérico requer várias iterações, além de geralmente introduzir ruído do tipo speckle no plano de reconstrução [18,19].

Neto et al. [20] propuseram a implementação de hologramas digitais de modulação completa de amplitude e fase. Cada pixel do elemento é composto por duas regiões de relevo de fase que podem assumir valores de fase 0 e $\pi / 2, \pi / 2$ e $\pi, \pi$ e $3 \pi / 2$, ou $3 \pi / 2$ e 0 . A modulação de amplitude é obtida removendo pequenas partes de uma camada de alumínio depositada sobre o relevo de fase de cada pixel.

Hologramas gerados por computador obtidos por halftoning [21] foram investigados por Ishioka [22], Caulfield [23] e Pinhasi [24], porém esta técnica foi utilizada para gerar uma máscara utilizada para produção de hologramas operando em iluminação monocromática coerente. Recentemente, Pizolato et al. [25] utilizaram a técnica de halftoning para projetar hologramas de fase binários que funcionam com iluminação coerente. Cada pixel é constituído por duas regiões de relevo de fase que podem assumir valores de fase 0 e $\pi$. O projeto deste EOD dispensa cálculos iterativos computacionais e a fabricação do mesmo é realizada utilizando técnicas tradicionais de circuitos integrados.

A maioria dos trabalhos recentes que abordam holografia computacional utilizando luz branca descreve hologramas rainbow reconstruídos a partir da superposição de imagens de projeção de três ou mais hologramas produzidos em três cores diferentes [26,27]. Neste trabalho é proposto um EOD gerado por computador baseado na técnica de halftoning que utiliza iluminação não-coerente [28,29](vide anexos A e B). Este EOD apresenta as seguintes vantagens em relação aos trabalhos até então publicados: o método para a geração do EOD não utiliza processos computacionais iterativos e as imagens reproduzidas não apresentam distorções cromáticas visíveis ao olho humano. Estes EODs correspondem a elementos de fase binários e são produzidos através de técnicas de fabricação bem estabelecidas de circuitos integrados. $\mathrm{O}$ 
EOD de luz branca aqui proposto pode ser empregado em processamento óptico, sistemas de segurança para verificação da autenticidade de documentos, cartões de crédito e processos de fabricação de produtos.

A apresentação do trabalho está organizada conforme a seqüência. No Capítulo 2 são explicados alguns conceitos sobre elementos ópticos difrativos (EOD) e difração. O Capítulo 3 aborda os hologramas clássicos e digitais, que são um tipo de EOD. No Capítulo 4 são abordados os tópicos de coerência de uma fonte de onda luminosa. O Capítulo 5 apresenta o EOD de luz branca abordando projeto, funcionamento e construção. No Capítulo 6 são apresentados resultados experimentais da reconstrução óptica obtida com o EOD de luz branca proposto. Conclusões e considerações sobre o trabalho são realizadas no Capítulo 7. Referências bibliográficas são apontadas no Capítulo 8. 


\section{Capítulo 2}

\section{Introdução}

O EOD apresentado neste trabalho funciona segundo os princípios da óptica difrativa. Neste capítulo serão apresentados os conceitos fundamentais de difração e óptica difrativa.

\section{2-Óptica difrativa}

A óptica difrativa ou óptica binária [30] é uma nova tecnologia que elimina quase todas as etapas dos métodos tradicionais (abrasão e polimento) para a fabricação de elementos ópticos. Por operarem segundo os princípios da difração, estes elementos ópticos são denominados Elementos Ópticos Difrativos (EOD) [31].

Elementos ópticos difrativos são estruturas que difratam a luz, gerando uma distribuição de luz desejada. Segundo o princípio de Huygens-Fresnel [32,33], ilustrado na Figura 1, quando um elemento óptico difrativo é iluminado por uma frente de onda. Cada ponto da nova frente de onda $\sum$ que emerge da superfície do elemento age como uma fonte de luz pontual, gerando ondas esféricas de raio r'. A interferência construtiva ou destrutiva de cada onda esférica gera uma nova frente de onda $\sum$ '. 


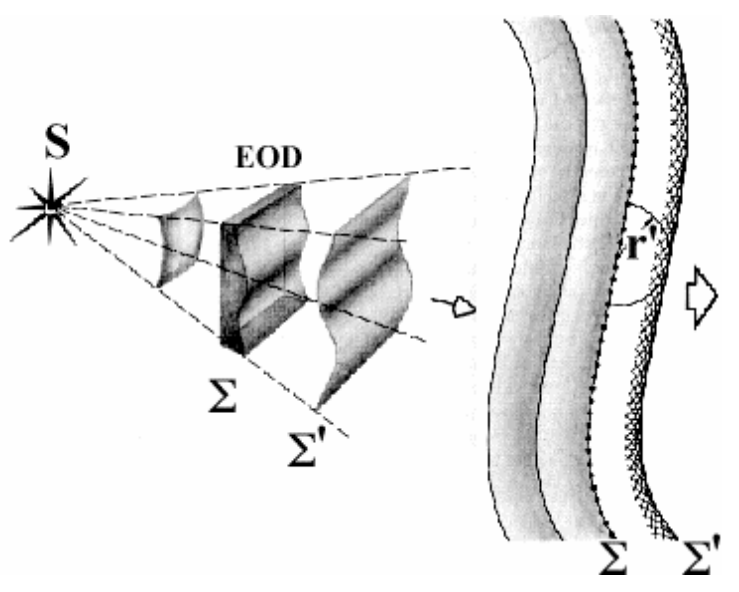

FIGURA 1- Princípio de Huygens-Fresnel [33], onde cada ponto de uma frente de onda incidente age como uma nova fonte de onda esférica, cuja interferência construtiva ou destrutiva de cada onda esférica por sua vez nos dá uma nova frente de onda.

Hologramas gerados por computador, redes de difração e microlentes de Fresnel são alguns exemplos de EODs que podem ser obtidos por intermédio de relevos gravados na superfície de um material transparente ou reflexivo, ou por padrões gravados em filmes fotográficos. Estes relevos ou padrões impõem uma modulação espacial na fase da luz incidente [30] que, após sofrer o efeito da difração, resulta em uma distribuição luminosa desejada em algum plano próximo do elemento difrativo, como é ilustrado na Figura 2. Geralmente, por ser necessário apenas introduzir um pequeno atraso na fase ou o bloqueio em cada ponto da frente de onda incidente, os EODs podem ser mais finos e leves que os elementos ópticos convencionais (refrativos). 


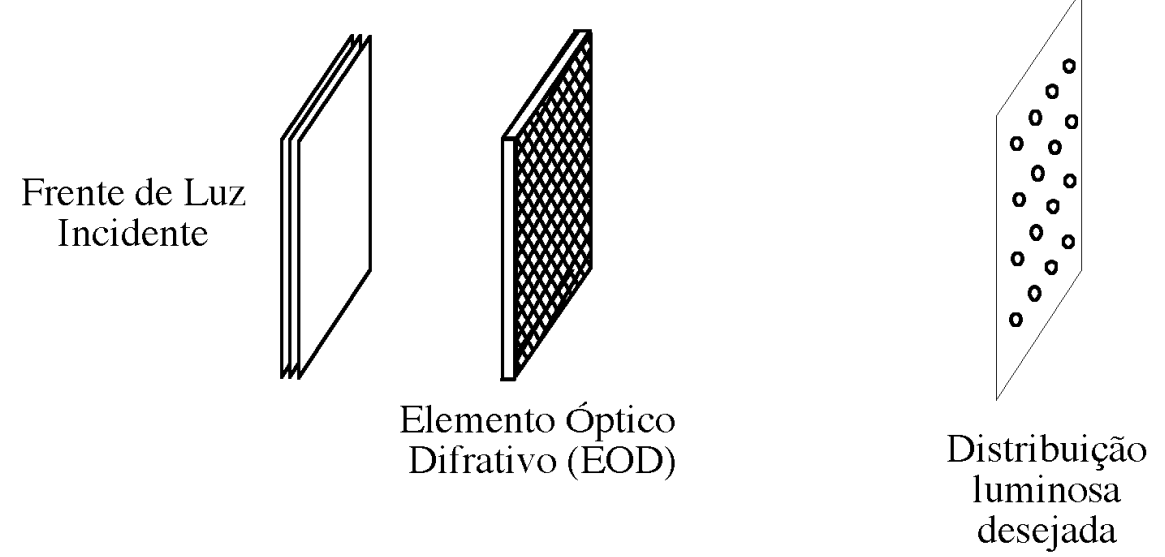

FIGURA 2-Obtenção de uma distribuição de luz desejada utilizando-se um Elemento Óptico Difrativo para a modulação de uma frente de luz incidente.

Os EODs são projetados com base nas propriedades de difração de sua superfície, geralmente uma interface micro-estruturada com detalhes geométricos próximos ao comprimento de onda da luz. Como geralmente é utilizada a teoria escalar da difração [18] para o cálculo destes elementos, as dimensões das micro-estruturas abordadas são maiores que $10 \lambda$, onde $\lambda$ é o comprimento de onda da luz incidente. Várias distribuições ópticas podem ser "gravadas" em um EOD modificando-se a geometria das microestruturas, que podem ser fabricadas utilizando as técnicas inicialmente desenvolvidas para a fabricação de circuitos integrados eletrônicos: litografia óptica, corrosão por plasma, deposição de filmes finos, corrosão úmida e litografia por feixe de elétrons. Estas técnicas podem gravar diretamente na superfície de qualquer material óptico as mais variadas geometrias, em dimensões extremamente reduzidas. Podem-se produzir dispositivos de alta qualidade em série, com propriedades ópticas complexas e impossíveis de serem implementadas com a tecnologia tradicional. A geometria dos elementos é obtida por cálculo numérico, considerando a difração da luz, as características ópticas do material utilizado (óxido de silício, nitreto de silício, $D L C$, etc.) e das micro-estruturas a serem projetadas. 

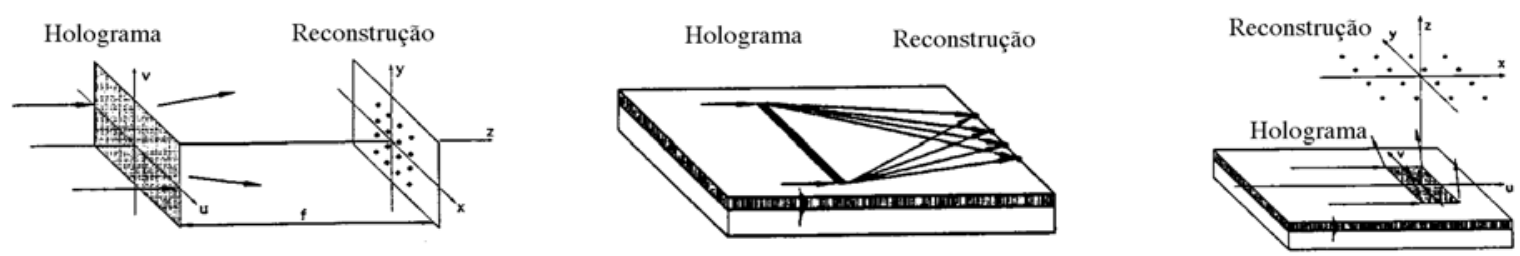

FIGURA 3- Os EODs podem ser classificados em três grupos [34]: (a) espaço-livre para espaço-livre; (b) onda-guiada para onda-guiada; e (c) onda-guiada para espaço-livre (ou espaço-livre para onda-guiada).

De acordo com as características de entrada e saída das ondas, os EODs podem ser classificados em três grupos [34]: (1) espaço-livre para espaço-livre; (2) onda-guiada para onda guiada; e (3) onda-guiada para espaço-livre (ou espaço-livre para onda-guiada). Exemplos destes três tipos de EODs são ilustrados com hologramas na Figura 3. Os hologramas do tipo (1) são chamados de espaço-livre para espaço-livre pois nenhuma onda guiada está envolvida. Por outro lado, guias de onda ópticos estão envolvidos nos grupos (2) e (3).

Entre as inúmeras aplicações desta tecnologia podem-se citar: fabricação de microlentes para sistemas de visão artificial [35], implementação de multiplexadores e demultiplexadores de luz [36], filtros holográficos para aplicações em reconhecimento de objetos e alvos [37,38], conexões ópticas e distribuição de sinais de relógio em micro-circuitos [38], correção da aberração cromática em sistemas ópticos [30,35], modulação e correção da luz laser; redes de difração; acoplamento entre laser e fibras ópticas [34] acoplamento entre fibra óptica e sensores [34], guias de onda [34,39], discos holográficos para a armazenagem de informações [31].

Dentre os EODs estão os hologramas rainbow [40] que podem ser replicados em larga escala utilizando técnica de embossing de baixo custo. Com esta metodologia, os hologramas podem ser replicados a um custo muito baixo. O primeiro passo da técnica é gravar um 
holograma com um objeto de interesse, em fotorresiste. Posteriormente, um laser é utilizado em processo de gravação, e o fotorresiste é exposto, produzindo um relevo que é coberto com um spray de prata. Esta máscara é imersa em um tanque com um eletrodo de níquel e uma corrente passa através do mesmo, depositando uma fina camada de níquel sobre a mesma, através de um processo de eletrodeposição. Esta camada de níquel é separada do fotorresiste e este relevo metálico criado é utilizado como uma espécie de carimbo no processo de reprodução.

Entre os processos de embossing muito conhecidos está o hot-embossing. Por este motivo, estes EODs foram rapidamente difundidos em aplicações de segurança na forma de selos holográficos para a verificação da autenticidade de produtos como cartões de créditos, livros, revistas, cédulas monetárias, CDs e DVDs. Na Figura 4 são ilustrados alguns exemplos de hologramas rainbow utilizados na verificação da autenticidade de cartões de crédito e cédulas monetárias.

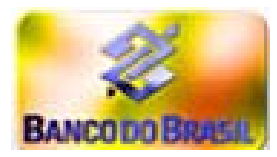

(a)

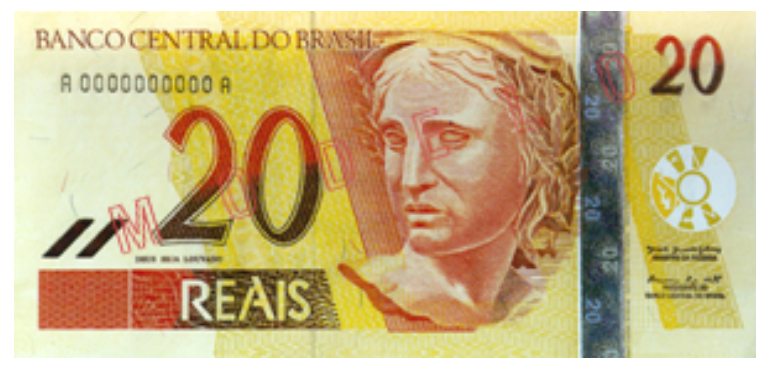

(b)

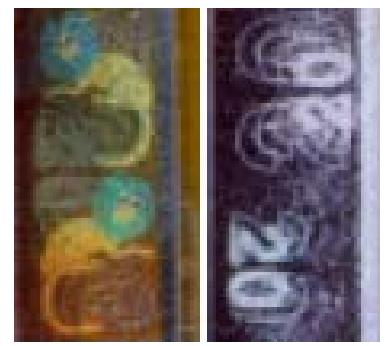

(c)

FIGURA 4- (a)Holograma rainbow convencional, (b) cédula monetária de 20 reais, emitida pelo Banco do

Brasil, utilizando um holograma rainbow como elemento de identificação; e (c) detalhe do holograma impresso na cédula de 20 reais.No holograma, são vistas duas imagens do mico-leão-dourado e da inscrição "20". 
Neste trabalho, os esforços foram centrados para o domínio da teoria, projeto e fabricação de EODs envolvidos no grupo (1): hologramas gerados por computador do tipo espaço-livre para espaço-livre, como ilustrado pela Figura 3(a) submetidos a iluminação não-coerente (luz branca por exemplo), com baixa distorção cromática e baixo custo de produção. 


\section{Capítulo 3}

\section{Introdução}

O EOD de luz branca abordado neste trabalho é um elemento óptico difrativo gerado por computador, que funciona sob iluminação parcialmente coerente em uma região localizada. Neste capítulo são apresentadas as diferenças básicas entre holografia clássica e digital. Atenção especial será dedicada aos hologramas gerados por computador.

\section{3- Holografia}

Na Holografia Clássica, as ondas de uma frente de luz são "armazenadas" em um holograma utilizando a interferência como processo de gravação. Na holografia computacional, as ondas são "armazenadas sinteticamente" no holograma utilizando cálculos computacionais. Em ambos os processos, a reconstrução óptica das ondas gravadas é obtida pela difração da luz. A Figura 5 apresenta o diagrama de blocos indicando a diferença entre os processos [41]. 
Holografia Clássica

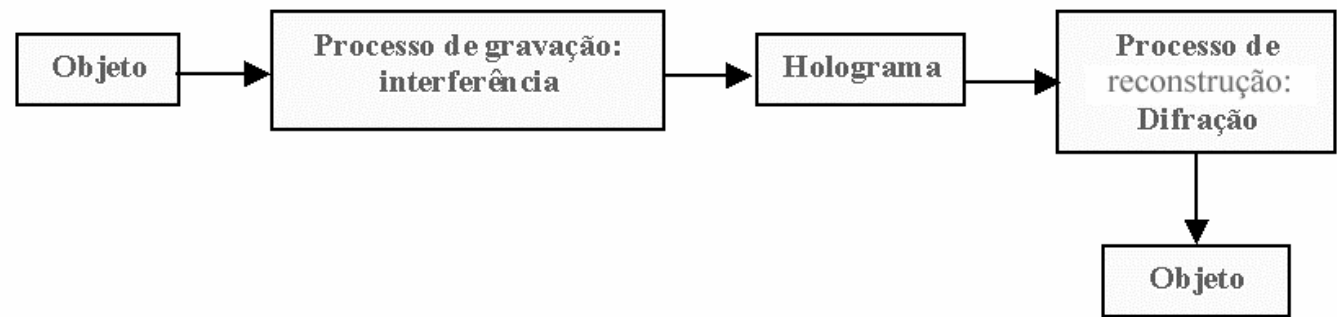

Holografia Computacional

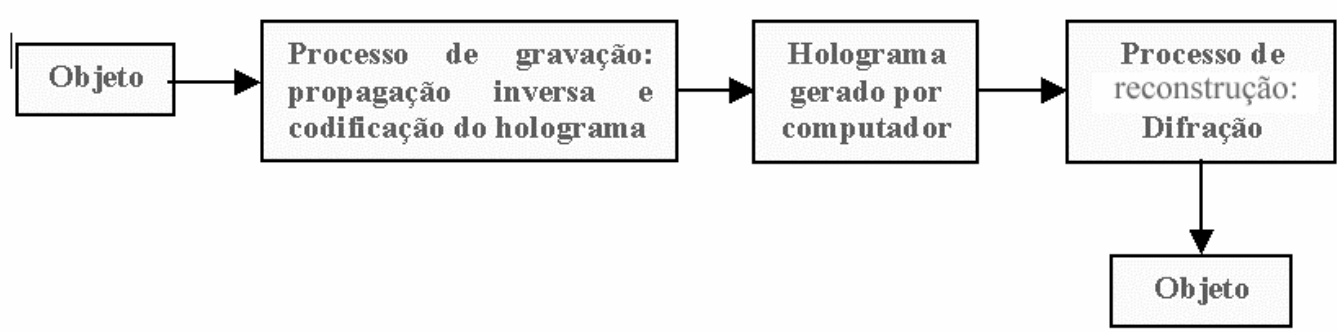

FIGURA 5- Comparação entre a Holografia Clássica e a Holografia Computacional.

Os hologramas gerados por computador são projetados por cálculo computacional considerando a difração escalar da luz [18], as características ópticas do meio em que o holograma será fabricado, que poderá ser uma distribuição de fase ou amplitude, e as características da distribuição de luz no plano de reconstrução do holograma.

É possível escolher entre o projeto de um holograma de Fourier ou de Fresnel. Um holograma de Fourier utiliza a difração de Fraunhofer para o cálculo da propagação da luz do plano do holograma ao plano de reconstrução, que também é implementada opticamente utilizando-se uma lente de Fourier para se obter a reconstrução óptica, como mostrado na Figura 6(a). Um holograma de Fresnel utiliza a difração de Fresnel ou a filtragem espacial para o cálculo da propagação da luz no espaço livre entre o plano do holograma ao plano de reconstrução óptica, como mostrado na Figura 6(b). O cálculo da difração pela filtragem espacial 
12

é realizado considerando a solução da equação de Helmholtz (vide Apêndice A) no domínio da frequência [32].

Se o holograma é iluminado por uma onda plana monocromática uniforme e coerente, com distribuição espacial de amplitudes igual a 1, logo após o holograma a distribuição de luz possui a forma: $1 \times g\left(x^{\prime}, y^{\prime}\right)=g\left(x^{\prime}, y^{\prime}\right)$. A propagação da luz da distribuição $g\left(x^{\prime}, y^{\prime}\right)$ resulta na distribuição óptica $g(x, y)$, localizada no plano de reconstrução.

No cálculo do holograma, as seguintes etapas devem ser consideradas:

a) Determinação da distribuição $g\left(x^{\prime}, y^{\prime}\right)$ que deve ser gerada no plano do holograma. $\mathrm{O}$ cálculo desta distribuição começa pelo cálculo da propagação inversa da distribuição de luz $f(x, y)$ a partir do plano de reconstrução, indo ao plano do Holograma. Pretende-se determinar uma distribuição $g\left(x^{\prime}, y^{\prime}\right)$ que gere o mais fielmente possível a reconstrução $g(x, y)$ a distribuição $f(x, y)$, com $0 \leq|f(x, y)| \leq 1$ e $0 \leq \alpha|g(x, y)| \leq 1$, onde $\alpha$ é um fator de escala real e positivo. A distribuição $f(x, y)$ precisa estar disponível de forma a permitir a manipulação computacional (geralmente valores discretos de amplitude). 

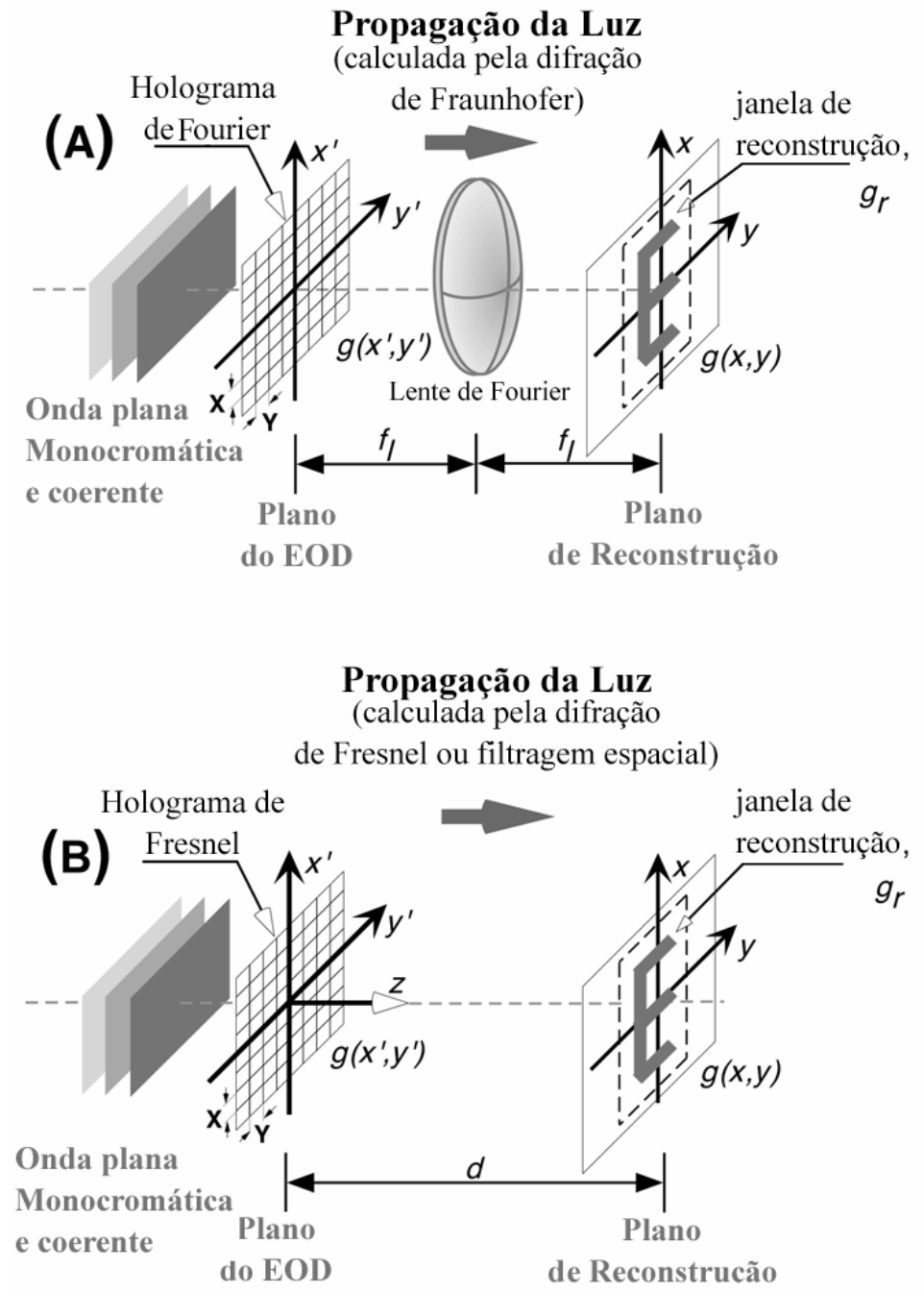

FIGURA 6- Reconstrução óptica de um EOD iluminado por uma onda plana monocromática coerente. (A) Reconstrução de um holograma de Fourier (difração de Fraunhofer) utilizando-se uma lente de Fourier; (B) Reconstrução de um holograma de Fresnel (difração de Fresnel), obtido pela propagação da luz de $g\left(x^{\prime}, y^{\prime}\right)$ pela distância $d[20]$.

b) A distribuição $f\left(x^{\prime}, y^{\prime}\right)$ resultante da propagação inversa da luz geralmente apresenta uma distribuição complexa de valores de fase e amplitude, que devem ser adaptados para as possíveis distribuições $g\left(x^{\prime}, y^{\prime}\right)$ do holograma, que neste caso é uma distribuição apenas de fase ou amplitude. As limitações físicas e práticas do meio em que será gravado o 
14

holograma irão determinar a escolha do método numérico utilizado para esta implementação.

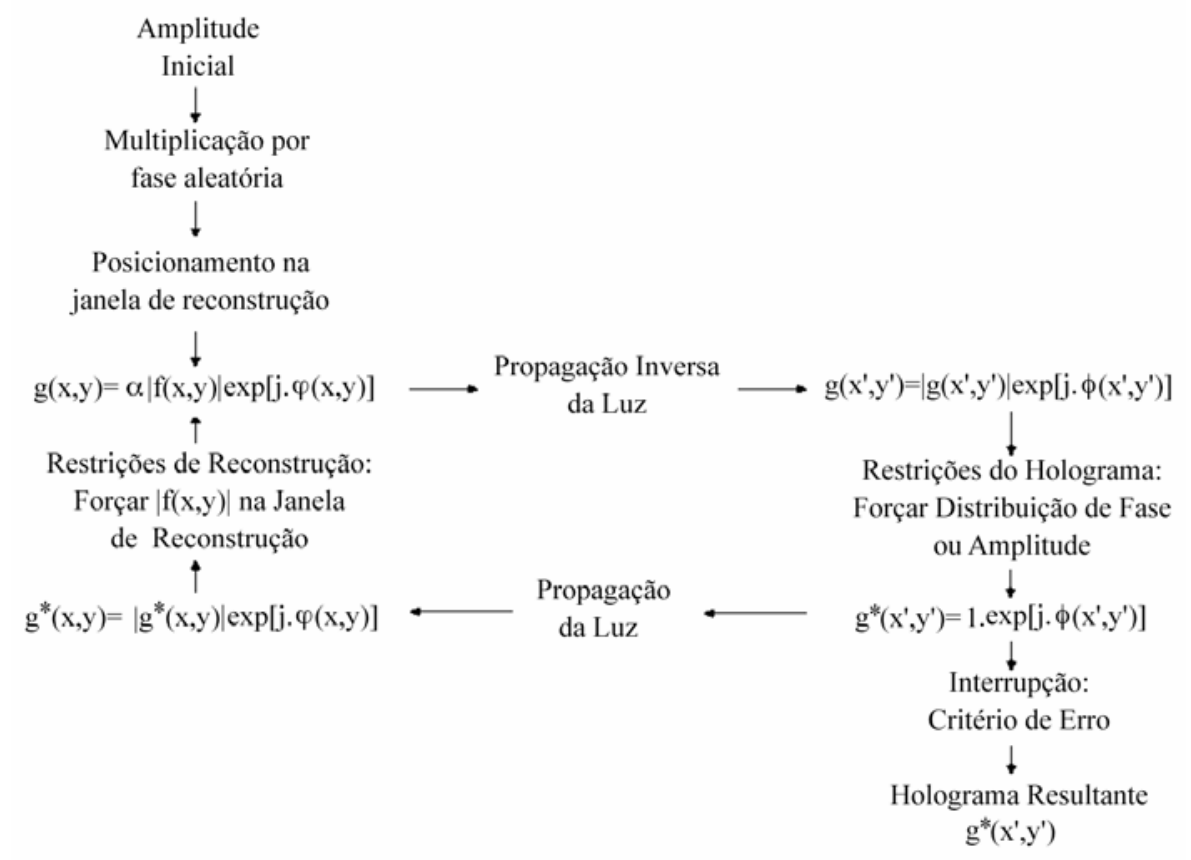

FIGURA 7-Diagrama esquemático do método iterativo da transformada de Fourier (Iterative Fourier

Transform Algorithm - IFTA) para o cálculos de hologramas em regime de modulação de fase ou de amplitude, com a reconstrução em intensidade [42].

O objetivo do cálculo do holograma é formar uma distribuição de luz no plano de reconstrução. Uma distinção é feita entre objetos de amplitude complexa (fase e amplitude determinadas) e objetos de intensidade determinada (apenas amplitude determinada). Desta maneira, para objetos de amplitude complexa tem-se:

$$
f(x, y)=|f(x, y)| \exp [i \varphi(x, y)]
$$

e para objetos de intensidade $i(x, y)$ tem-se:

$$
|f(x, y)|^{2}=i(x, y)
$$


onde os valores do argumento $\varphi(x, y)$ de $f(x, y)$ possuem total liberdade, podendo assumir quaisquer valores. Desta maneira tem-se:

$$
f(x, y)=\sqrt{i(x, y)} \exp [i \varphi(x, y)]
$$

Vários métodos foram propostos para o cálculo de hologramas por computador, entre eles o algoritmo iterativo da transformada de Fourier (Iterative Fourier Transform Algorithm - IFTA), introduzido na holografia digital por Gerchberg \& Saxton [7] e por Hirsh et al. [8].

O IFTA, descrito na Figura 7, oferece os melhores resultados práticos na codificação de hologramas gerados computador com comprimento de banda (SBP - Space Band Bandwith Product) de 256x256 ou mais células (pixels). O IFTA foi posteriormente modificado por Wyrowski [16], que implementou neste algoritmo o conceito de liberdade de fase durante as iterações para o cálculo de hologramas com modulação em níveis discretos.

No IFTA, uma iteração é realizada calculando-se a propagação inversa da luz do plano de reconstrução ao plano do holograma, onde as restrições do holograma são aplicadas (imposição de uma distribuição de fase). Na seqüência, calcula-se a propagação da luz do plano do holograma ao plano de reconstrução, onde as restrições referentes a distribuição desejada são aplicadas (determinar a intensidade da reconstrução desejada $i(x, y)$ ). Para objetos em intensidade, atribui-se uma distribuição de fase aleatória a $\varphi(x, y)$ na primeira iteração para auxiliar a convergência do algoritimo.

Infelizmente, este método numérico requer várias iterações, além de geralmente introduzir ruído do tipo speckle no plano de reconstrução. Cem ou mais iterações são necessárias dependendo da complexidade da reconstrução desejada $f(x, y)$ ou $i(x, y)$. Também é possível que não exista uma distribuição de fase ou amplitude $g\left(x^{\prime}, y^{\prime}\right)$ que satisfaça $g(x, y) \approx \alpha f(x, y)$ ou $|g(x, y)|$ $\approx \alpha[i(x, y)]^{1 / 2}$ sobre toda a região do plano de reconstrução [42]. 
16

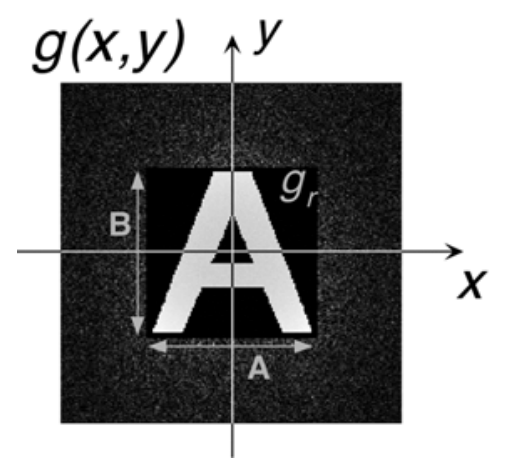

FIGURA 8-Janela de reconstrução, localizada no centro do plano de reconstrução, utilizada para melhorar a reconstrução do holograma. Fora da região $g_{r}$ de dimensões $A \times B$, a fase e a amplitude da distribuição $g(x, y)$ pode variar livremente [42].

Liberdade nos valores dos parâmetros pode ser introduzida no IFTA para auxiliar na convergência numérica, como por exemplo:

c) Liberdade de fase e amplitude para as distribuições fora da janela de reconstrução $g_{r}$, mostrada na Figura 8. Fora da região $g_{r}$, os valores de fase e amplitude de $g(x, y)$ podem variar livremente. O processo de codificação do holograma consiste em encontrar a distribuição $g\left(x^{\prime}, y^{\prime}\right)$ que satisfaça as restrições de modulação do holograma e garanta que a distribuição do objeto $f(x, y)$ está contida dentro de uma região $A \times B$ definida no plano de reconstrução $g(x, y)$, chamada de janela de reconstrução $g_{r}$.

d) Liberdade de fase na janela de reconstrução $g_{r}$ : para objetos em intensidade, a fase $\varphi(x, y)$ pode variar livremente dentro da região $g_{r}$.

e) Liberdade do fator de escala $\alpha$ : é possível variar $\alpha$ sobre a janela de reconstrução $g_{r}$ de maneira a se obter uma redução do erro dentro de $g_{r}$.

Neste trabalho, o EOD de luz branca é gerado por computador e calculado sem a necessidade métodos iterativos computacionais. 


\section{Capítulo 4}

\section{Introdução}

O EOD proposto neste trabalho funciona sob iluminação não-coerente. Neste capítulo serão apresentados alguns conceitos sobre coerência da luz.

\section{4-Coerência de uma fonte luminosa}

\section{1-O experimento de Young}

Difração é um fenômeno que ocorre quando uma frente de onda luminosa atravessa um orifício ou contorna um objeto cuja dimensão é da mesma ordem de grandeza que o seu comprimento de onda $\lambda$. Segundo Sommerfeld [32], difração é definida como "qualquer desvio da trajetória de raios de luz de caminhos retilíneos que não podem ser interpretados como reflexão ou refração". A difração é causada pelo confinamento de uma onda, quando este confinamento é comparável ao comprimento de onda da radiação incidente.

Um exemplo clássico que ilustra o fenômeno da difração é o experimento de Young $[33,43]$, no qual uma frente de onda incidente em um anteparo com duas fendas, de largura definida $a$, sofre o fenômeno de difração, e surgem então pontos de máximos e mínimos de intensidade luminosa, que podem ser observados pela formação de franjas claras e escuras, como na Figura 9. 


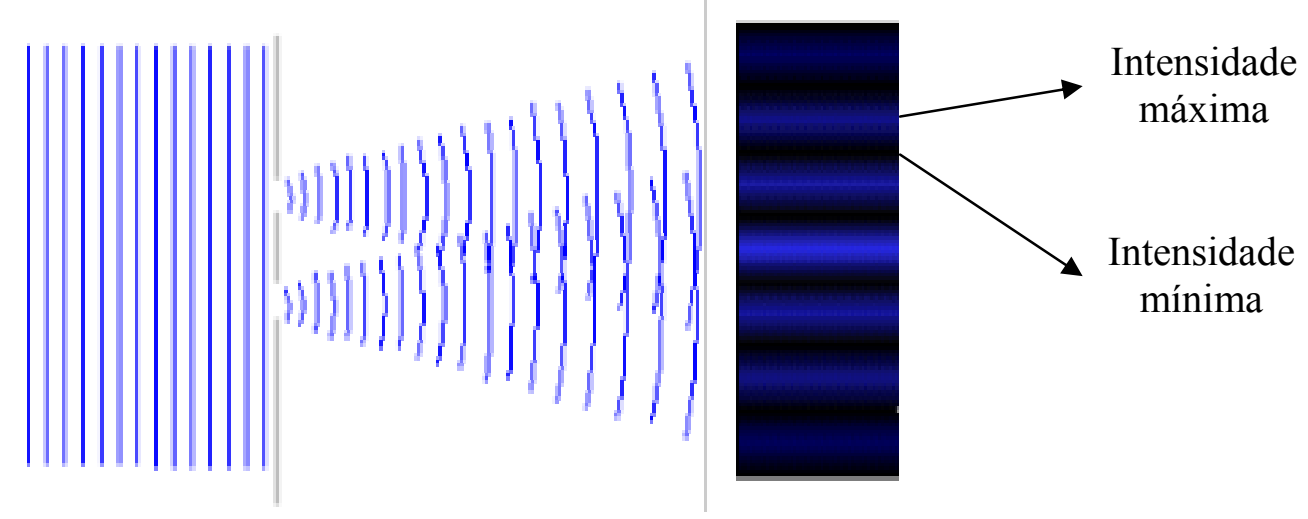

FIGURA 9-Difração da luz por duas fendas, produzindo máximos e mínimos de intensidade luminosa, observados como franjas de interferência claras e escuras.

A Figura 10 ilustra a diferença de caminhos percorridos pela onda incidente num experimento de Young. A distância entre as fendas é d e a grandeza $d \operatorname{sen} \theta$ é a diferença de percurso entre um feixe de luz que parte da extremidade superior da primeira fenda e outro que parte da extremidade inferior da segunda fenda. Considerando cada ponto na frente de onda uma fonte puntiforme de luz, a expressão geral dos pontos de intensidade nula na Figura de difração numa fenda é dada por:

$$
m \lambda \equiv 2 d \operatorname{sen} \theta
$$

onde m é um número inteiro

$\lambda$ é o comprimento de onda da luz incidente ;

d é a distância entre as fendas;

$\theta$ é o ângulo definido na Figura 10. 
Uma ilustração da diferença de caminho entre dois feixes de luz transmitidos pela parte inferior e superior da fenda pode ser vista na Figura 10.

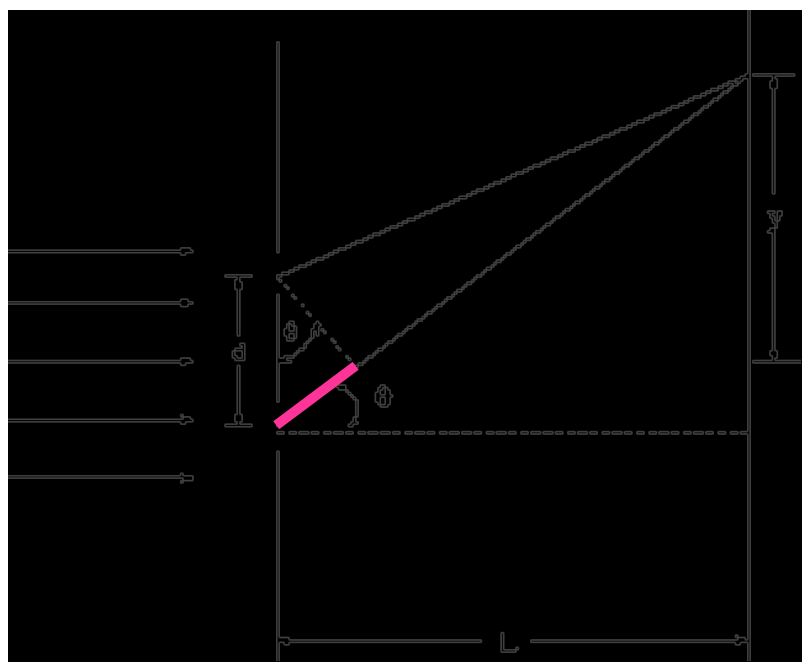

FIGURA 10-Diferença de caminhos entre dois feixes de luz que incidem na parte inferior e superior da fenda, em destaque.

Este experimento pode ser utilizado para medir o grau de coerência de uma fonte luminosa como será mostrado neste capítulo.

\section{2-Coerência temporal e espacial de uma fonte luminosa}

A coerência de uma fonte luminosa é a medida de correlação de fase entre ondas eletromagnéticas emitidas pela mesma. Existem dois tipos de coerência: coerência temporal e espacial.

A coerência temporal é a medida da correlação da fase de ondas eletromagnéticas em diferentes pontos ao longo da direção de propagação das ondas que emergem de uma fonte. Esta medida informa o quão monocromática é a fonte de iluminação. 
Já o conceito de coerência espacial, que é utilizado neste trabalho, é definido como a medida de correlação da fase das ondas eletromagnéticas em diferentes pontos na direção transversal à direção de propagação. Esta medida determina o quão uniforme é a fase da frente de onda. A medida do grau de correlação de uma fonte luminosa pode ser definida pelo coeficiente de correlação, $\gamma_{12}(t)$. A função $\gamma_{12}(t)$ é uma função periódica de $t$, que considera uma medida de correlação de um trem de ondas tomada entre um intervalo de tempo definido pelos instantes t e $t$ $+\tau$, onde $\mathrm{t}$ é o instante inicial, $\tau$ é um intervalo de tempo determinado e $\mathrm{t}+\tau$ o instante final.

Analisando o módulo do valor do grau de coerência $\gamma_{12}(t)$, podem ocorrer três situações distintas:

$$
\begin{aligned}
& \text { Se }\left|\gamma_{12}(t)\right|=1 \rightarrow \text { Coerência completa; } \\
& \text { Se } 0<\left|\gamma_{12}(t)\right|<1 \rightarrow \text { Coerência parcial; } \\
& \text { Se }\left|\gamma_{12}(t)\right|=0 \rightarrow \text { Incoerência completa. }
\end{aligned}
$$

$\mathrm{O}$ conceito de coerência espacial de uma fonte luminosa policromática com diâmetro $\rho$ e comprimento de onda de emissão médio $\bar{\lambda}$ é ilustrado na Figura 11. Sejam dois pontos consecutivos, espacialmente coerentes entre si $\mathrm{P}_{1}$ e $\mathrm{P}_{2}$, cujas distâncias em relação à fonte policromática são $\mathrm{S}_{1}$ e $\mathrm{S}_{2}$.

O grau de coerência da fonte, $\gamma$, pode ser determinado experimentalmente realizando-se o experimento da dupla fenda de Young, ilustrado na Figuras 9-10, Seção 4.1. Neste caso, o grau de coerência da fonte pode ser determinado por:

$$
\gamma \equiv \frac{I_{\max }-I_{\min }}{I_{\max }+I_{\min }}
$$

onde $\mathrm{I}_{\max }$ e $\mathrm{I}_{\min }$ correspondem às intensidades máximas e mínimas obtidas no experimento. 
A condição para que haja coerência espacial para uma iluminação policromática é, segundo o teorema de Van Cittert-Zernike [43], que se estabeleça uma relação entre a distância de dois pontos consecutivos coerentes, $d\left(P_{1}, P_{2}\right)$ de uma frente de onda que se propaga ao longo de uma distância R, emergindo de uma fonte luminosa estendida, de diâmetro $\rho$, e de comprimento de onda médio $\bar{\lambda}$, definida por (6).

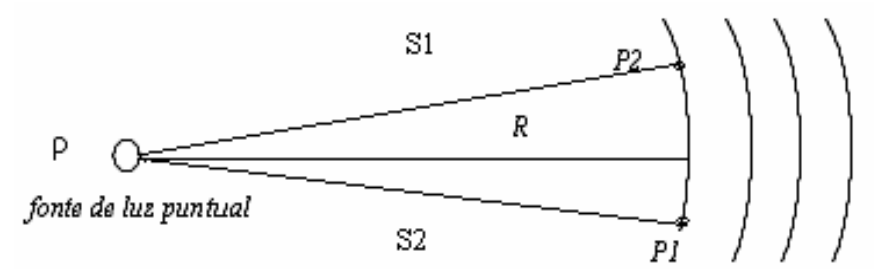

FIGURA 11-Relação entre a distância entre dois pontos espacialmente coerentes emergindo de uma fonte luminosa de diâmetro $\rho$, de comprimento de onda $\bar{\lambda}$, a uma distância $\mathrm{R}$ de propagação.

Segundo o teorema de Van Cittert-Zernike [43], para ocorrer coerência espacial da fonte luminosa ilustrada pela Figura 11 é necessário satisfazer a seguinte equação :

$$
d\left(P_{1}, P_{2}\right)=\frac{0.16 R \bar{\lambda}}{\rho}
$$

onde $\rho$ é o diâmetro da fonte de iluminação estendida; $\bar{\lambda}$ é o comprimento de onda médio da fonte luminosa ; $d\left(P_{1}, P_{2}\right)$ é a distância de dois pontos consecutivos coerentes de uma frente de onda que se propaga ao longo de uma distância $\mathrm{R}$, emergindo da fonte luminosa.

A diferença de fase $\delta$ [43] entre dois pontos coerentes da frente de onda emitida pela fonte luminosa da Figura 11 é definida por : 
22

$$
\delta \equiv \frac{2 \pi\left(S_{1}-S_{2}\right)}{\bar{\lambda}}
$$

onde $\bar{\lambda}$ é o comprimento de onda médio da fonte luminosa; $S_{1}$ e $S_{2}$ são as distâncias em relação à fonte policromática. 


\section{Capítulo 5}

\section{Introdução}

Nos capítulos anteriores foram apresentados alguns conceitos necessários para a apresentação do EOD de luz branca. Neste capítulo serão apresentados o projeto, funcionamento e o processo de fabricação deste EOD.

\section{5-O Elemento de luz branca}

\section{1-A técnica de halftoning}

O método para representação de imagens em tons de cinza utilizando pixels binários é conhecido como halftoning [44]. Esta técnica foi utilizada neste trabalho para projetar o elemento de luz branca proposto.

$\mathrm{Na}$ técnica de halftoning ou "meio-tom" imagens em níveis de cinza são codificadas por clusters de pixels brancos e pretos. Numa imagem codificada por halftoning uma pequena área que contenha pixels brancos e pretos. A uma determinada distância, da ordem de $30 \mathrm{~cm}$, o olho humano integra o conteúdo desta pequena área, de forma que o observador percebe somente a intensidade média da mesma. Esta propriedade de integração do olho humano é básica para a técnica de halftoning.

As Figuras $12(a) e(b)$ mostram, respectivamente, as imagens original e obtida através de cálculo numérico utilizando a técnica de halftoning, com 256 níveis de cinza. Um grupo de 
$n x n$ pixels binários pode produzir $n^{2}+1$ níveis de cinza. Neste caso, cada cluster da imagem em halftoning é composto por 4x4 pixels como mostrado na Figura 13.

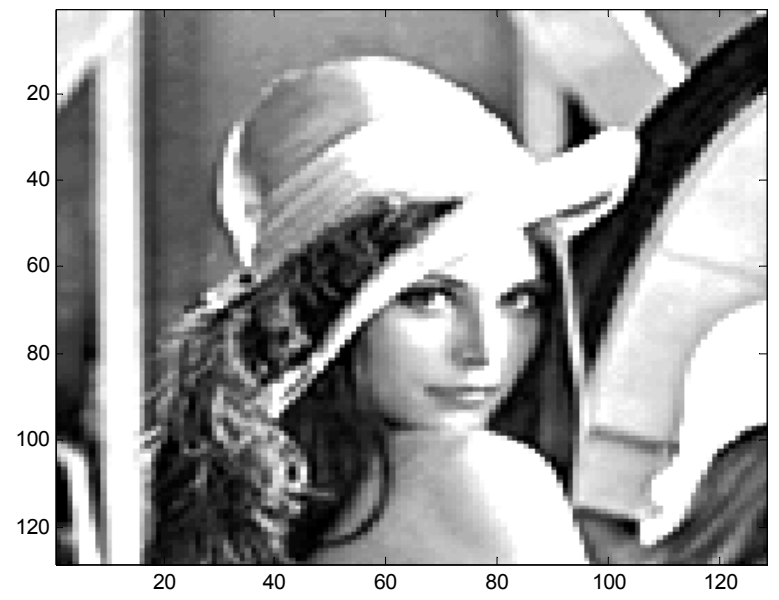

(a)

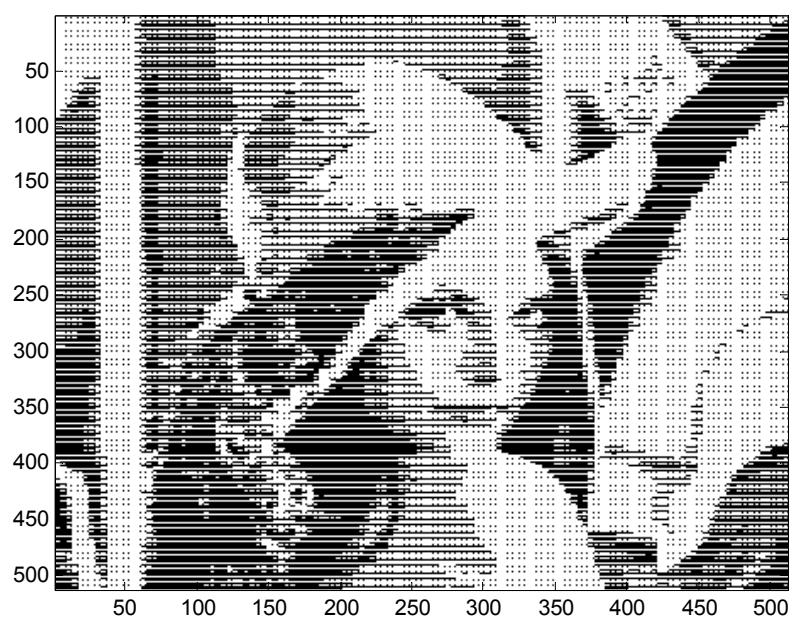

(b)

FIGURA 12(a)- Imagem original de Lenna 128x128 pixels;(b) Imagem obtida a partir da imagem original, através da técnica de halftoning. 


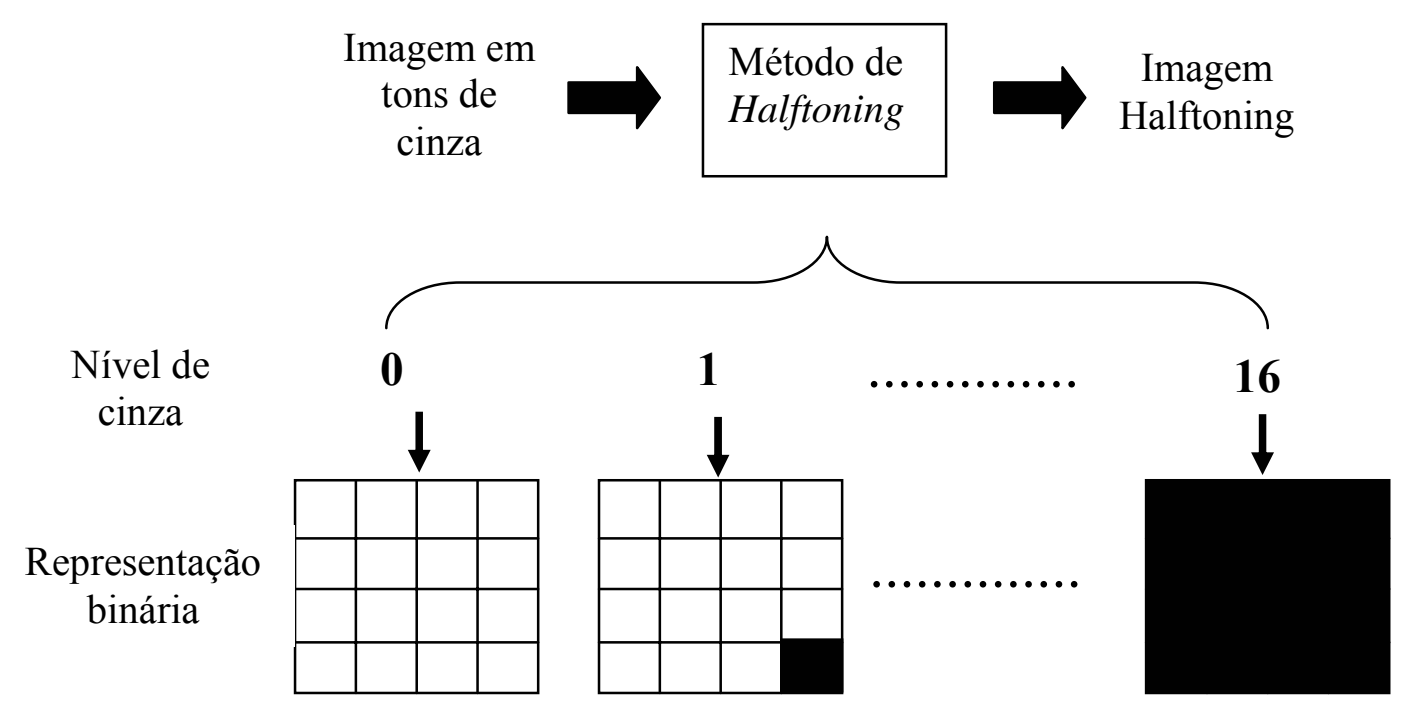

FIGURA 13- Técnica de halftoning aplicada a uma imagem com 17 níveis de cinza.

\section{2-Processo de codificação do elemento de luz branca}

O elemento de luz branca foi fabricado utilizando-se técnica de óptica binária de baixo custo. Considerando-se o custo e o tempo que estão envolvidos num processo para gerar perfis de fase contínuos, foi proposto um EOD binário com níveis de atraso de fase de 0 e $\pi$ radianos. As máscaras utilizadas no processo de fabricação destes elementos foram geradas através da técnica halftoning [44] em que cada pixel com um tom de cinza é representado por um conjunto de subpixels pretos e brancos $[21,25]$.

Os EODs de fase foram projetados para informação binária. A informação binária foi mapeada como mostrado na Figura 14: cada pixel com nível 1 é transformado em quatro pixels com valor de fase $\mathrm{e}^{\mathrm{j} 0}$, e cada pixel com nível 0 é transformado em quatro pixels ( dois pixels com valor de fase $\mathrm{e}^{\mathrm{j} 0}$ e os outros dois pixels com valor de fase $\left.\mathrm{e}^{\mathrm{j} \pi}\right)$. 


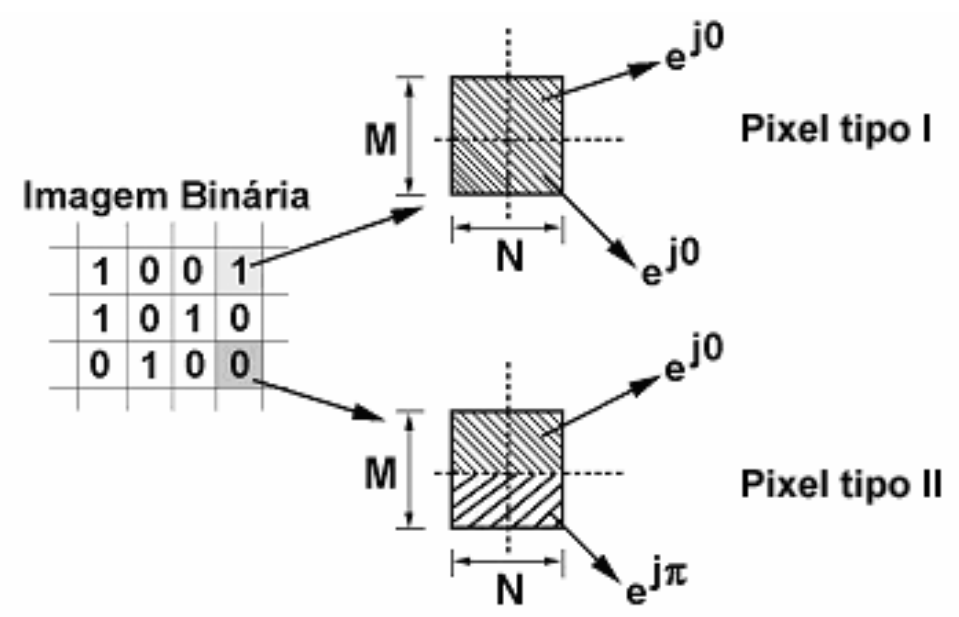

FIGURA 14-Projeto do EOD para uma informação binária

Pode-se classificar dois tipos de pixels codificados conforme ilustrado na Figura 14. Um bloco de pixels composto de 4 pixels de fases $\mathrm{e}^{\mathrm{j} 0}, \mathrm{e}^{\mathrm{j} 0}, \mathrm{e}^{\mathrm{j} 0}, \mathrm{e}^{\mathrm{j} 0}$, o qual foi denominado pixel tipo I. Outro bloco de pixels composto de 4 pixels de fases $\mathrm{e}^{\mathrm{j} 0}, \mathrm{e}^{\mathrm{j} 0}, \mathrm{e}^{\mathrm{j} \pi}, \mathrm{e}^{\mathrm{j} \pi}$, o qual foi denominado pixel tipo II. A seguir serão apresentados os padrões de intensidades luminosas geradas quando uma frente de onda atravessa os pixels tipo I e II.

\section{3-Simulação e funcionamento do elemento de luz branca}

A codificação dos elementos de luz branca foi realizada conforme a metodologia descrita na Seção 5.2. O EOD de luz branca é composto por pixels tipo I e II. Desta forma, simulou-se inicialmente o comportamento de uma frente de onda luminosa modulada por este dois tipos de pixels, segundo a propagação de Fresnel no espectro angular, dada por (8). 


$$
A\left(\frac{\alpha}{\lambda}, \frac{\beta}{\lambda}, z\right) \equiv \int_{\infty}^{\infty} U(x, y, z) \exp \left[-j 2 \pi\left(\frac{\alpha}{\lambda} x+\frac{\beta}{\lambda} y\right)\right] d x d y
$$

Onde A é a amplitude resultante da perturbação $U(x, y, z)$, e $\alpha=\lambda f_{x}$; e $\beta=\lambda f_{y}$, e $f_{x}$ e $f_{y}$ são as freqüências referentes ao plano de coordenadas xy. Assim, a função transferência do sistema é dada por (9)

$$
H\left(f_{x}, f_{y}\right)=\left\{\exp \left[j 2 \pi \frac{z}{\lambda} \sqrt{1-\left(\lambda f_{x}\right)^{2}-\left(\lambda f_{y}\right)^{2}}\right], \text { para } \sqrt{f_{x}{ }^{2}+f_{y}^{2}}<\frac{1}{\lambda}\right.
$$

O espectro de uma função de saída de um sistema, $G_{2}\left(f_{x}, f_{y}\right)$ está relacionado com o espectro de entrada $G_{1}\left(f_{x}, f_{y}\right)$ pela função transferência, de tal forma que:

$$
G_{2}\left(f_{x}, f_{y}\right) \equiv H\left(f_{x}, f_{y}\right) G_{1}\left(f_{x}, f_{y}\right)
$$

O diagrama do algoritmo para o cálculo da propagação da luz modulada pelos pixels tipos I e II é ilustrado na Figura 15.

$$
\text { Pixels tipo I e II }
$$
dos pixels tipo I e II

Propagação de Fresnel

FIGURA 15-Diagrama do algoritmo para o cálculo da propagação da luz modulada pelos

$$
\text { pixels tipos I e II }
$$


Analisando a propagação da intensidade luminosa ao longo do eixo é possível observar a formação de padrões de difração. Para uma distância de $2 \mathrm{~cm}$ foram observados os padrões de difração para os pixels tipo I e II como ilustrados nas Figuras 16-17.

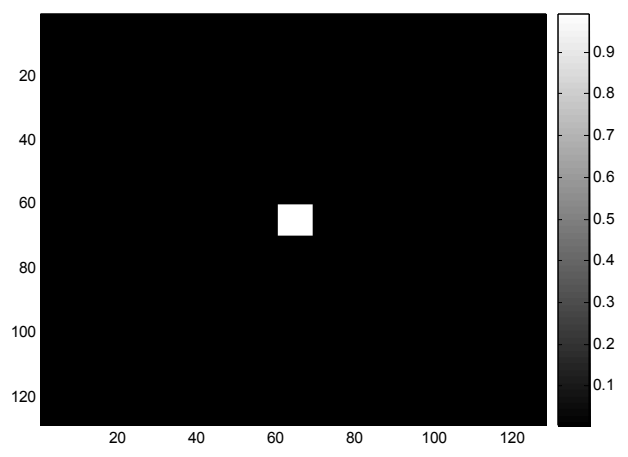

(a)

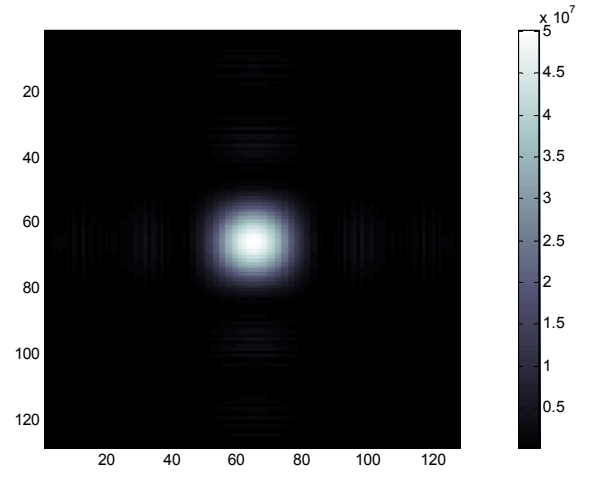

(b)

FIGURA 16-(a)pixel tipo I e (b)sua respectiva intensidade de propagação.

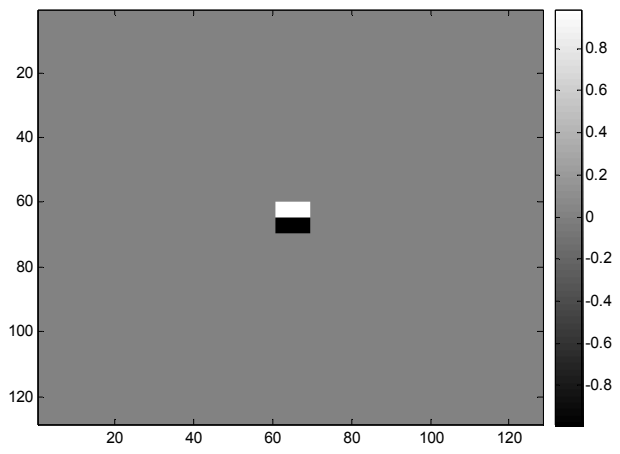

(a)

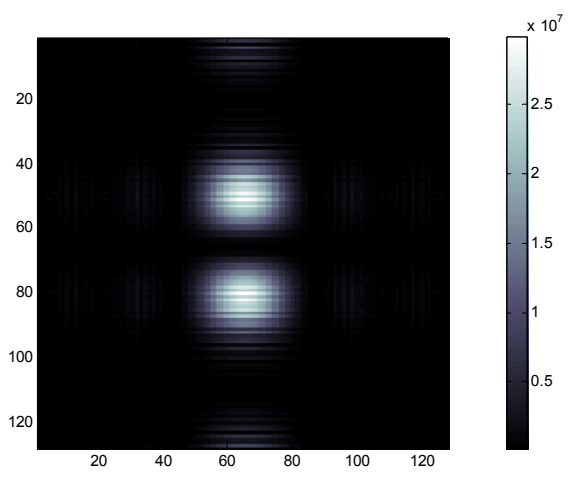

(b)

FIGURA 17- (a)Pixel tipo II e (b) intensidade de propagação do pixel tipo II. 
Estes pixels dos tipos I e II podem ser interpretados como ondas, cujas propagações podem ser calculadas pelas transformadas de Fourier já conhecidas [45]. No caso do pixel tipo I, que modula fase 0 , este se comporta como uma função $\Pi(x)$, cuja transformada de Fourier é $\sin c(s)$. Analogamente, o pixel tipo II, que apresenta fases 0 e $\pi$, tem um comportamento semelhante ao da função $-\frac{1}{2} \Pi\left(x+\frac{1}{2}\right)+\frac{1}{2} \Pi\left(x-\frac{1}{2}\right)$, cuja transformada de Fourier é $-i \sin c(s) \sin c(\pi \mathrm{s})$. As funções matemáticas dos pixels dos tipos I e II e suas transformadas de Fourier estão ilustradas nas Figuras 18 e 19. Estas figuras ilustram os padrões de difração ou transformadas de Fourier (vide Apêndice B) dos pixels tipos I e II.

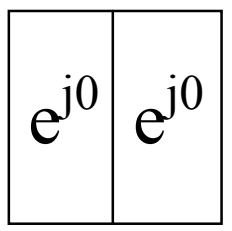

(a)

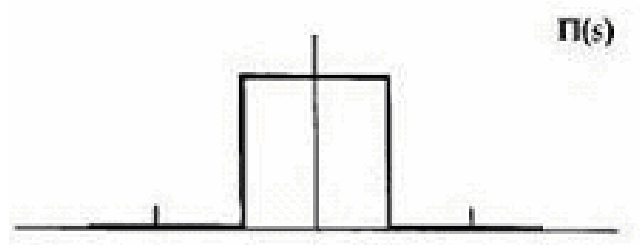

(b)

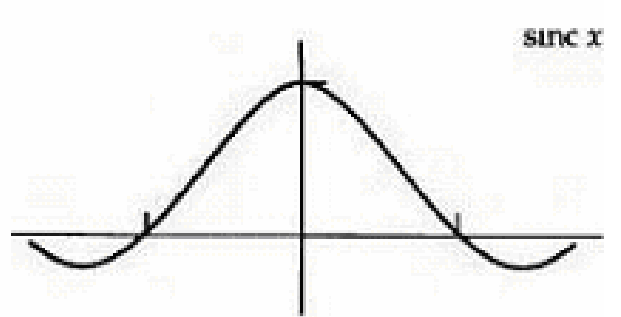

(c)

FIGURA 18-(a) Modelo proposto para o pixel tipo I ; (b) sua representação como função $r e c t(x)$ e (c) sua transformada de Fourier, $\sin c(s)$. 


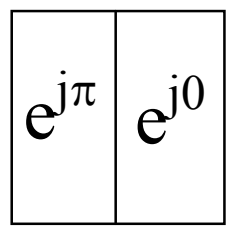

(a)

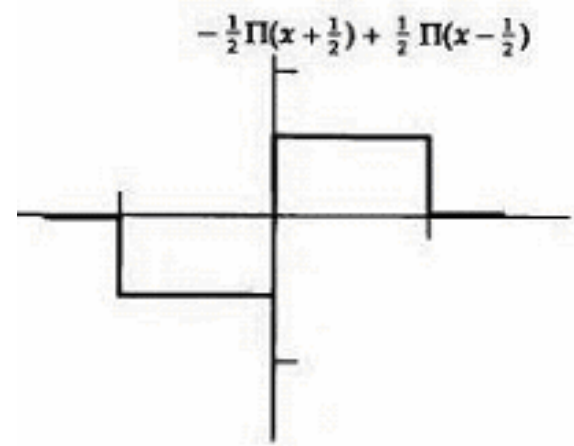

(b)

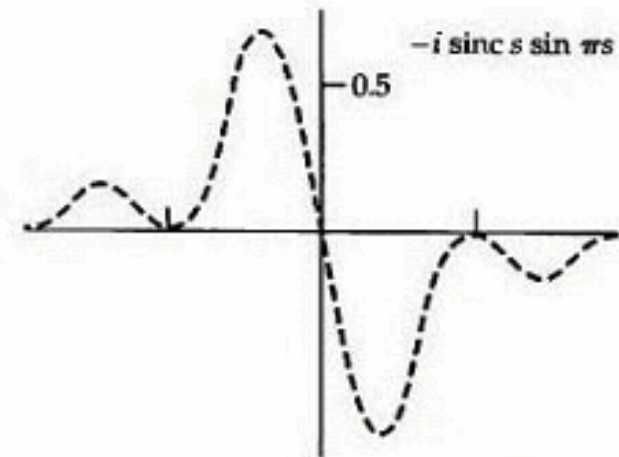

(c)

FIGURA 19- Modelo para o pixel tipo II e (b) sua representação como função $-\frac{1}{2} \prod\left(x+\frac{1}{2}\right)+\frac{1}{2} \prod\left(x-\frac{1}{2}\right) ;$ e (c)sua transformada de Fourier, $-i \sin c(s) \sin c(\pi \mathrm{s})$.

O EOD de luz branca é composto por um conjunto de pixels tipo I e II. Desta forma, é possível calcular o padrão de difração para cada tipo de pixel no plano de reconstrução para compor a imagem resultante. Cada pixel dos tipos I e II podem ser abordados como microhologramas de Fresnel. A seguir será apresentado e descrito o algoritmo para a simulação do EOD de luz branca. 


\section{4- Simulação do EOD de luz branca}

O EOD de luz branca foi projetado segundo a técnica de halftoning descrita na Seção 5.1. Uma imagem original de 128 x 128 pixels, com 256 níveis de cinza, foi transformada numa imagem halftoning de 512 x 512 pixels. Neste processo, cada nível de cinza da imagem original foi mapeado para uma matriz de 4 x 4 pixels. A partir da imagem de halfoning, foi gerado o EOD de fase conforme mostrado na Seção 5.2.

A simulação do comportamento da modulação de uma frente de onda luminosa parcialmente coerente em uma região localizada através do EOD de fase foi implementada segundo os diagramas esquemáticos dos algoritmos presentes nas Figuras 20-21. Neles foi utilizado o cálculo da propagação da luz utilizando a aproximação de Fresnel no espectro angular, mostrada em (8). O cálculo da reconstrução da imagem foi dividido em duas etapas : cálculo da propagação de Fresnel para pixels tipo I e cálculo da propagação de Fresnel para pixels tipo II. Desta forma, é obtida a função transferência (vide anexo B) para cada caso, obtida a partir de (12). Fazendo-se a operação de convolução bidimensional [32] da imagem gerada por halftoning com cada função transferência obtém-se a imagem de saída para cada tipo de pixel. Como o sistema é linear, utilizando o princípio da superposição, as imagens de saída para cada tipo de pixel podem ser somadas para a obtenção da imagem no plano de reconstrução. 
32

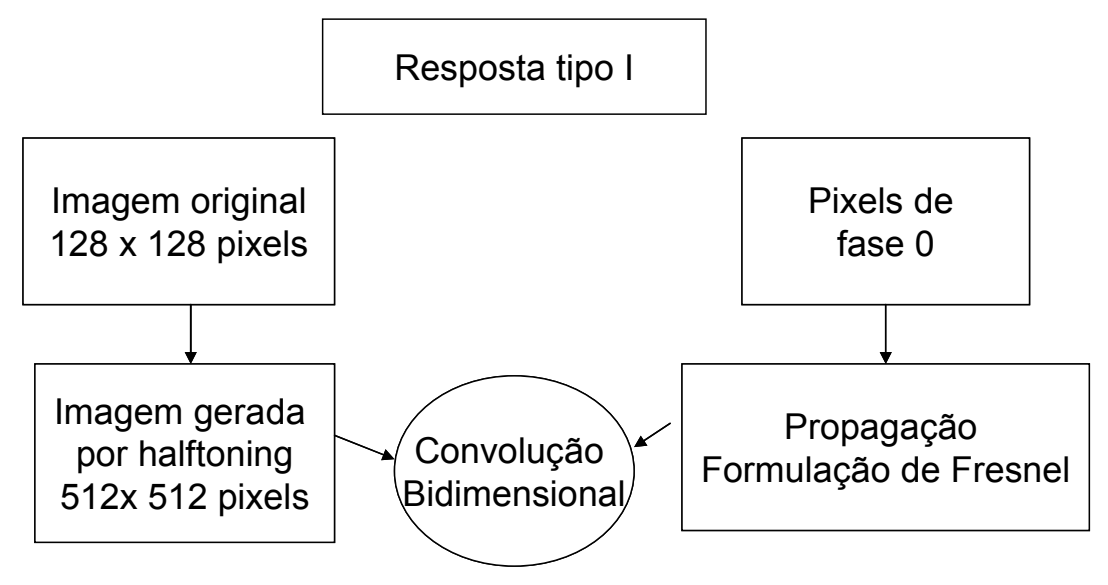

FIGURA 20- Diagrama de blocos do algoritmo para cálculo da resposta impulsional dospixels tipo I.

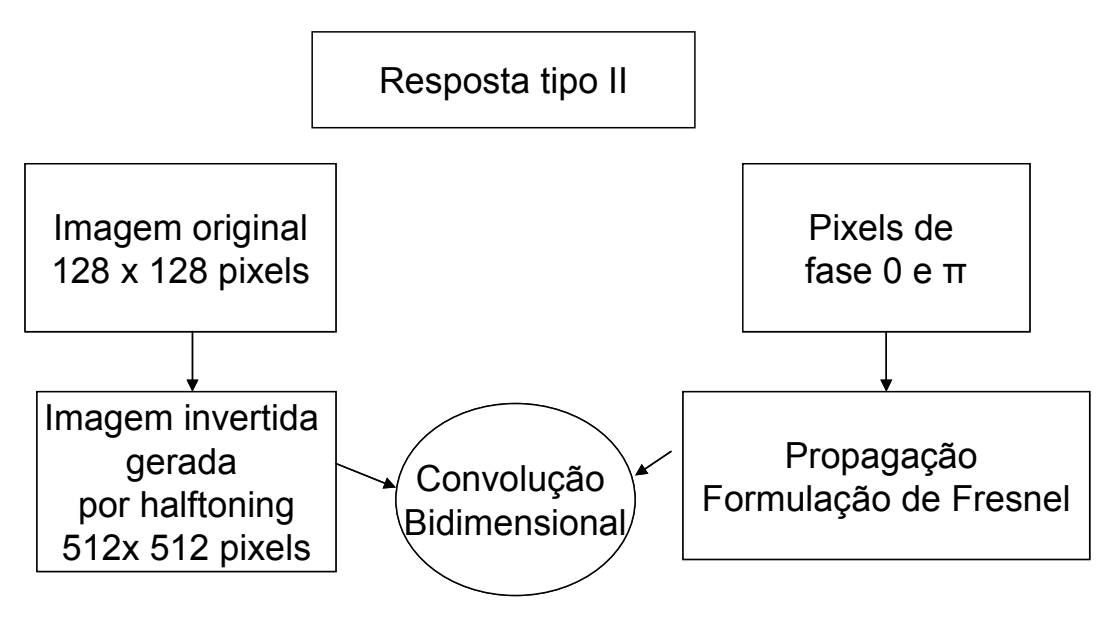

FIGURA 21- Diagrama de blocos do algoritmo para cálculo da resposta impulsional dos pixels tipo II.

Foram feitas simulações computacionais para as distâncias $(0$ e $2 \mathrm{~cm})$ entre o plano do EOD e o plano de reconstrução. Os resultados podem ser visualizados nas Figuras 22(a-b). 


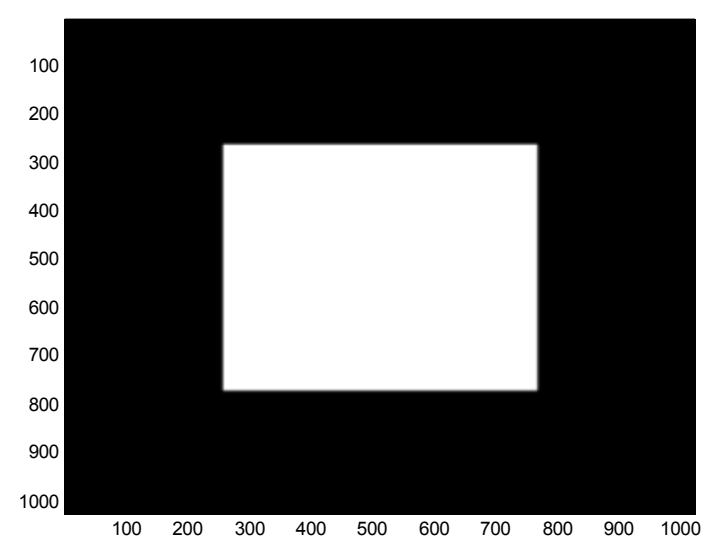

(a)

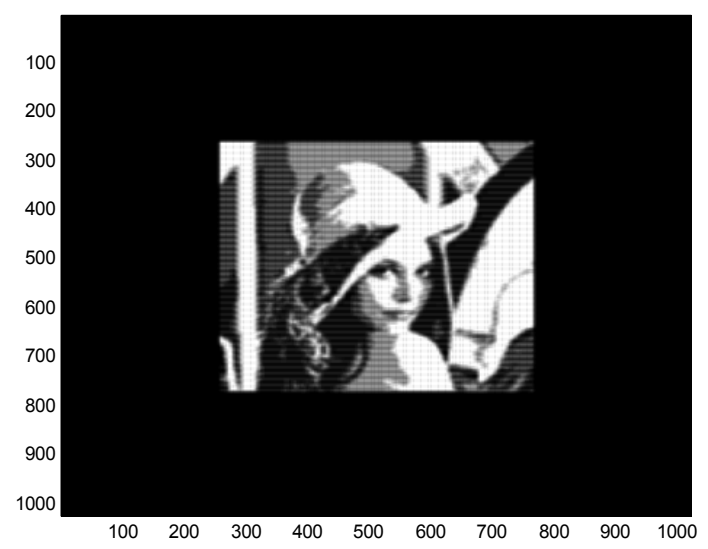

(b)

FIGURA 22- Reconstrução simulada para o EOD gerado a partir da figura Lenna para uma distância do plano do EOD ao plano de reconstrução de (a) $0 \mathrm{~cm}$ e (b) $2 \mathrm{~cm}$.

Observa-se na Figura 22 que para uma distância muito próxima entre o plano do EOD e o plano de reconstrução não há a formação de imagem. Já para uma distância de $2 \mathrm{~cm}$ entre os planos ocorre a formação de uma imagem. A Figura 22(b) ilustra o caso em que ocorre coerência local nas regiões dos pixels tipo I e II. Como conseqüência há a formação dos padrões simulados e mostrados nas Figuras 16-17 da Seção 5.3.

Para a construção de EOD de luz branca foram escolhidas quatro imagens de dimensão 128 x 128 pixels como mostrado na Figura 23. O EOD de fase foi gerado utilizando o mesmo processo aplicado anteriormente nesta seção. Na Figura 24 são mostradas as reconstruções ópticas simuladas computacionalmente para uma distância de propagação de $2 \mathrm{~cm}$. Estes resultados mostram que há uma determinada distância de propagação, neste caso $2 \mathrm{~cm}$, em que ocorre coerência espacial local nas regiões dos pixels tipo I e II. Estas regiões podem ser interpretadas como micro-hologramas de Fresnel, cuja soma das reconstruções origina a imagem de interesse. 


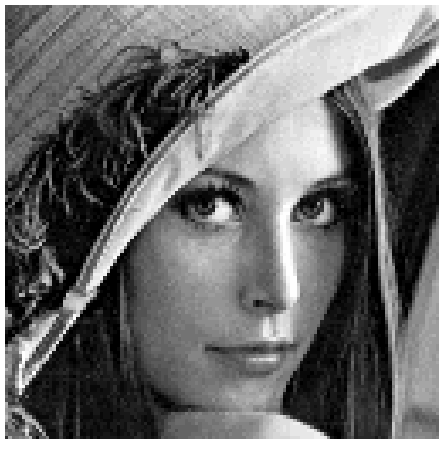

(a)

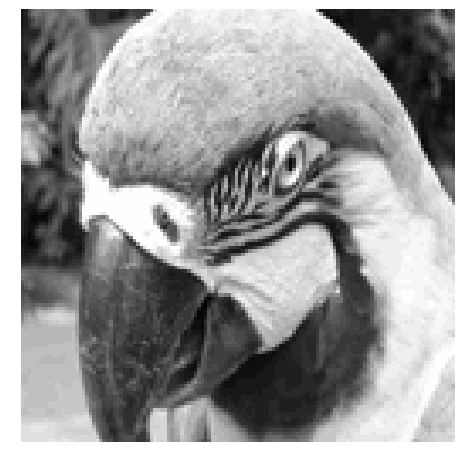

(c)

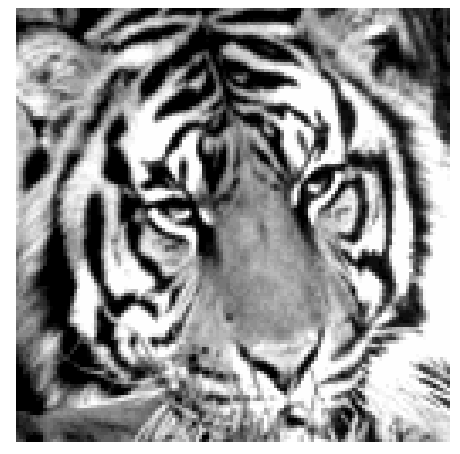

(b)

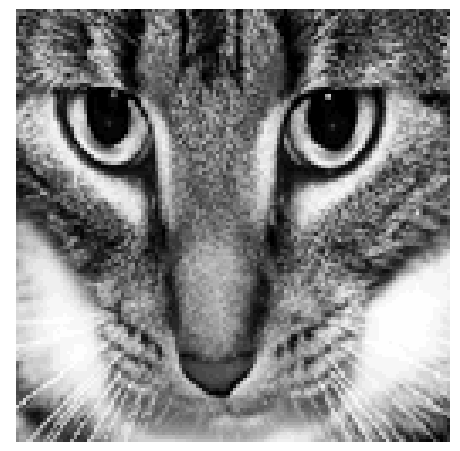

(d)

FIGURA 23- Figuras utilizadas no algoritmo para gerar o EOD de luz branca: (a) Lenna; (b) tigre, (c) periquito; (d) gato. 


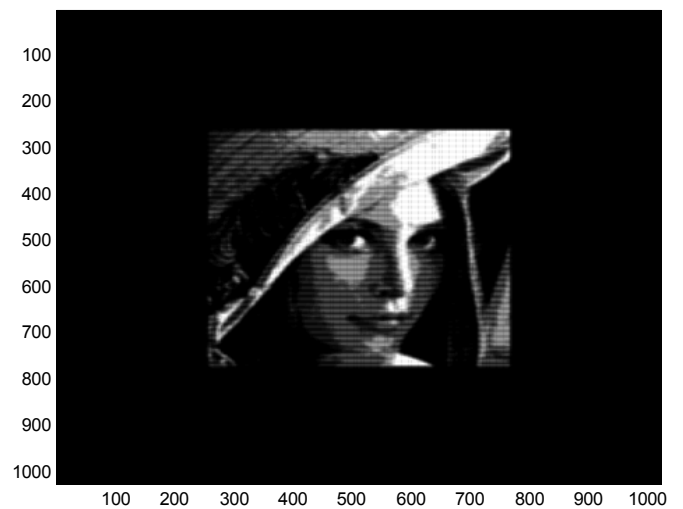

(a)

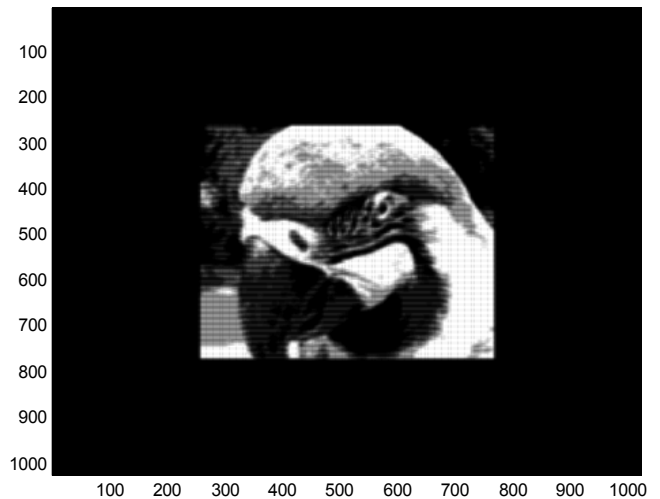

(c)

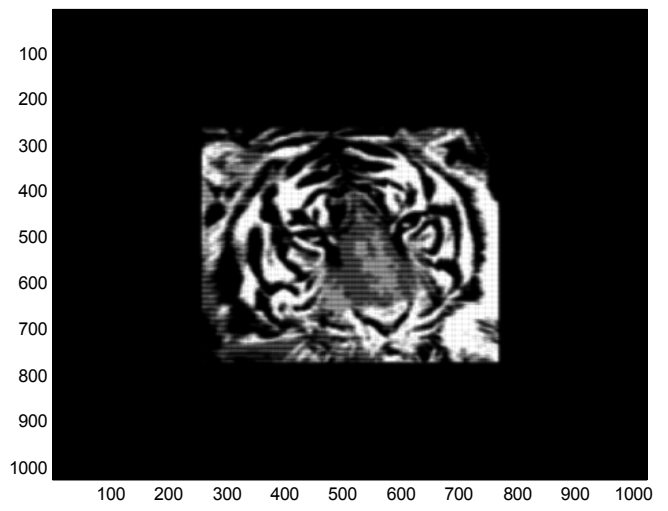

(b)

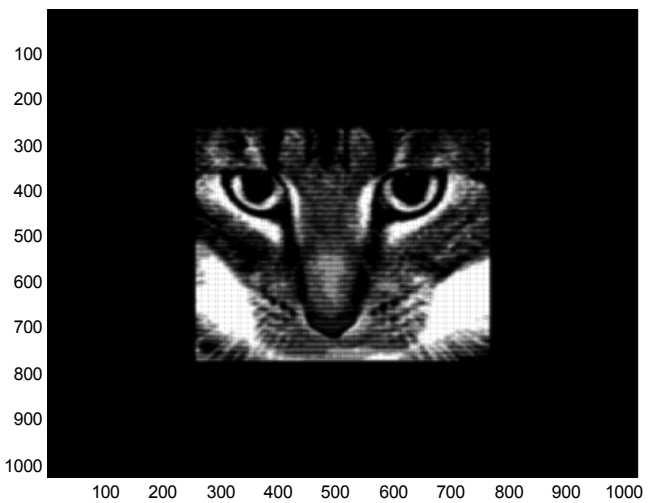

(d)

FIGURA 24- Reconstrução simulada para o EOD gerado a partir das figuras (a)Lenna, (b) tigre, (c) periquito e (d) gato, para uma distância do plano do EOD ao plano de reconstrução de $2 \mathrm{~cm}$. Estas figuras são as mesmas utilizadas para a fabricação do elemento de luz branca. 


\section{5-Construção do elemento de luz branca}

Nesta seção são descritos os processos de fabricação do elemento de luz branca, que foi fabricado com a colaboração do Laboratório de Sistemas Integráveis da Escola Politécnica - USP - Brasil.

A modulação de fase no EOD é descrita por (11) [18].

$$
\operatorname{th}(x, y)=\frac{\lambda}{2 \pi(n-1)} \phi(x, y)
$$

onde : $\phi(x, y)(0 \leq \phi(x, y) \leq 2 \pi)$ é a distribuição de fase, th $(x, y)$ é a variação de espessura necessária para gerar o padrão de difração, $\lambda$ é o comprimento de onda de operação e $n$ é o índice de refração do material da rede de fase. Visto que o EOD funciona no espectro visível foi escolhido $\lambda=633 \mathrm{~nm}$.

O EOD foi fabricado empregando óptica binária de baixo custo e a seqüência de etapas para fabricação é mostrada esquematicamente na Figura 25. Considerando o custo e o tempo deste processo, o qual gera perfis de fase contínuos, foi proposto um EOD binário com níveis de atraso de fase de 0 e $\pi$ radianos, que são gerados por etapas de fotolitografia e corrosão por plasma [20].

Um substrato de vidro de qualidade óptica com diâmetro de três polegadas foi utilizado como base para as estruturas de deslocamento de fase. Estas estruturas foram implementadas em filme fino de fotorresiste cujo índice de refração é $n_{R}=1,65$.

Substituindo $\phi(x, y)=\pi \mathrm{em}(10)$, a espessura de rede encontrada é th(x,y) $=633 /[2(1.65-$ $1)]=486,9 \mathrm{~nm}$. 
Neste trabalho, foi utilizado um processo de seis etapas, que são bem controladas e conhecidas para aplicações em micromecânica e microeletrônica. Estas etapas são apresentadas a seguir :

a) Limpeza das lâminas de vidro. O substrato de vidro utilizado apresenta diâmetro de 3 polegadas e espessura de $1,0 \mathrm{~mm}$;

b) Aplicação (spin) de álcool isopropílico, 20 seg., 2500 rpm;

c) Aplicação do promotor de aderência, 20 seg., 2500 rpm;

d) Aplicação do fotoresiste TOKYO OHKA ONPR - 800, 20 seg., $2500 \mathrm{rpm}$, a espessura do fotorresiste obtida foi de $1,1 \mu \mathrm{m}$;

e) Pré-Cura, $90 \mathrm{seg} @ 90^{\circ} \mathrm{C}$;

f) Exposição UV, $40 \mathrm{seg}$., $25 \mathrm{~mW} / \mathrm{cm}^{2}$. O fotolito utilizado para a transferência do padrão desejado foi gerado sobre um filme transparente por uma plotter (AGFA AVANTRA 30e 2400 dpi) com máxima resolução de $15 \mu \mathrm{m}$.

g) Revelação, 2 partes de revelador : 1 parte de $\mathrm{H}_{2} \mathrm{O}$-DI. O tempo de revelação foi mantido constante em 60 s. O revelador empregado foi o HPRD-402;

h) Pós cura, $30 \min @ 105^{\circ} \mathrm{C}$;

i) Medição de altura de degrau antes da corrosão. Verificação da altura de degraus do fotorresiste, antes da corrosão por plasma, via técnica de perfilometria;

j) Corrosão por plasma. Os substrato com fotorresiste foi submetido a corrosão por plasma de $\mathrm{CF}_{4}+20 \% \mathrm{H}_{2}$, durante 10 minutos; 
k) Medição de altura de degrau após a remoção do fotorresiste. Verificação das alturas de degraus após a remoção do fotorresiste remanescente da corrosão, via perfilometria.

$\mathrm{Na}$ Figura 26, pode ser visto o EOD de fase de luz branca produzido através da metodologia descrita nesta seção.

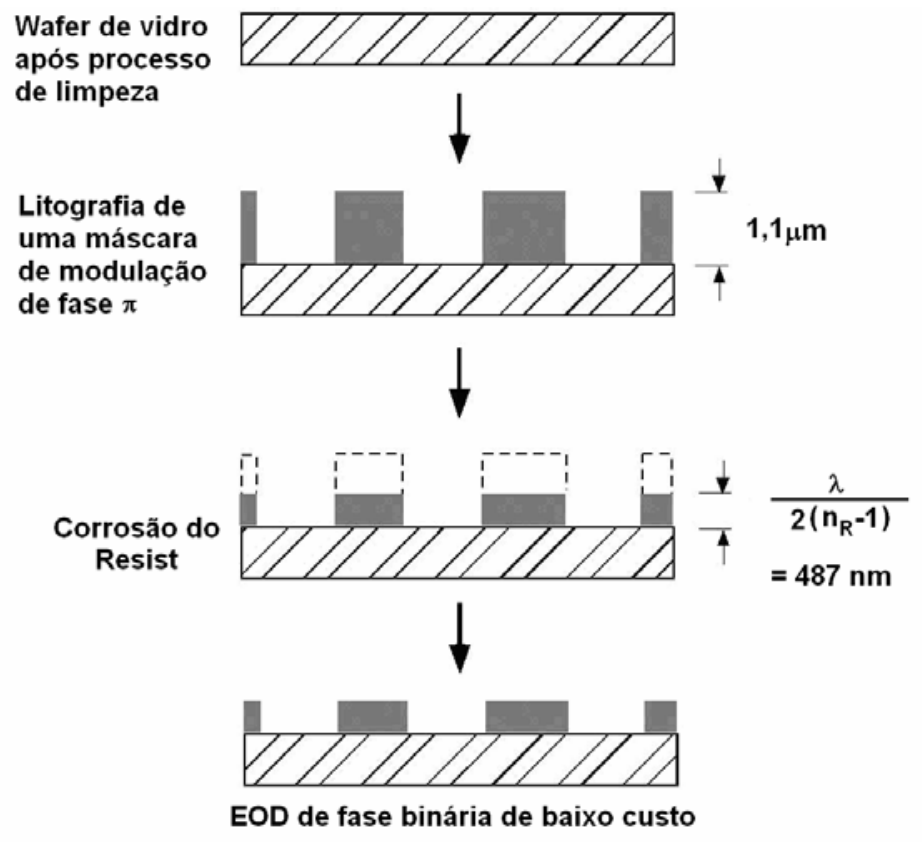

FIGURA 25- Visão esquemática da seqüência do processo de fabricação do EOD no modo transmissão.

Devido ao baixo custo de fabricação foi utilizada uma máscara que consiste de um filme transparente tipo fotolito. O padrão a ser transferido foi impresso no filme transparente por uma plotter com máxima definição $15 \mu \mathrm{m}$ ( AGFA AVANTRA 30e 2400 dpi ). Nenhuma máscara gerada por feixe de elétrons é necessária. 


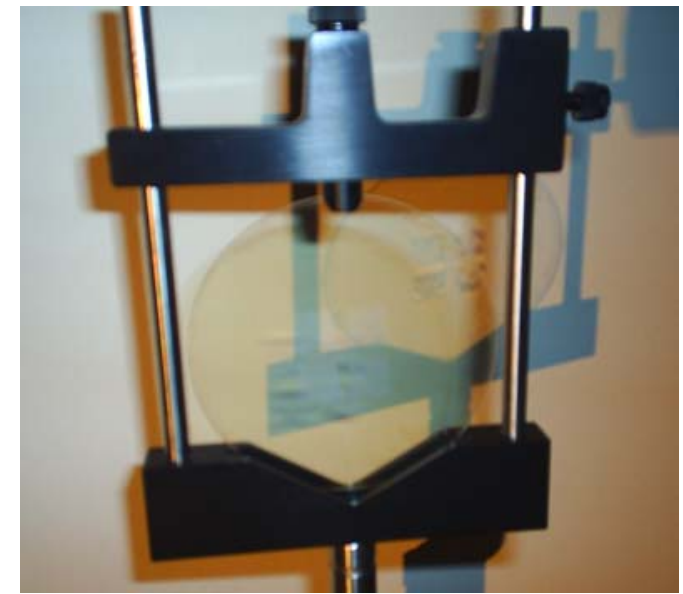

FIGURA 26- Montagem do EOD de luz branca realizada no laboratório de óptica do departamento de engenharia elétrica da EESC-USP. No plano posterior, observa-se o anteparo, onde a imagem é projetada. 
40

\section{Capítulo 6}

\section{Introdução}

No capítulo anterior foram apresentados a metodologia de projeto, funcionamento e construção do EOD de fase que opera sob iluminação parcialmente coerente em uma região localizada. Neste capítulo serão apresentados os resultados experimentais referentes às reconstruções ópticas utilizando os EODs fabricados através do método proposto.

\section{6-Resultados experimentais}

\section{1- Medida do contraste}

O EOD de fase projetado e construído é iluminado com uma fonte luminosa não-coerente. Logo, torna-se necessário avaliar o contraste obtido através da fonte luminosa utilizada.

A iluminação utilizada no processo de reconstrução óptica corresponde a uma lâmpada dicróica halógena ( $12 \mathrm{~V}, 50 \mathrm{~W}$ e comprimento de onda médio $\bar{\lambda}=633 \mathrm{~nm})$ da marca OSRAM mostrada na Figura 27. 


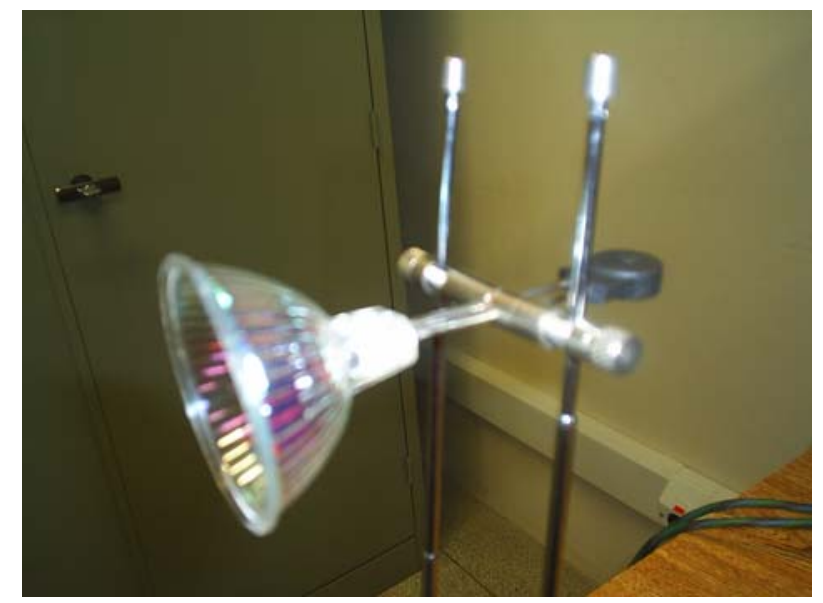

FIGURA 27- Lâmpada dicróica halógena $12 \mathrm{~V}, 50 \mathrm{~W}, \bar{\lambda}=633 \mathrm{~nm}$, da marca OSRAM, utilizada para obtenção da reconstrução óptica do elemento de luz branca.

Para a determinação do contraste da fonte luminosa utilizada para a reconstrução óptica do EOD de luz branca foram feitos três experimentos: difração da luz por uma fenda dupla (experimento de Young); difração da luz através de uma grade de difração, cujo período da rede é $10 \mu \mathrm{m}$, ou seja, da mesma ordem de grandeza da dimensão dos pixels do EOD; e difração da luz através do EOD de luz branca.

A montagem óptica utilizada nos experimentos acima está ilustrada na Figura 28. Para a reconstrução óptica do elemento de luz branca e posteriormente o cálculo do contraste da fonte luminosa empregada, foi realizada uma montagem, como visto na Figura 28, utilizandoe : suportes da marca Newport; uma lâmpada dicróica halógena $12 \mathrm{~V}, 50 \mathrm{~W}, \bar{\lambda}=633 \mathrm{~nm}$, da marca OSRAM (vide Figura 27); uma pupila Newport; uma câmera CCD Solid State COHU, acoplada a um PC; uma placa de aquisição NI-IMAQ 2.2 da National Instruments; e duas lentes, de distâncias focais $\mathrm{f}=0,15 \mathrm{~m}$ e $\mathrm{f}=0,25 \mathrm{~m}$, com o objetivo de projetar as imagens no plano do sensor da câmera CCD. 
42

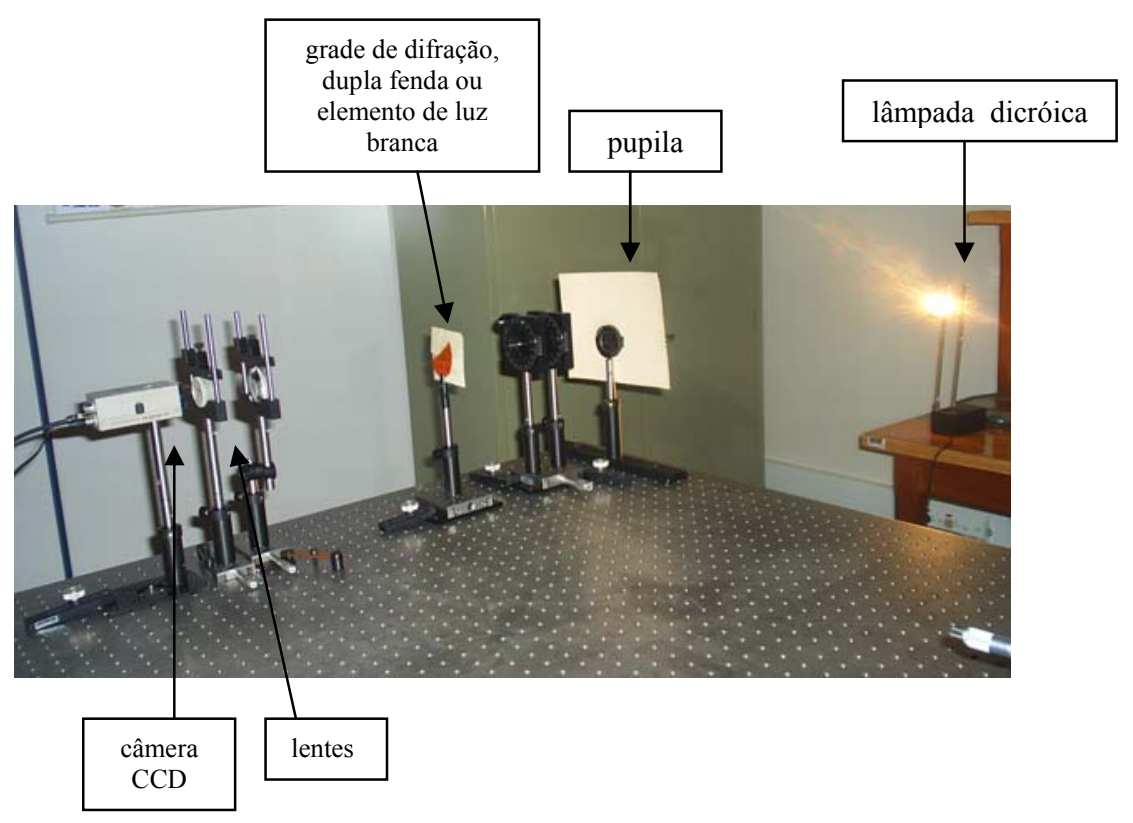

FIGURA 28-Montagem experimental para cálculo do grau de coerência realizada através de três metodologias: difração por uma fenda dupla, difração através de uma grade de difração e difração através do elemento de luz branca.

O grau de coerência da fonte luminosa foi calculado em cada experimento utilizando a formulação de (5). De acordo com (6), Seção 4.2, como a dimensão dos pixels é $20 \mu \mathrm{m}$, a distância $d\left(P_{1}, P_{2}\right)$, entre dois pontos coerentes em uma frente de onda, é a mínima distância entre dois pixels, $20 \mu \mathrm{m}$. O diâmetro do filamento da luz dicróica $\rho$ é $3 \mathrm{~mm}$, e o comprimento de onda médio $\bar{\lambda}$ é $633 \mathrm{~nm}$. O valor mínimo da distância $\mathrm{R}$ da fonte ao plano do EOD calculado para que haja coerência espacial é $0,6 \mathrm{~m}$. Tendo em vista estes resultados, a fenda dupla, a grade de difração e o elemento de luz branca foram posicionados a esta distância mínima da fonte luminosa, para que a condição de coerência fosse observada. A distância entre o plano do EOD 
de luz branca e o plano da câmera CCD foi fixada em $2 \mathrm{~cm}$, como constatado na reconstrução simulada computacionalmente.

Para cada experimento foram calculados quatro valores de contraste: um para a iluminação da lâmpada dicróica somente e outros três com a lâmpada dicróica associada separadamente com filtros (verde, vermelho e azul). Para o cálculo destes contrastes foi implementado um algoritmo simples para identificar os máximos e mínimos de intensidade nas imagens geradas em cada experimento pelos diferentes comprimentos de onda. Os resultados do cálculo dos contrastes dos experimentos são mostrados nas Tabelas I, II e III.

Tabela I. Contrastes determinados através da difração por uma grade de difração obtido com a fonte de luz branca separadamente e com filtros vermelho, verde e azul .

\begin{tabular}{|c|c|c|}
\hline \multicolumn{2}{|c|}{ 1.Grade de Difração } & Contraste \\
\hline Tipo de iluminação & $\begin{array}{c}\text { Comprimento de } \\
\text { onda } \lambda(\mathbf{n m})\end{array}$ \\
\hline Branca & 633 & 0,7899 \\
\hline Vermelha & 700 & 0,8168 \\
\hline Verde & 530 & 0,8216 \\
\hline Azul & 470 & 0,8155 \\
\hline
\end{tabular}


44

Tabela II. Contraste determinados através da difração por uma fenda dupla obtido com a fonte de luz branca separadamente e com filtros vermelho, verde e azul .

\section{Fenda de Young}

\begin{tabular}{|c|c|c|}
\hline Tipo de iluminação & $\begin{array}{c}\text { Comprimento de } \\
\text { onda } \boldsymbol{\lambda}(\mathbf{n m})\end{array}$ & Contrastes \\
\hline Branca & 633 & 0,8000 \\
\hline Vermelha & 700 & 0,8242 \\
\hline Verde & 530 & 0,7326 \\
\hline Azul & 470 & 0,7089 \\
\hline
\end{tabular}

Tabela III.(a) Contrastes determinados através da difração pelo elemento de luz branca Lenna obtidos com a fonte de luz branca separadamente e com filtros vermelho, verde e azul.

\begin{tabular}{|l|c|c|c|}
\hline \multicolumn{3}{|c|}{ 3.Elementos de luz branca } \\
\hline \multirow{4}{*}{ a) Lenna } & Tipo de iluminação & $\begin{array}{c}\text { Comprimento de } \\
\text { onda } \lambda(\mathbf{n m})\end{array}$ & Contrastes \\
\cline { 2 - 4 } & Branca & 633 & 0,7385 \\
\cline { 2 - 4 } & Vermelha & 700 & 0,8022 \\
\cline { 2 - 4 } & Verde & 530 & 0,7364 \\
\cline { 2 - 4 } & Azul & 470 & 0,7754 \\
\hline
\end{tabular}


Tabela III.(b) Contrastes determinados através da difração pelo elemento de luz branca gato obtidos com a fonte de luz branca separadamente e com filtros vermelho, verde e azul.

\begin{tabular}{|c|c|c|c|}
\hline & Tipo de iluminação & $\begin{array}{c}\text { Comprimento de } \\
\text { onda } \lambda(\mathbf{n m})\end{array}$ & Contrastes \\
\cline { 2 - 4 } & Branca & 633 & 0,7034 \\
\cline { 2 - 4 } & Vermelha & 700 & 0,7509 \\
\cline { 2 - 4 } & Verde & 530 & 0,7706 \\
\cline { 2 - 4 } & Azul & 470 & 0,7385 \\
\hline
\end{tabular}

Tabela III.(c) Contrastes determinados através da difração pelo elemento de luz branca tigre obtidos com a fonte de luz branca separadamente e com filtros vermelho, verde e azul.

\begin{tabular}{|l|c|c|c|}
\hline \multirow{4}{*}{ c)Tigre } & Tipo de iluminação & $\begin{array}{c}\text { Comprimento de } \\
\text { onda } \lambda(\mathbf{n m})\end{array}$ & Contrastes \\
\cline { 2 - 4 } & Branca & 633 & 0,7024 \\
\cline { 2 - 4 } & Vermelha & 700 & 0,7324 \\
\cline { 2 - 4 } & Verde & 530 & 0,7754 \\
\cline { 2 - 4 } & Azul & 470 & 0,7385 \\
\hline
\end{tabular}


46

Tabela III.(d) Contrastes determinados através da difração pelo elemento de luz branca periquito obtidos com a fonte de luz branca separadamente e com filtros vermelho, verde e azul.

\begin{tabular}{|c|c|c|c|}
\hline & Tipo de iluminação & $\begin{array}{c}\text { Comprimento de } \\
\text { onda } \lambda(\mathbf{n m})\end{array}$ & Contrastes \\
\cline { 2 - 4 } & Branca & 633 & 0,7376 \\
\cline { 2 - 4 } d)Periquito & Vermelha & 700 & 0,8022 \\
\cline { 2 - 4 } & Verde & 530 & 0,7501 \\
\cline { 2 - 4 } & Azul & 470 & 0,7698 \\
\hline
\end{tabular}

Os resultados dos experimentos com a fenda dupla, a grade de difração e o elemento de luz branca mostrados nas Tabelas I, II e III indicam contrastes para a luz branca e para os comprimentos de onda verde, vermelho e azul. Nota-se que o contraste obtido através da fonte de luz branca e de suas componentes estão muito próximos. Estão ilustradas nas Figuras 29-32 as reconstruções ópticas do EOD de luz branca para os seguintes casos: lâmpada dicróica somente e lâmpada dicróica associada com filtros isolados (vermelho, verde e azul). 


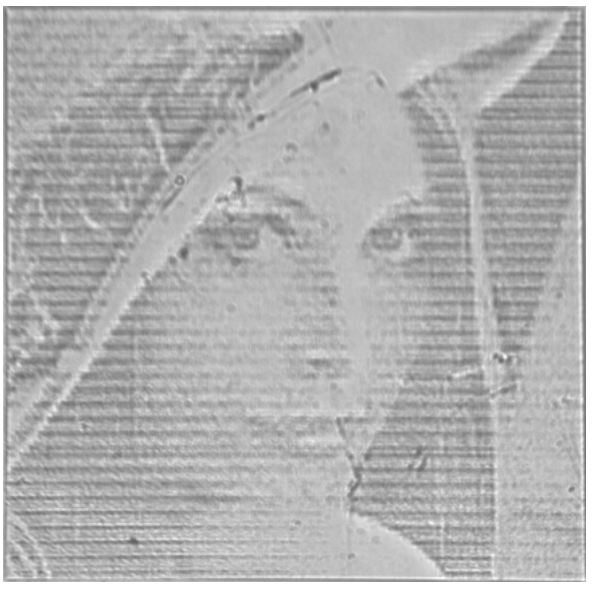

(a)

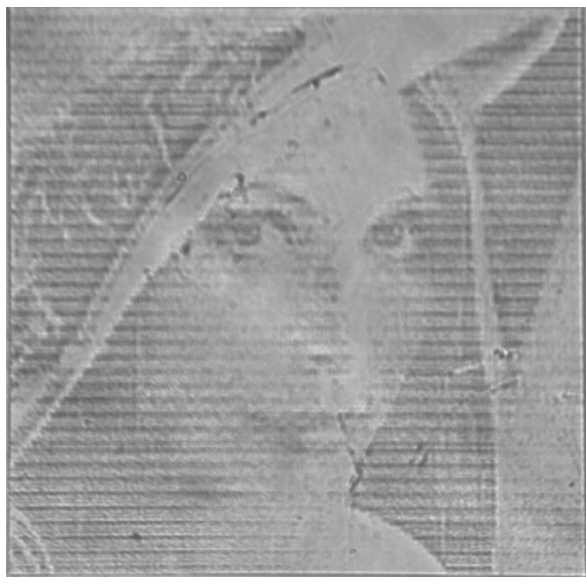

(c)

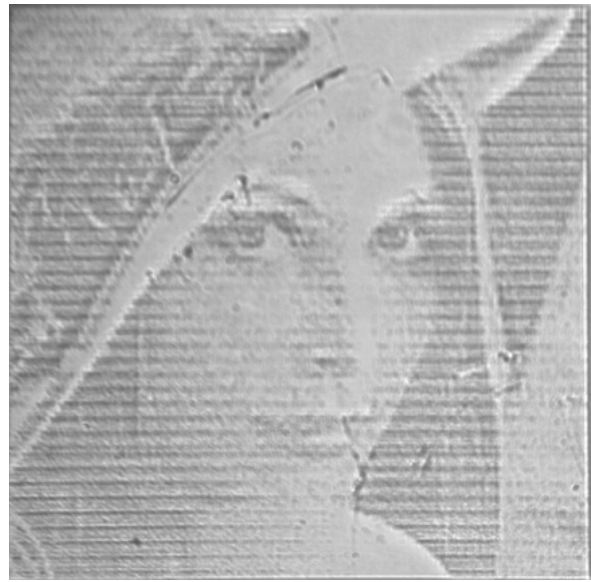

(b)

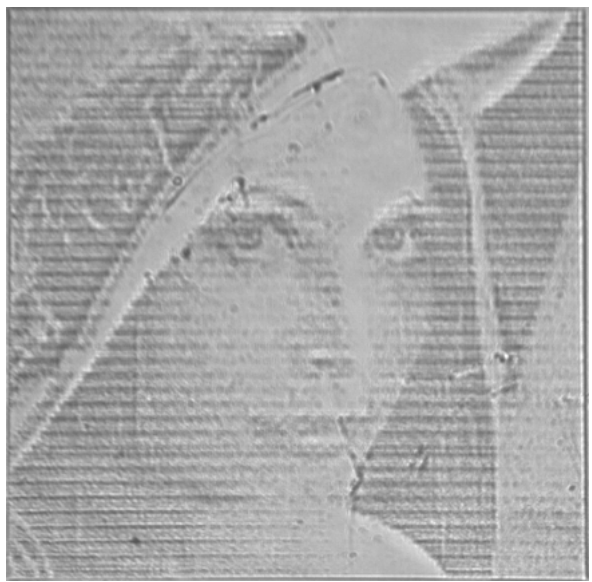

(d)

FIGURA 29- Reconstruções ópticas geradas a partir do elemento de luz branca "Lenna" utilizando: (a)

lâmpada dicróica somente; e lâmpada dicróica com filtros (b) vermelho; (c) verde e (d) azul. 


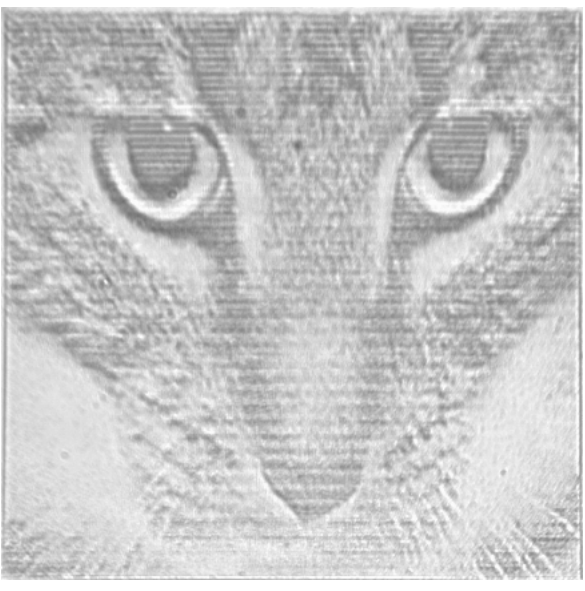

(a)

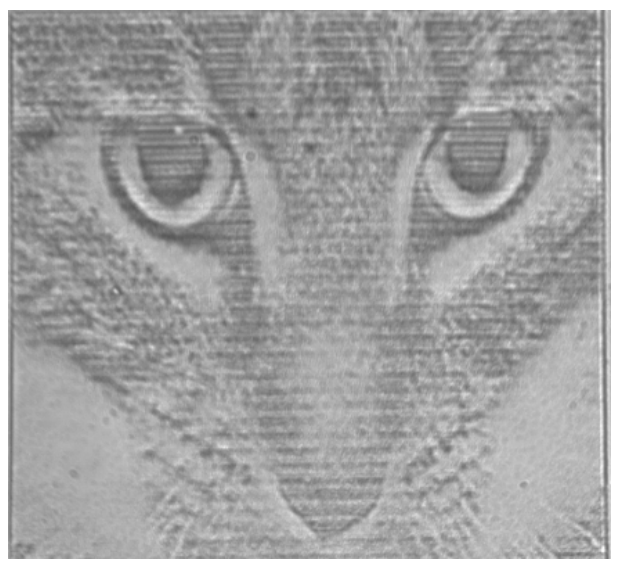

(c)

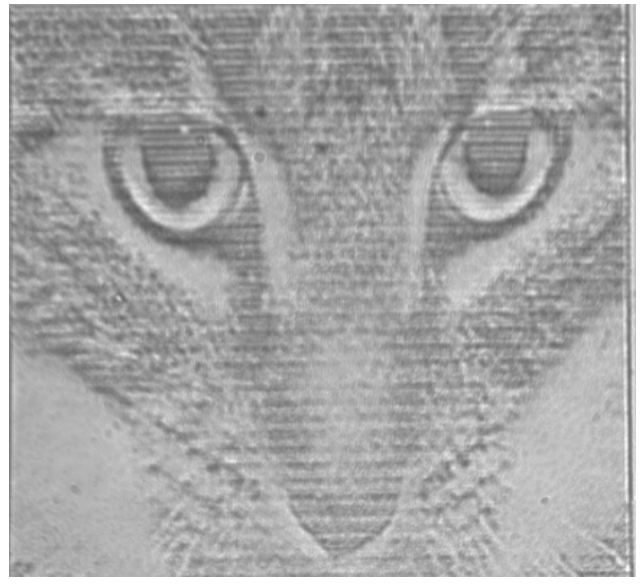

(b)

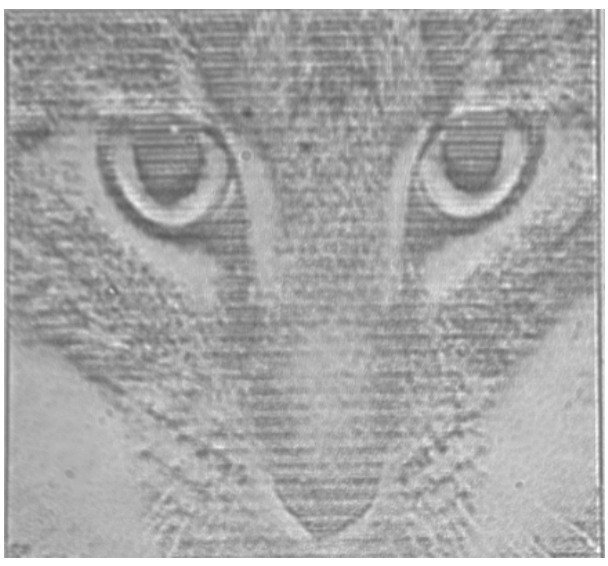

(d)

FIGURA 30- Reconstruções ópticas geradas a partir do elemento de luz branca "gato" utilizando: (a) lâmpada dicróica somente; e lâmpada dicróica com filtros (b) vermelho; (c) verde e (d) azul. 


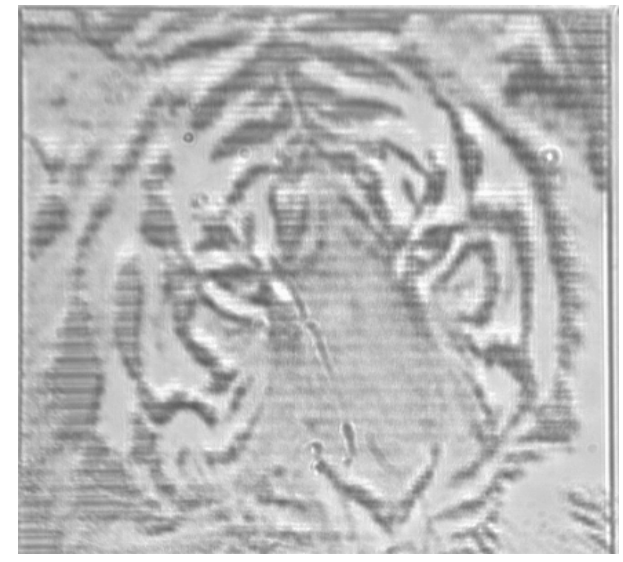

(a)

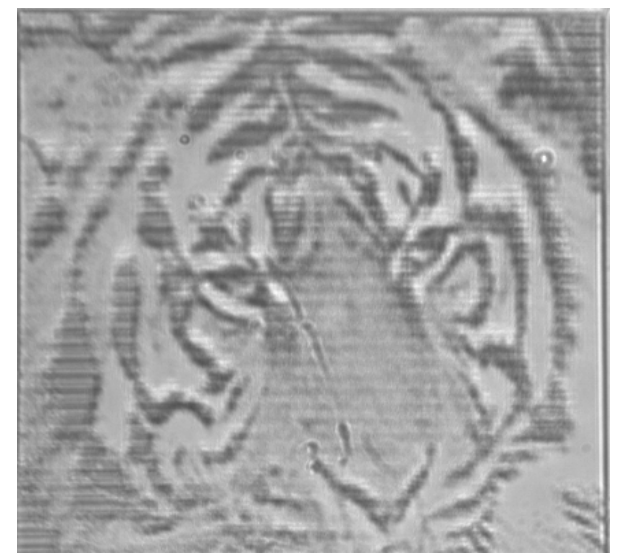

(c)

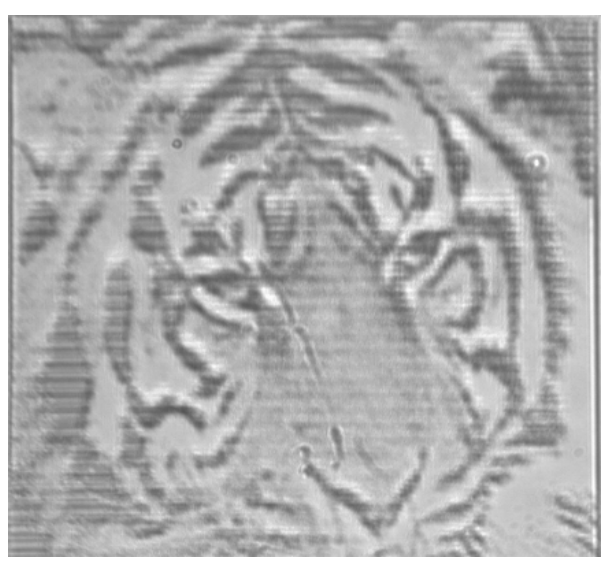

(b)

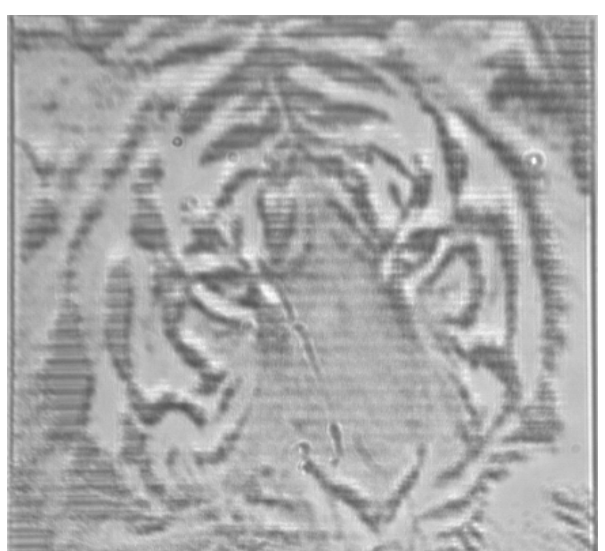

(d)

FIGURA 31- Reconstruções ópticas geradas a partir do elemento de luz branca "tigre" utilizando: (a)

lâmpada dicróica somente; e lâmpada dicróica com filtros (b) vermelho; (c) verde e (d) azul. 


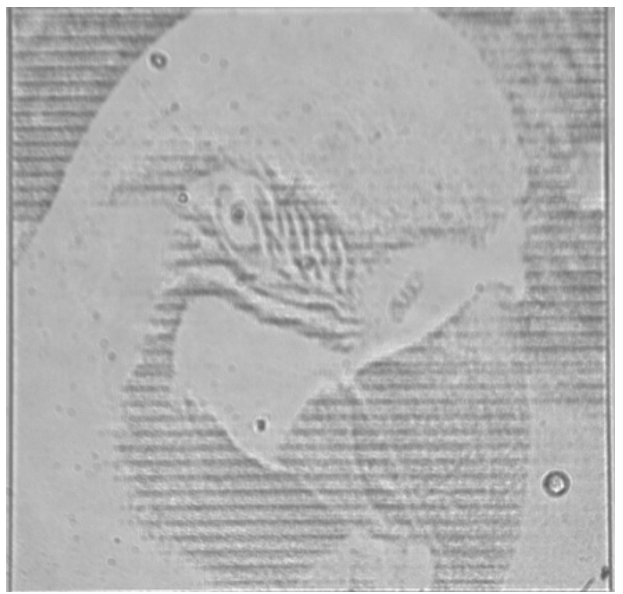

(a)

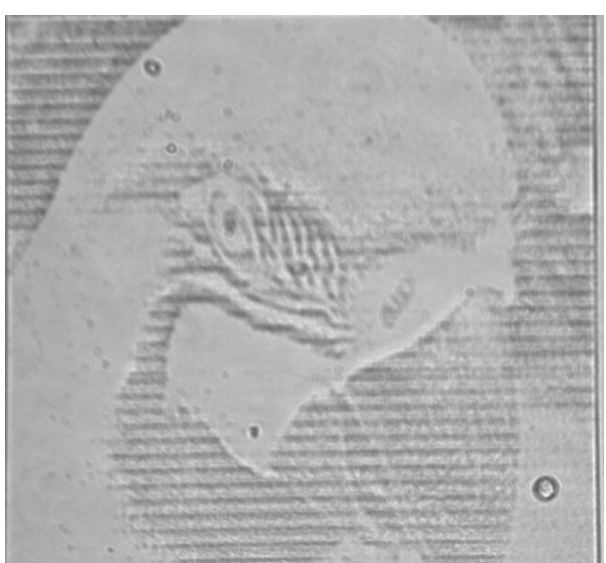

(c)

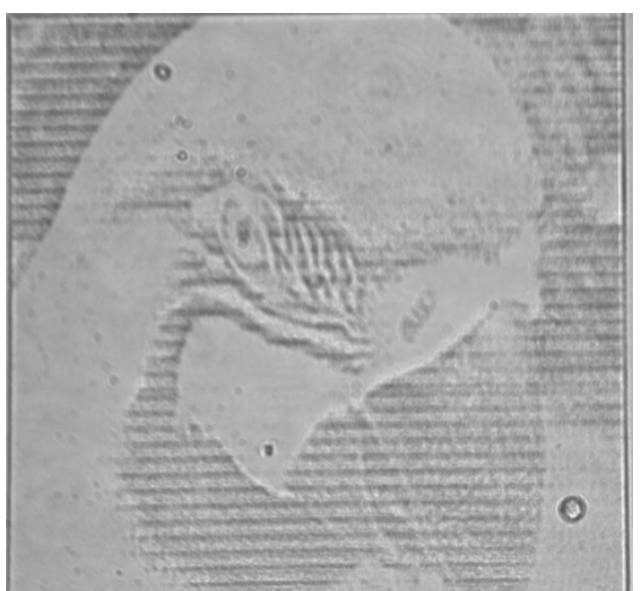

(b)

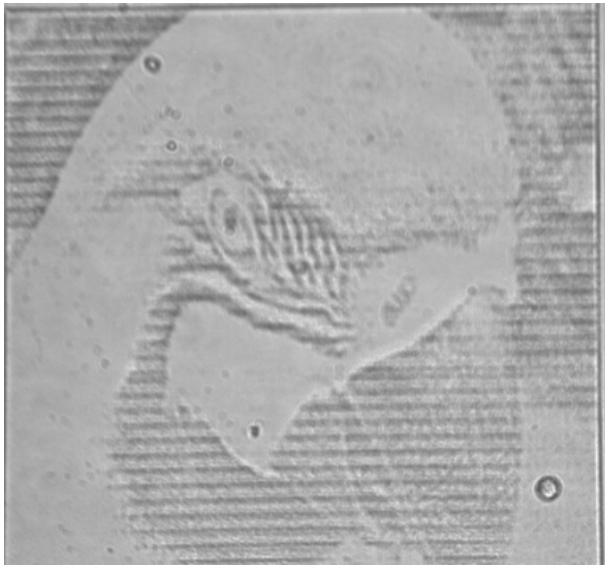

(d)

FIGURA 32- Reconstruções ópticas geradas a partir do elemento de luz branca "periquito" utilizando: (a)

lâmpada dicróica somente; e lâmpada dicróica com filtros (b) vermelho; (c) verde e (d) azul. 
Como pode ser visto nas Figuras 29(a), 30(a), 31(a) e 32(a), as reconstruções ópticas geradas pelos elementos ópticos difrativos de luz branca apresentam boa nitidez e resultados satisfatórios. Não foi observada distorção cromática considerável, como o efeito rainbow constatado em outros hologramas de luz branca convencionais. As reconstruções ópticas do EOD de luz branca obtidas com luz branca somente, e com suas componentes vermelha, verde e azul são muito semelhantes. Segundo o conceito de amostragem (vide Apêndice C), os intervalos de amostragem são proporcionais ao comprimento de onda $\lambda$. Entretanto, a diferença de tamanho dos pixels das imagens de reconstrução geradas pelos três comprimentos de onda não é perceptível ao olho humano e, segundo o princípio da superposição, descrito no Apêndice $B$, cada pixel da imagem resultante gerada a partir do elemento de luz branca iluminado com a lâmpada dicróica é a soma de todos os pixels de cada imagem gerada pelos diferentes comprimentos de onda que a compõem. Os pixels se sobrepõem e o olho humano integra a imagem, de tal forma que distorções cromáticas não são observadas. 
52

\section{Capítulo 7}

\section{Introdução}

No capítulo anterior foram apresentados resultados experimentais referentes as reconstruções ópticas utilizando os EODs construídos. Neste capítulo serão destacadas algumas conclusões e considerações em relação ao EOD de luz branca proposto.

\section{7-Conclusões}

O cálculo e simulação do elemento de luz branca foram propostos a partir de um algoritmo que utiliza a transformada de Fourier como ferramenta para o cálculo da propagação de luz através do elemento binário, construído utilizando uma imagem gerada pela técnica de halftoning, obtida rearranjando-se regiões de pixels que apresentam coerência espacial local. Esta proposta de fabricação utiliza óptica binária de baixo custo, uma vez que foi introduzida uma modulação de fases 0 e $\pi$.

Uma das vantagens da utilização deste algoritmo é a eliminação de métodos iterativos, utilizados na maioria dos hologramas gerados por computador. Utilizando conceitos da técnica de halftoning no algoritmo proposto, pode-se gerar uma máscara para produzir o elemento de luz branca facilmente, utilizando uma impressora de alta resolução e técnicas de fabricação de circuito impresso.

Uma outra vantagem deste EOD de fase de luz branca é que os resultados da reconstrução óptica mostram mínima distorção cromática, imperceptível ao olho humano, ao contrário do 
observado em hologramas de luz branca convencionais. Outras vantagens importantes são o baixo custo e o tempo envolvidos no processo de fabricação do EOD de luz branca proposto, já que este utiliza técnicas simples de fabricação de circuitos impressos.

Os resultados obtidos a partir da reconstrução óptica e simulada do EOD de fase de luz branca apresentam semelhança entre si, o que indica que o algoritmo proposto neste trabalho foi capaz de reproduzir este comportamento óptico do elemento, de forma simples e sem necessidade de métodos complexos ou iterativos.

O EOD de luz branca poderia ser utilizado em diversas aplicações: processamento óptico não-corente (correlatores ópticos), sistemas de segurança para autenticação de informações (documentos, cartões de crédito) e projeção de imagens holográficas como arte. 
54

\section{Capítulo 8}

\section{8-Referências Bibliográficas}

[1]GABOR, D.(1948). “A new microscope principle”. Nature, vol. 161, pp.777.

[2] DENISYUK, Y. N.(1997). "From Lippmann photography to selectograms via white light holography”. Journal of imaging science and tecnology. vol 41(3), pp.205-210, mai/jun.

[3] BENTON, S. A.(1969). "On a method for reducing the information content of holograms .Journal of Optical Society of America, vol.59, pp.1969.

[4] SIEBERT, L. D.(1967). "Front-lighted pulse laser holography". Applied Physics Letters, vol. 11(10), pp.326.

[5] MOLLENST, G. ; WAHL, H.(1968). "Electron holography and reconstruction with laser light”.Naturwissenschaften, vol.55(7), pp. 340.

[6] TANNER, L.H. (1968). “A study of fringe clarity in laser interferometry and holography. Journal of Physics e Scientific Instruments, vol.1(5), pp. 517.

[7] GERCHBERG, R. W ; SAXTON, W.O. (1972). Optik vol.35, pp. 237.

[8] HIRSCH, P.M.; JORDAN, J.A.; LESEM, L.B. (1971). US Patent Nº 3.619.022.

[9] BROWN, B. R.; LOHMANN, A.W.(1969). IBM J. Res. \& Dev. vol. 13, pp160.

[10] LOHMANN, A.W; PARIS, D.P. (1967). Applied Optics vol.6, pp.1739.

[11] BROWN, B. R.; LOHMANN, A.W.(1969). IBM J. Res. \& Dev. vol. 14, pp. 380

[12] LEE, W. H.(1974). Binary Synthetic Holograms. Applied Optics vol. 13, 1677-1682.

[13] SELDOWITZ, M. A.; ALLEBACH, J. P.; SWEENEY, D. W.(1987).Synthesis of digital holograms by direct binary search. Applied Optics, vol. 26, nº 14, pp. 2788-2797. 
[14] HAUCK, R.; BRYNGDAHL, O.(1984). Computer-Generated Holograms with PulseDensity Journal of Optical Society of America A1, 5-10.

[15] WYROWSKI, F.(1989). Iterative quantization of digital amplitude holograms. Applied Optics, vol. 28, nº18, pp.3864-3870.

[16] WYROWSKI, F.(1989). Diffractive optical elements: iterative calculation of quantized, blase phase structures. Journal of Optical Society of America A, vol.7, nº, pp.961-969.

[17] TURUNEN, J. ; WYROWSKI, F. (1997) - In : Diffractive Optics for Industrial and Commercial Applications (Akademie Verlag, Alemanha).

[18] Y. FU et al.Temporal wavelet analysis for deformation and velocity measurement in speckle interferometry. In: SPIE Optical Engineering Press, ISSN 0091-3286,1994.

[19] ARSENAULT H.; SHENG Y. An Introduction to Optics in Computers. In: SPIE Optical Engineering Press, ISBN 0-8194-0825-5, 1992.

[20] NETO; L. G. et al (2003). Design, fabrication and characterization of a full complexamplitude modulation difractive optical element. Journal of Microlithography Microsystems and Microfabrication, vol.2, n², pp. 96-104.

[21] PIZOLATO JUNIOR; J. C. Novas Técnicas de contraste de fase para a verificação de padrões cifrados, [Tese], Escola de Engenharia de São Carlos, Universidade de São Paulo, 2006.

[22] ICHIOKA, Y.; IZUMI, M.; SUZUKI, T.(1971). Scanning halftone plotter and computergenerated continuous-tone hologram. Applied Optics vol. 10(2), pp. 403.

[23] CAULFIELD, H. J.; MUELLER P. et al (1983). Continuous tone holograms by halftoning. In: PROCEEDINGS OF SPIE, vol. 437.

[24] PINHASI, Y.; PERI, D.(1993). “A generalized analysis of binary half-tone representation of images".Optics Communications, vol. 101(3-4), pp. 277-285. 
[25] PIZOLATO JUNIOR, J. C.; et al.(2007). Zeroth-order phase-contrast technique, Applied Optics, vol. 10. No prelo.

[26] MERZLYAKOV, N. S.; MOZEROV, M. G. (1998). “Computer-generated True-color Rainbow Holograms”.Optics and Lasers in Engineering, vol. 29, pp.369-376.

[27] SANDO, Y.; ITOH, M.; YATAGAI, T.(2004). “Color computer-generated hologram from projection images”. Optical Society of America, vol. 12(11), pp.2487-2493.

[28]GONÇALVES, C.; et al. White light computer-generated element based on halftoning. In: XXX Encontro Nacional de Física da Matéria Condensada, 2007, São Lourenço.

[29] GONÇALVES, C. et al. White light computer-generated element based on halftoning. In: OSA Topical meetings, 2007,Vancouver, Canadá.

[30] VELDKAMP, W. B.; MCHUGH, T. J. (1992).“Binary Optics”, Scientific American, maio, pp.92-97.

[31] Consulte artigos em “Applied Optics - Diffractive Optics”. vol. 34, n¹4.

[32]GOODMAN, J.W. Foundations of Scalar Diffraction Theory. In: "Introduction to Fourier Optics”. McGraw-Hill Publishing Company, 1988.

[33] HECHT, E. “Optics”, Addison-Wesley Publishing Company, Inc,1984.

[34] LI, M.; et al.(1996). “Optical Waveguide Fan out Elements Using Dislocated Gratings for Both Outcoupling and Phase Shifting”, IEEE Photonics Technology Letters, vol. 8, $\mathrm{n}^{\circ} 9$.

[35]VELDKAMP, W. B. "Wireless Focal Planes: On the Road to Amacronic Sensors", IEEE Journal of Quantum Electronics, vol.29, nº. 2, February 1993, p.801-813.

[36] AGRAWAL, G. P. “Fiber-Optics Comunication Systems”, John Wiley \& Sons, Inc, 1992, p.282.

[37] SHENG.,Y; ROBERGE, D., NETO,L.G; L. SHEN e PAUL-HUS G, “Programmable phasemostly holograms and correlation filters", Laser and Opt. Tech., vol. 28, nº.2, pp.129-143, 1996 
[38] SHENG.,Y et al. (1996). “Optoelectronic Devices and Systems for Processing”,A. Critical Reviews Series, SPIE Optical Engineering Press, pp.103-127.

[39] BULLA, D.A.P; et al. (2002)“Design and Fabrication of $\mathrm{SiO}_{2} / \mathrm{Si}_{3} \mathrm{~N}_{4}$ Integrated-Optics Waveguides with Application to Free-Space Optical Interconnects", IEEE Transactions on Microwave Theory and Techniques - Special Issue on Selected Papers of the International Microwave and Optoelectronics Conference - IMOC'99.

[40] VAN RENESSE, R.L. In: “Optical document security”, $2^{\text {nd }}$ Edition, Artech House Optoelectronics Library,1997.

[41] BRYNGDAHL, O.; WYROWSKI, F.(1990). Digital Holography - Computer-Generated Holograms. E. Wolf, Progress in Optics XXVIII, Elsevier Science Publishers B.V.

[42] ROBERTO, L. B. Algoritmos para o Cálculo de Hologramas Gerados por Computador. [Dissertação], Escola de Engenharia de São Carlos, Universidade de São Paulo, 2000.

[43] BORN, M.; WOLF, E. "Principles of Optis-Eletromagnetic Theory of Propagation Interference and Difraction of Light", Editora Pergamon, 1980.

[44] GONZALEZ, R. C ; WOODS, R. E. In:“Digital Image Processing”, $2^{\text {nd }}$ Edition, Prentice Hall, 2002.

[45] BRACEWELL, R. N. In: “The Fourier Transform \& Its Applications”, $3{ }^{\text {rd }}$ Edition, McGraw-Hill Science/Engineering/Math ,1999. 
Apêndice A

\section{A-Transformada de Fourier}

$$
F\{g\} \equiv \iint_{-\infty}^{\infty} g(x, y) \exp \left[-j 2 \pi\left(f_{x} x+f_{y} y\right)\right] d x d y
$$

Onde $f_{x}$ e $f_{y}$ são as freqüências relativas às coordenadas do plano xy.

\section{B-Equação de Helmholtz}

$$
A\left(\frac{\alpha}{\lambda}, \frac{\beta}{\lambda}, z\right) \equiv \int_{-\infty}^{\infty} U(x, y, z) \exp \left[-j 2 \pi\left(\frac{\alpha}{\lambda} x+\frac{\beta}{\lambda} y\right)\right] d x d y
$$

Onde A é o espectro angular de uma perturbação $U$, e $\alpha=\lambda f_{x} ; \beta=\lambda f_{y}$. 


\section{Apêndice B}

\section{Resposta impulsional, função transferência, e sistemas lineares invariantes}

Muitos fenômenos físicos apresentam uma resposta a vários estímulos como sendo identicamente iguais à soma de suas várias respostas contabilizadas individualmente. Quando isto ocorre, o sistema é chamado linear. Exemplos destes são redes elétricas compostas de resistores, capacitores e resistores, que são lineares para várias entradas. Analogamente, a equação de onda descrita pela propagação da luz ao longo de muitos meios permite a análise de operações de imagem como um mapeamento linear de distribuições luminosas de um objeto em distribuições luminosas de uma imagem.

Analisar a formação de imagens utilizando-se a propriedade de linearidade é uma vasta simplificação matemática, a qual recorre-se à teoria de sistemas lineares. A vantagem de se utilizar esta teoria é a habilidade de expressar a resposta (seja corrente, tensão, amplitude da luz ou intensidade luminosa) em termos de respostas a estímulos elementares. Quando um estímulo é decomposto em uma combinação linear de pequenos estímulos, cada um destes produz uma resposta, e a resposta total é calculada como a soma de todas as respostas aos estímulos elementares.

Se a iluminação utilizada em um sistema óptico apresenta coerência espacial local, a luz pode ser descrita como um campo de valores complexos de amplitude, e é interessante descrevêla como uma distribuição de valores reais de intensidade. Para sistemas lineares invariantes no tempo, como o caso de um sistema óptico com iluminação parcialmente coerente, a análise de 
60

Fourier é uma ferramenta útil para simplificar os cálculos de funções de saída do sistema, no caso, as imagens reproduzidas.

A transformada de Fourier de uma função $g(x, y)$ é representada por $F\{g\}$ e é definida por:

$$
F\{g\} \equiv \int_{-\infty}^{\infty} g(x, y) \exp \left[-j 2 \pi\left(f_{x} x+f_{y} y\right) d x d y\right]
$$

onde $\mathrm{g}(\mathrm{x}, \mathrm{y})$ é a função de entrada, $\mathrm{f}_{\mathrm{x}}$ e $\mathrm{f}_{\mathrm{y}}$ são freqüências no plano de coordenadas.

Da mesma forma, a transformada de Fourier inversa é definida por:

$$
F\{G\} \equiv \iint_{-\infty}^{\infty} G\left(f_{x}, f_{y}\right) \exp \left[j 2 \pi\left(f_{x} x+f_{y} y\right) d f_{x} d f_{y}\right]
$$

Considerando que a fonte luminosa esteja a uma distância considerável, de forma que seja vista como puntual, esta fonte pode ser representada por uma função delta de Dirac, definida por:

$$
\delta(x, y) \equiv \lim _{N \rightarrow \infty} N^{2} \exp \left[\left(-N^{2} \pi\left(x^{2}+y^{2}\right)\right)\right]
$$

onde $\mathrm{N}$ é um valor arbitrário. A transformada de Fourier para a função $\delta$ é então:

$$
F\{\delta(x, y)\} \equiv \lim _{N \rightarrow \infty}\left\{\exp \left[-\frac{\pi\left(f_{x}^{2}+f_{y}^{2}\right)}{N^{2}}\right]\right\} \equiv 1
$$

O espectro da função delta se estende ao longo do domínio das freqüências.

Segundo o teorema da convolução, sejam $F[g(x, y)] \equiv G\left(f_{x}, f_{y}\right)$ e $F[h(x, y)] \equiv H\left(f_{x}, f_{y}\right)$, tem-se:

$$
F\left\{\iint_{-\infty}^{\infty} g\left(x^{\prime}, y^{\prime}\right) h\left(x-x^{\prime}, y-y^{\prime}\right) d x^{\prime} d y^{\prime}\right\} \equiv G\left(f_{x}, f_{y}\right) H\left(f_{x}, f_{y}\right)
$$

onde x' e y' são coordenadas do plano xy.

Outra função de interesse em sistemas lineares invariantes, como um sistema óptico com iluminação parcialmente coerente, é a função transferência. No caso do holograma de Fresnel, sejam z a distância de um plano onde situa-se o holograma e o plano de reconstrução de sua 
imagem e $\lambda$ o comprimento de onda da fonte luminosa empregada no sistema óptico, a função transferência $H\left(f_{x}, f_{y}\right)$ é definida por:

$$
H\left(f_{x}, f_{y}\right)=\left\{\exp \left[j 2 \pi \frac{z}{\lambda} \sqrt{1-\left(\lambda f_{x}\right)^{2}-\left(\lambda f_{y}\right)^{2}}\right], \text { para } \sqrt{f_{x}{ }^{2}+f_{y}^{2}}<\frac{1}{\lambda}\right.
$$

O espectro de uma função de saída de um sistema, $G_{2}\left(f_{x}, f_{y}\right)$ está relacionado com o espectro de entrada $G_{1}\left(f_{x}, f_{y}\right)$ pela função transferência, de tal forma que:

$$
G_{2}\left(f_{x}, f_{y}\right) \equiv H\left(f_{x}, f_{y}\right) G_{1}\left(f_{x}, f_{y}\right)
$$

Para calcular a imagem de reconstrução, calcula-se a função transferência do sistema e, posteriormente, faz-se uma operação de convolução com a imagem de interesse, a fim de se obter a sua reconstrução. 
62

\section{Apêndice C}

\section{Amostragem no plano de freqüências}

O processo de holografia, tanto analógico como digital, envolve invariavelmente a criação de um campo complexo no plano do holograma, um campo que deve ser regenerado com o processo de reconstrução da frente de onda. Para hologramas gerados por computador, este campo é calculado utilizando um computador, e deve ser amostrados e os valores complexos são computados em cada ponto de amostra. Para saber quantas amostras do campo devem ser computadas, deve-se considerar que o objetivo é criar um campo do holograma que seja a transformada de Fourier do campo do objeto que deseja-se reproduzir. Considerando o caso do holograma de Fresnel, a relação entre a largura de banda do campo do holograma e o tamanho do objeto pode ser aproximada por uma função. Um objeto no caso é visto como uma função $U_{0}(x, y) \exp \left[j \frac{\pi}{\lambda z}\left(x^{2}+y^{2}\right)\right]$, onde $\mathrm{U}_{0}$ é a amplitude da intensidade luminosa, $\mathrm{x}$ e y são coordenadas espaciais, $\lambda$ é o comprimento de onda da iluminação e z é a distância entre o plano do holograma e o plano de reconstrução, como visto na Figura A1. A presença de uma distribuição de fase ao longo do objeto não afeta a distribuição de intensidade, que é a quantidade que deseja-se recriar através do campo do holograma. As larguras de banda do holograma podem ser obtidas, de acordo com Goodman[32] como :

$$
2 B_{x}=\frac{L_{x^{\prime}}+L_{x}}{\lambda z}
$$




$$
2 B_{y}=\frac{L_{y^{\prime}}+L_{y}}{\lambda z}
$$

onde $L_{x^{\prime}}, L_{x}, L_{y^{\prime}}, L_{y}$ são freqüências espaciais locais e $\mathrm{B}_{\mathrm{x}} \mathrm{e} \mathrm{B}_{\mathrm{y}}$ são as larguras de banda nas direções dos eixos $\mathrm{x}$ e y respectivamente.

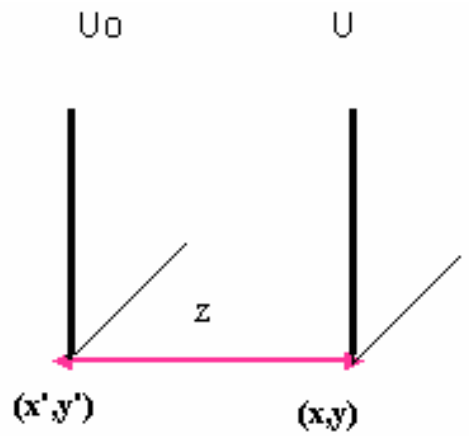

FIGURA A1-Ilustração do holograma de Fresnel; $(x, y)$ são as coordenadas do plano do holograma e $\left(x^{\prime}, y^{\prime}\right)$ as coordenadas do plano de reconstrução.

A largura de banda depende da extensão do campo de um objeto e do campo do holograma. Os intervalos de amostragem nos eixos x e y neste caso são definidos como:

$$
\begin{gathered}
\Delta x=\frac{\lambda z}{L_{x^{\prime}}+L_{x}} \\
\Delta y=\frac{\lambda z}{L_{y^{\prime}}+L_{y}}
\end{gathered}
$$

Sendo assim, o número total de amostras em x e y, necessárias para reconstruir o objeto através do holograma é:

$$
N_{x}=\frac{L_{x}}{\Delta_{x}}
$$


64

$$
N_{y}=\frac{L_{y}}{\Delta_{y}}
$$

De acordo com as equações 1 a 6 , observa-se que para cada comprimento de onda há um determinado número de amostras requeridas e um intervalo de amostragem. Todas as contribuições provenientes da luz branca, ou seja, vários comprimentos de onda são somados a fim de se obter a imagem de reconstrução resultante, segundo o princípio da superposição. Estes valores podem ser alterados conforme o comprimento de onda da iluminação utilizada. Considerando que neste trabalho foi utilizada luz branca, cujo comprimento de onda médio $\bar{\lambda}$ é da ordem de $633 \mathrm{~nm}$, a soma de várias contribuições relativas a vários comprimentos de onda vai gerar a imagem de reconstrução. 
Dedicatória

“À minha mãe, minha primeira e grande professora”. 
Agradecimentos

Ao professor Dr. Luiz Gonçalves Neto, pela orientação e amizade durante a elaboração deste trabalho.

À Coordenadoria de Aperfeiçoamento de Pessoal de Nível Superior, CAPES, pela bolsa de estudos concedida.

A todos os colegas, professores e funcionários do Departamento de Engenharia Elétrica da EESC/USP pela colaboração e amizade.

Ao Dr. José Carlos Pizolato Junior, pelo apoio e auxílio durante a execução deste trabalho.

A meus pais, José Carlos e Rosely, aos quais agradeço pela compreensão, paciência e apoio oferecido para a conclusão de meus estudos. 


\section{SUMÁRIO}

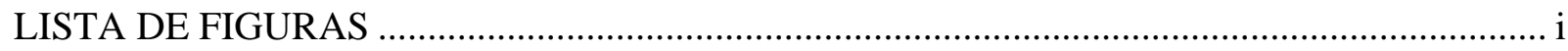

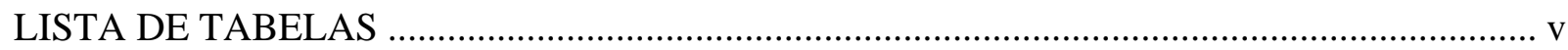

LISTA DE ABREVIATURAS E SIGLAS …...................................................................... vi

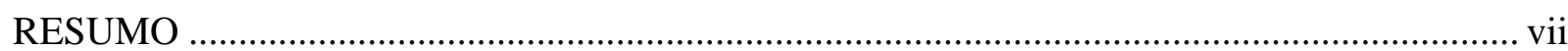

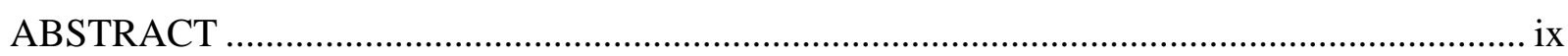

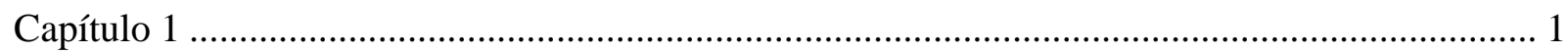

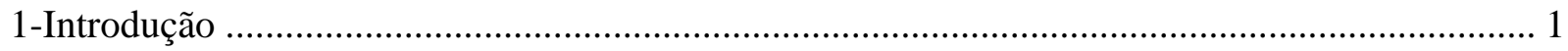

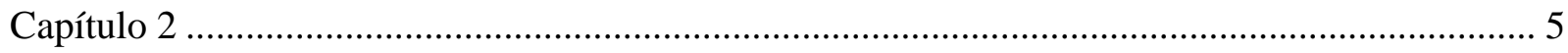

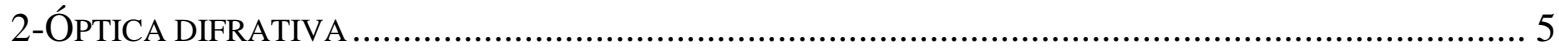

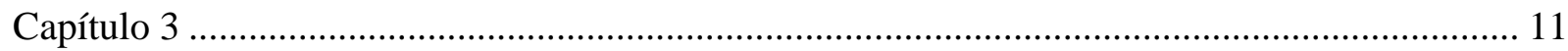

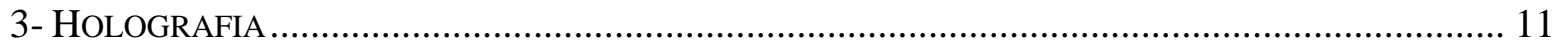

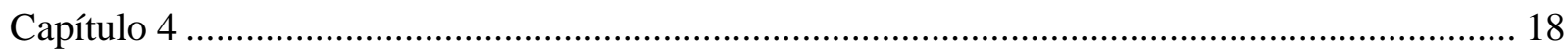

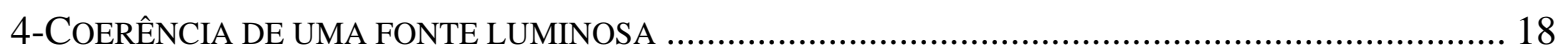

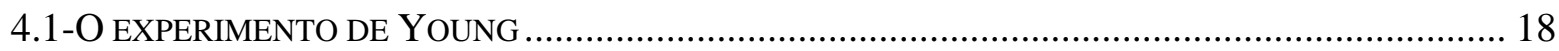

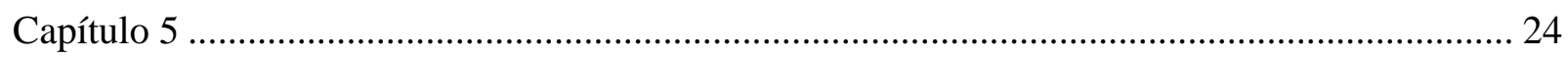

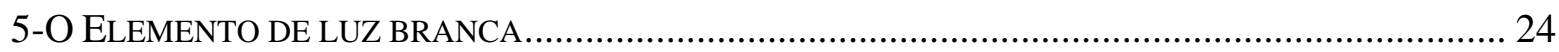

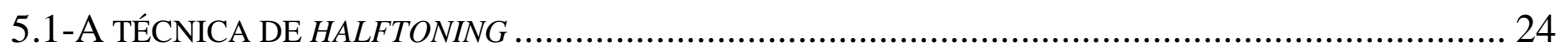

5.2-PROCESSO DE CODIFICAÇÃO DO ELEMENTO DE LUZ BRANCA .............................................. 26

5.3-SIMULAÇÃO E FUNCIONAMENTO DO ELEMENTO DE LUZ BRANCA …....................................... 27

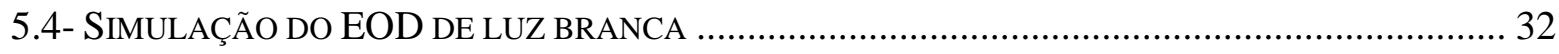

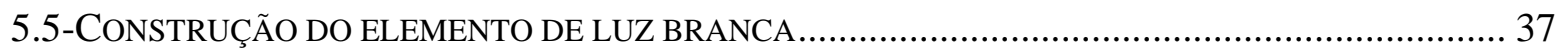

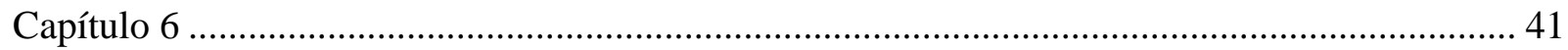




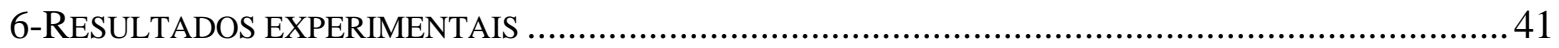

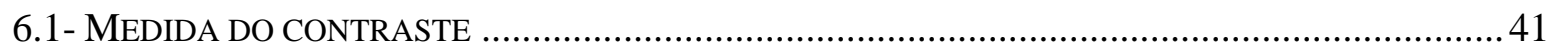

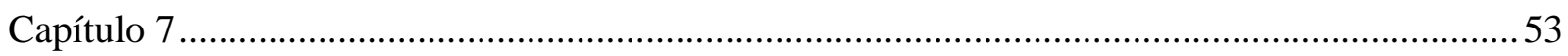

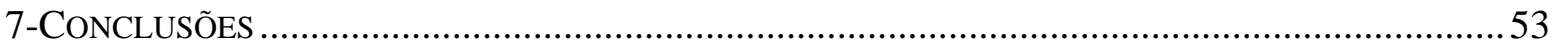

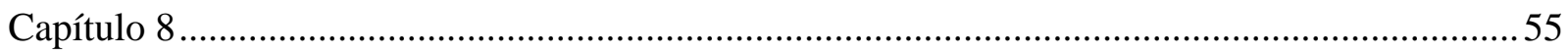

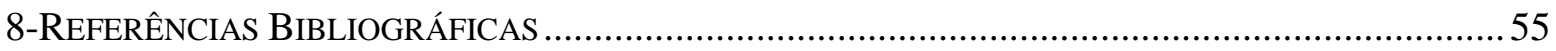

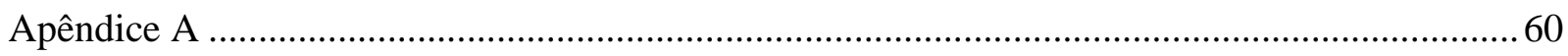

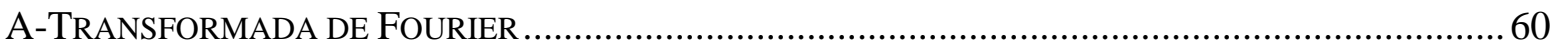

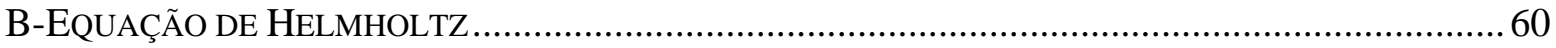

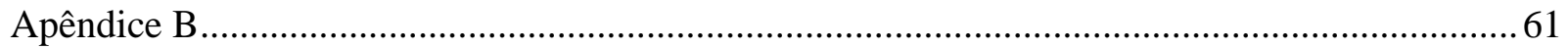

RESPOSTA IMPULSIONAL, FUNÇÃO TRANSFERÊNCIA, E SISTEMAS LINEARES INVARIANTES...........61

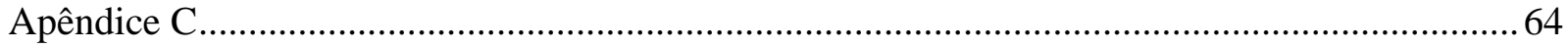

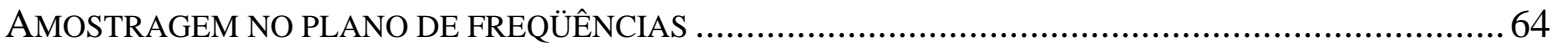

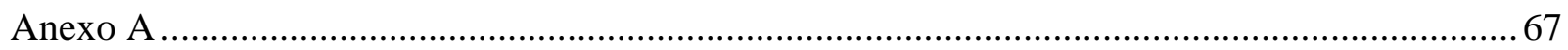

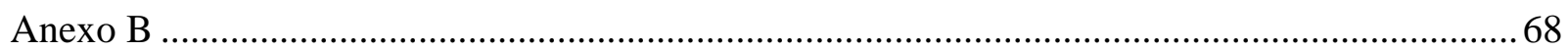




\section{LISTA DE FIGURAS}

FIGURA 1- Princípio de Huygens-Fresnel [33], onde cada ponto de uma frente de onda incidente age como uma nova fonte de onda esférica, cuja interferência construtiva ou destrutiva de cada onda esférica por sua vez nos dá uma nova frente de onda.

FIGURA 2-Obtenção de uma distribuição de luz desejada utilizando-se um Elemento Óptico Difrativo para a modulação de uma frente de luz incidente.

FIGURA 3- Os EODs podem ser classificados em três grupos [34]: (a) espaço-livre para espaço-livre; (b) onda-guiada para onda-guiada; e (c) onda-guiada para espaço-livre (ou espaço-livre para onda-guiada).

FIGURA 4- (a)Holograma rainbow convencional, (b) cédula monetária de 20 reais, emitida pelo Banco do Brasil, utilizando um holograma rainbow como elemento de identificação; e (c) detalhe do holograma impresso na cédula de 20 reais.No holograma, são vistas duas imagens do mico-leão-dourado e da inscrição "20".

FIGURA 5- Comparação entre a Holografia Clássica e a Holografia Computacional.

FIGURA 6- Reconstrução óptica de um EOD iluminado por uma onda plana monocromática coerente. (A) Reconstrução de um holograma de Fourier (difração de Fraunhofer) utilizando-se uma lente de Fourier; (B) Reconstrução de um holograma de Fresnel (difração de Fresnel), obtido pela propagação da luz de $g\left(x^{\prime}, y^{\prime}\right)$ pela distância $d[20]$. 
FIGURA 7-Diagrama esquemático do método iterativo da transformada de Fourier (Iterative Fourier Transform Algorithm - IFTA) para o cálculos de hologramas em regime de modulação de fase ou de amplitude, com a reconstrução em intensidade [42].

FIGURA 8-Janela de reconstrução, localizada no centro do plano de reconstrução, utilizada para melhorar a reconstrução do holograma. Fora da região $g_{r}$ de dimensões $A \times B$, a fase e a amplitude da distribuição $g(x, y)$ pode variar livremente [42].

FIGURA 9-Difração da luz por duas fendas, produzindo máximos e mínimos de intensidade luminosa, observados como franjas de interferência claras e escuras. 18

FIGURA 10-Diferença de caminhos entre dois feixes de luz que incidem na parte inferior e superior da fenda, em destaque.

FIGURA 11-Relação entre a distância entre dois pontos espacialmente coerentes emergindo de uma fonte luminosa de diâmetro $\rho$, de comprimento de onda $\bar{\lambda}$, a uma distância $\mathrm{R}$ de propagação.

FIGURA 12(a)- Imagem original de Lenna 128x128 pixels;(b) Imagem obtida a partir da imagem original

FIGURA 13- Técnica de halftoning aplicada a uma imagem com 17 níveis de cinza................. 25

FIGURA 14-Projeto do EOD para uma informação binária ...................................................... 26

FIGURA 15-Diagrama do algoritmo para o cálculo da propagação da luz modulada pelos ........ 27

FIGURA 16-(a)pixel tipo I e (b)sua respectiva intensidade de propagação.................................. 28

FIGURA 17- (a)Pixel tipo II e (b) intensidade de propagação do pixel tipo II........................... 28

FIGURA 18-(a) Modelo proposto para o pixel tipo I ; (b) sua representação como função rect $(x)$ e (c) sua transformada de Fourier, $\sin c(s)$ 
FIGURA 19- Modelo para o pixel tipo II e (b) sua representação como função $-\frac{1}{2} \prod\left(x+\frac{1}{2}\right)+\frac{1}{2} \prod\left(x-\frac{1}{2}\right) ; \quad$ e $\quad$ (c)sua transformada de Fourier, $-i \sin c(s) \sin c(\pi \mathrm{s})$

FIGURA 20- Diagrama de blocos do algoritmo para cálculo da resposta impulsional dospixels tipo I.

FIGURA 21- Diagrama de blocos do algoritmo para cálculo da resposta impulsional dos pixels tipo II

FIGURA 22- Reconstrução simulada para o holograma gerado a partir da figura Lenna para uma distância do plano do holograma ao plano de reconstrução de (a) $0 \mathrm{~cm}$ e (b) $2 \mathrm{~cm}$......

FIGURA 23- Figuras utilizadas no algoritmo para gerar o holograma de luz branca: (a) Lenna; (b) tigre, (c) periquito; (d) gato.

FIGURA 24- Reconstrução simulada para o holograma gerado a partir das figuras (a)Lenna, (b) tigre, (c) periquito e (d) gato, para uma distância do plano do holograma ao plano de reconstrução de $2 \mathrm{~cm}$. Estas figuras são as mesmas utilizadas para a fabricação do elemento de luz branca.

FIGURA 25- Visão esquemática da seqüência do processo de fabricação do EOD no modo transmissão. Devido ao baixo custo de fabricação foi utilizada uma máscara que consiste de um filme transparente tipo fotolito. O padrão a ser transferido foi impresso no filme transparente por uma plotter com máxima definição $15 \mu \mathrm{m}$ ( AGFA AVANTRA 30e 2400 dpi ). Nenhuma máscara gerada por feixe de elétrons é necessária. 
iv

FIGURA 26- Montagem do holograma de luz branca realizada no laboratório de óptica do departamento de engenharia elétrica da EESC-USP. No plano posterior, observa-se o anteparo, onde a imagem é projetada.

FIGURA 27- Lâmpada dicróica halógena $12 \mathrm{~V}, 50 \mathrm{~W}, \bar{\lambda}=633 \mathrm{~nm}$, da marca OSRAM, utilizada para obtenção da reconstrução óptica do elemento de luz branca.

FIGURA 28-Montagem experimental para cálculo do grau de coerência realizada através de três metodologias: difração por uma fenda dupla, difração através de uma grade de difração e difração através do elemento de luz branca.

FIGURA 29- Reconstruções ópticas geradas a partir do elemento de luz branca "Lenna" utilizando: (a) lâmpada dicróica somente; e lâmpada dicróica com filtros (b) vermelho; (c) verde e (d) azul.

FIGURA 30- Reconstruções ópticas geradas a partir do elemento de luz branca "gato" utilizando: (a) lâmpada dicróica somente; e lâmpada dicróica com filtros (b) vermelho; (c) verde e (d) azul. 48

FIGURA 31- Reconstruções ópticas geradas a partir do elemento de luz branca "tigre" utilizando: (a) lâmpada dicróica somente; e lâmpada dicróica com filtros (b) vermelho; (c) verde e (d) azul. 49

FIGURA 32- Reconstruções ópticas geradas a partir do elemento de luz branca "periquito" utilizando: (a) lâmpada dicróica somente; e lâmpada dicróica com filtros (b) vermelho; (c) verde e (d) azul. 


\section{LISTA DE TABELAS}

TABELA I. Contrastes determinados através da difração por uma grade de difração obtido com a fonte de luz branca separadamente e com filtros vermelho, verde e azul 43

TABELA II. Contrastes determinados através da difração por uma fenda dupla obtido com a fonte de luz branca separadamente e com filtros vermelho, verde e azul. .44

TABELA III.(a) Contrastes determinados através da difração pelo elemento de luz branca Lenna obtidos com a fonte de luz branca separadamente e com filtros vermelho, verde e azul. 44

TABELA III.(b) Contrastes determinados através da difração pelo elemento de luz branca gato obtidos com a fonte de luz branca separadamente e com filtros vermelho, verde e azul. .45

TABELA III.(c) Contrastes determinados através da difração pelo elemento de luz branca tigre obtidos com a fonte de luz branca separadamente e com filtros vermelho, verde e azul. .45

TABELA III.(d) Contrastes determinados através da difração pelo elemento de luz branca periquito obtidos com a fonte de luz branca separadamente e com filtros vermelho, verde e azul. .46 
vi

LISTA DE ABREVIATURAS E SIGLAS

CAPES - Coordenadoria de Aperfeiçoamento de Pessoal de Nível Superior

EESC - Escola de Engenharia de São Carlos

EOD - Elemento Óptico Difrativo

FFT - Fast Fourier Transform

FT- Fourier Transform

IFTA - Iterative Fourier Transform Algorithm

USP-Universidade de São Paulo

POLI- Escola Politécnica da USP 


\section{RESUMO}

\section{Palavras-chave: hologramas gerados por computador, luz branca, halftoning.}

Hologramas podem ser produzidos utilizando-se técnicas tradicionais de holografia ou podem ser gerados também por computador, conhecidos como hologramas gerados por computador(HGCs). A maioria destes hologramas opera usando luz monocromática. Por outro lado, os hologramas podem também operar com luz branca. Estes elementos de luz branca são usados em diversas aplicações, como segurança, para verificar a autenticidade dos cartões de crédito e outros documentos, porque seus processos de fabricação são difíceis e caros de serem reproduzidos. Entretanto, os hologramas de luz branca convencionais operam baseados na reflexão da luz, e apresentam alguns efeitos indesejáveis, como distorções cromáticas, como o efeito rainbow.

Neste trabalho foi proposto um elemento óptico difrativo de luz branca gerado por computador. O elemento é calculado baseado na técnica de halftoning e na coerência espacial parcial de uma fonte de luz branca estendida. Os elementos da fase são produzidos através de técnicas de fabricação bem estabelecidas de circuitos integrados, e as simulações óticas são apresentadas. Não há necessidade de métodos iterativos.

Os resultados das reconstruções ópticas e simuladas deste elemento de luz branca são muito semelhantes e produzem imagens nítidas, não sendo observadas distorções cromáticas.

O elemento de luz branca ainda não foi descrito na literatura, e algumas de suas aplicações podem ser um correlator óptico ou arte holográfica. 
viii

Este trabalho foi realizado no laboratório de óptica do departamento da engenharia elétrica do EESC, e financiado por CAPES (Coordenadoria de Aperfeiçoamento de Pessoal de Nível Superior). 


\section{ABSTRACT}

\section{Keywords: Computer -generated holograms, white light, halftoning.}

Holograms can be produced using traditional holography techniques or may be also generated by computer, wich are known as $\mathrm{CGHs(Computer-generated} \mathrm{holograms).} \mathrm{Most}$ of these holograms operate using monochromatic light. On the other hand, holograms can also operate with white light. These white light holograms are used in several applications, such as security, to verify the autencity of credit cards end other documents, because their fabrication processes are dificult to reproduce and are expensive. However, convencional white light holograms operate based on reflection of light, and present some undesirable effects, like chromatic distortions, such as rainbow effect.

In this work it was proposed a computer-generated phase optical difractive element designed to operate under white light illumination. The element is calculated based on the halftoning technique and in the partial spatial coherence of a white light extended source. Phase elements are manufactured using well-established integrated circuits fabrication techniques and optical simulations are shown. No iterative methods are necessary.

Simulated and optical reconstructions results are very similar and produce good clear images, and no chromatic distortions are observed.

The white light element was not yet described on literature, and some of its applications may be an optical correlator or holographic art.

This work was carried at the laboratory of optics of the department of electrical engineering of the EESC, and supported by CAPES (Coordenadoria de Aperfeiçoamento de Pessoal de Nível Superior). 


\section{Capítulo 1}

\section{1-Introdução}

A técnica de holografia clássica foi proposta por Gabor [1], em 1948, ao observar que uma frente de onda de referência em coerência com a luz difratada ou espalhada por um objeto permite que as informações de amplitude e de fase das ondas difratadas sejam gravadas. Esta mesma técnica foi utilizada por Denisyuk [2] e Benton [3] utilizando iluminação não-coerente na fabricação de hologramas. Denisyuk combinou as técnicas de holografia convencional de Gabor e de fotografia colorida para a produção de hologramas que poderiam ser vistos através de uma iluminação não-coerente de um bulbo incandescente. Já os hologramas de Benton, também conhecidos como hologramas rainbow, empregavam a iluminação não-coerente de uma luz branca para visualizar o holograma. Estes hologramas minimizavam o efeito de distorções cromáticas, porém ocorria perda de informação gravada em uma dimensão.

Após a descoberta do laser nos anos 60, trabalhos de holografia convencional que utilizavam como fonte de iluminação coerente de um laser foram divulgados [4-6]. Além dos métodos holográficos convencionais, vários outros foram propostos para o cálculo de hologramas gerados por computador ( HGCs ), entre eles o algoritmo iterativo da transformada de Fourier (Iterative Fourier Transform Algorithm - IFTA), introduzido na holografia digital por Gerchberg \& Saxton [7] e por Hirsh et al. [8]; o desvio de fase de Brown \& Lohmann [9-11]; o holograma binário sintético em amplitude de Lee [12]; a pesquisa binária direta, de Seldowitz et al. [13]; o holograma com modulação de densidade de pulso de Hanck \& Bryngdahl [14] e a quantização iterativa de hologramas de amplitude digital de Wyrowski [15].

O IFTA foi posteriormente modificado por Wyrowski [15-17], que implementou neste algoritmo o conceito de liberdade de fase durante as iterações para o cálculo de hologramas com 
modulação em níveis discretos. Infelizmente, este método numérico requer várias iterações, além de geralmente introduzir ruído do tipo speckle no plano de reconstrução [18,19].

Neto et al. [20] propuseram a implementação de hologramas digitais de modulação completa de amplitude e fase. Cada pixel do elemento é composto por duas regiões de relevo de fase que podem assumir valores de fase 0 e $\pi / 2, \pi / 2$ e $\pi, \pi$ e $3 \pi / 2$, ou $3 \pi / 2$ e 0 . A modulação de amplitude é obtida removendo pequenas partes de uma camada de alumínio depositada sobre o relevo de fase de cada pixel.

Hologramas gerados por computador obtidos por halftoning [21] foram investigados por Ishioka [22], Caulfield [23] e Pinhasi [24], porém esta técnica foi utilizada para gerar uma máscara utilizada para produção de hologramas operando em iluminação monocromática coerente. Recentemente, Pizolato et al. [25] utilizaram a técnica de halftoning para projetar hologramas de fase binários que funcionam com iluminação coerente. Cada pixel é constituído por duas regiões de relevo de fase que podem assumir valores de fase 0 e $\pi$. O projeto deste EOD dispensa cálculos iterativos computacionais e a fabricação do mesmo é realizada utilizando técnicas tradicionais de circuitos integrados.

A maioria dos trabalhos recentes que abordam holografia computacional utilizando luz branca descreve hologramas rainbow reconstruídos a partir da superposição de imagens de projeção de três ou mais hologramas produzidos em três cores diferentes [26,27]. Neste trabalho é proposto um EOD gerado por computador baseado na técnica de halftoning que utiliza iluminação não-coerente [28,29](vide anexos A e B). Este EOD apresenta as seguintes vantagens em relação aos trabalhos até então publicados: o método para a geração do EOD não utiliza processos computacionais iterativos e as imagens reproduzidas não apresentam distorções cromáticas visíveis ao olho humano. Estes EODs correspondem a elementos de fase binários e são produzidos através de técnicas de fabricação bem estabelecidas de circuitos integrados. $\mathrm{O}$ 
EOD de luz branca aqui proposto pode ser empregado em processamento óptico, sistemas de segurança para verificação da autenticidade de documentos, cartões de crédito e processos de fabricação de produtos.

A apresentação do trabalho está organizada conforme a seqüência. No Capítulo 2 são explicados alguns conceitos sobre elementos ópticos difrativos (EOD) e difração. O Capítulo 3 aborda os hologramas clássicos e digitais, que são um tipo de EOD. No Capítulo 4 são abordados os tópicos de coerência de uma fonte de onda luminosa. O Capítulo 5 apresenta o EOD de luz branca abordando projeto, funcionamento e construção. No Capítulo 6 são apresentados resultados experimentais da reconstrução óptica obtida com o EOD de luz branca proposto. Conclusões e considerações sobre o trabalho são realizadas no Capítulo 7. Referências bibliográficas são apontadas no Capítulo 8. 


\section{Capítulo 2}

\section{Introdução}

O EOD apresentado neste trabalho funciona segundo os princípios da óptica difrativa. Neste capítulo serão apresentados os conceitos fundamentais de difração e óptica difrativa.

\section{2-Óptica difrativa}

A óptica difrativa ou óptica binária [30] é uma nova tecnologia que elimina quase todas as etapas dos métodos tradicionais (abrasão e polimento) para a fabricação de elementos ópticos. Por operarem segundo os princípios da difração, estes elementos ópticos são denominados Elementos Ópticos Difrativos (EOD) [31].

Elementos ópticos difrativos são estruturas que difratam a luz, gerando uma distribuição de luz desejada. Segundo o princípio de Huygens-Fresnel [32,33], ilustrado na Figura 1, quando um elemento óptico difrativo é iluminado por uma frente de onda. Cada ponto da nova frente de onda $\sum$ que emerge da superfície do elemento age como uma fonte de luz pontual, gerando ondas esféricas de raio r'. A interferência construtiva ou destrutiva de cada onda esférica gera uma nova frente de onda $\sum$ '. 


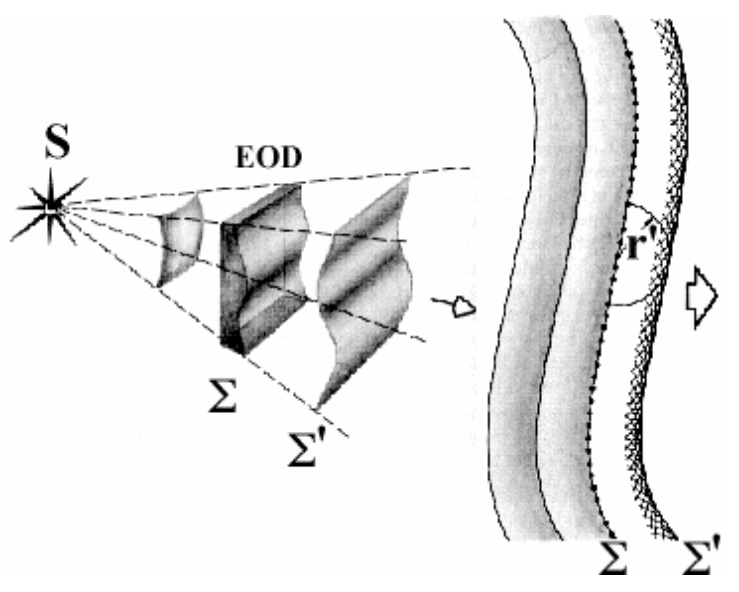

FIGURA 1- Princípio de Huygens-Fresnel [33], onde cada ponto de uma frente de onda incidente age como uma nova fonte de onda esférica, cuja interferência construtiva ou destrutiva de cada onda esférica por sua vez nos dá uma nova frente de onda.

Hologramas gerados por computador, redes de difração e microlentes de Fresnel são alguns exemplos de EODs que podem ser obtidos por intermédio de relevos gravados na superfície de um material transparente ou reflexivo, ou por padrões gravados em filmes fotográficos. Estes relevos ou padrões impõem uma modulação espacial na fase da luz incidente [30] que, após sofrer o efeito da difração, resulta em uma distribuição luminosa desejada em algum plano próximo do elemento difrativo, como é ilustrado na Figura 2. Geralmente, por ser necessário apenas introduzir um pequeno atraso na fase ou o bloqueio em cada ponto da frente de onda incidente, os EODs podem ser mais finos e leves que os elementos ópticos convencionais (refrativos). 


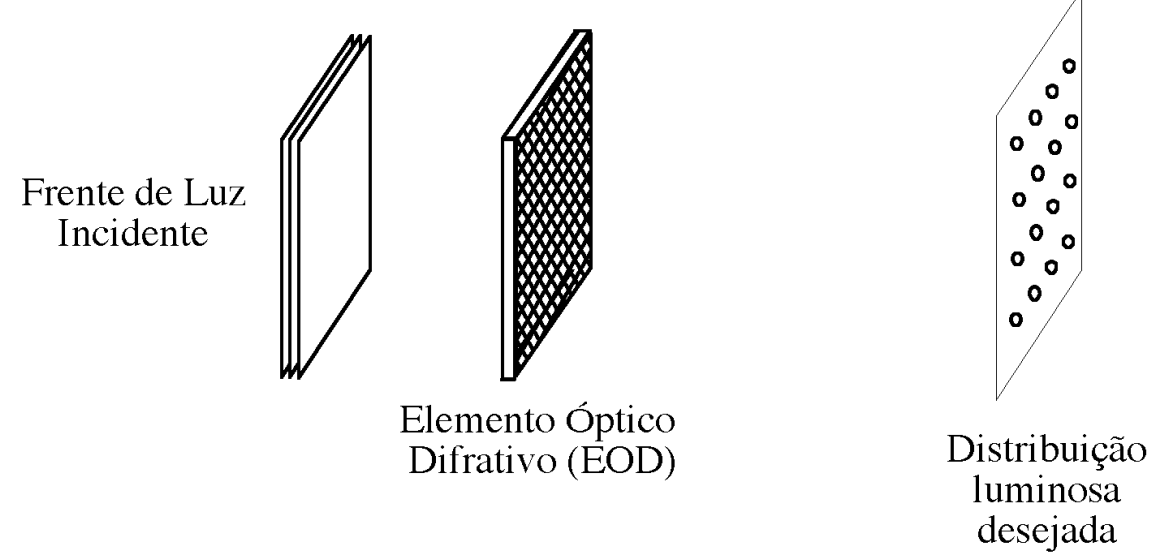

FIGURA 2-Obtenção de uma distribuição de luz desejada utilizando-se um Elemento Óptico Difrativo para a modulação de uma frente de luz incidente.

Os EODs são projetados com base nas propriedades de difração de sua superfície, geralmente uma interface micro-estruturada com detalhes geométricos próximos ao comprimento de onda da luz. Como geralmente é utilizada a teoria escalar da difração [18] para o cálculo destes elementos, as dimensões das micro-estruturas abordadas são maiores que $10 \lambda$, onde $\lambda$ é o comprimento de onda da luz incidente. Várias distribuições ópticas podem ser "gravadas" em um EOD modificando-se a geometria das microestruturas, que podem ser fabricadas utilizando as técnicas inicialmente desenvolvidas para a fabricação de circuitos integrados eletrônicos: litografia óptica, corrosão por plasma, deposição de filmes finos, corrosão úmida e litografia por feixe de elétrons. Estas técnicas podem gravar diretamente na superfície de qualquer material óptico as mais variadas geometrias, em dimensões extremamente reduzidas. Podem-se produzir dispositivos de alta qualidade em série, com propriedades ópticas complexas e impossíveis de serem implementadas com a tecnologia tradicional. A geometria dos elementos é obtida por cálculo numérico, considerando a difração da luz, as características ópticas do material utilizado (óxido de silício, nitreto de silício, $D L C$, etc.) e das micro-estruturas a serem projetadas. 

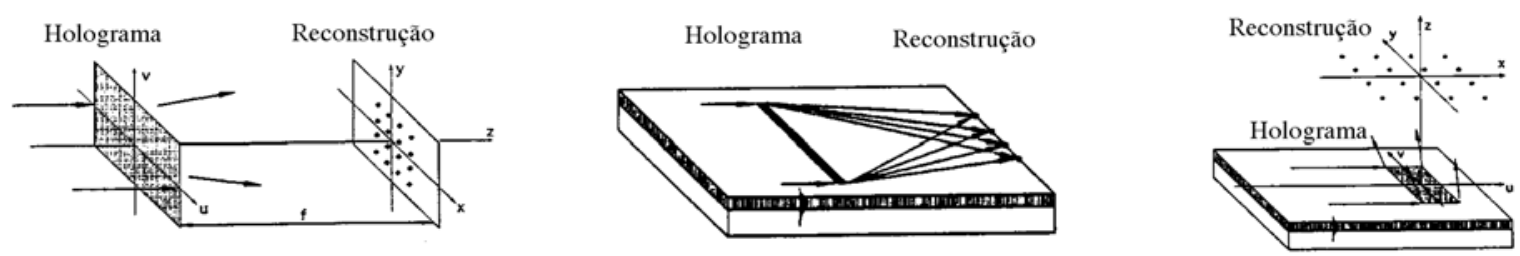

FIGURA 3- Os EODs podem ser classificados em três grupos [34]: (a) espaço-livre para espaço-livre; (b) onda-guiada para onda-guiada; e (c) onda-guiada para espaço-livre (ou espaço-livre para onda-guiada).

De acordo com as características de entrada e saída das ondas, os EODs podem ser classificados em três grupos [34]: (1) espaço-livre para espaço-livre; (2) onda-guiada para onda guiada; e (3) onda-guiada para espaço-livre (ou espaço-livre para onda-guiada). Exemplos destes três tipos de EODs são ilustrados com hologramas na Figura 3. Os hologramas do tipo (1) são chamados de espaço-livre para espaço-livre pois nenhuma onda guiada está envolvida. Por outro lado, guias de onda ópticos estão envolvidos nos grupos (2) e (3).

Entre as inúmeras aplicações desta tecnologia podem-se citar: fabricação de microlentes para sistemas de visão artificial [35], implementação de multiplexadores e demultiplexadores de luz [36], filtros holográficos para aplicações em reconhecimento de objetos e alvos [37,38], conexões ópticas e distribuição de sinais de relógio em micro-circuitos [38], correção da aberração cromática em sistemas ópticos [30,35], modulação e correção da luz laser; redes de difração; acoplamento entre laser e fibras ópticas [34] acoplamento entre fibra óptica e sensores [34], guias de onda [34,39], discos holográficos para a armazenagem de informações [31].

Dentre os EODs estão os hologramas rainbow [40] que podem ser replicados em larga escala utilizando técnica de embossing de baixo custo. Com esta metodologia, os hologramas podem ser replicados a um custo muito baixo. O primeiro passo da técnica é gravar um 
holograma com um objeto de interesse, em fotorresiste. Posteriormente, um laser é utilizado em processo de gravação, e o fotorresiste é exposto, produzindo um relevo que é coberto com um spray de prata. Esta máscara é imersa em um tanque com um eletrodo de níquel e uma corrente passa através do mesmo, depositando uma fina camada de níquel sobre a mesma, através de um processo de eletrodeposição. Esta camada de níquel é separada do fotorresiste e este relevo metálico criado é utilizado como uma espécie de carimbo no processo de reprodução.

Entre os processos de embossing muito conhecidos está o hot-embossing. Por este motivo, estes EODs foram rapidamente difundidos em aplicações de segurança na forma de selos holográficos para a verificação da autenticidade de produtos como cartões de créditos, livros, revistas, cédulas monetárias, CDs e DVDs. Na Figura 4 são ilustrados alguns exemplos de hologramas rainbow utilizados na verificação da autenticidade de cartões de crédito e cédulas monetárias.

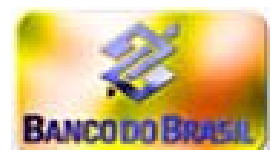

(a)

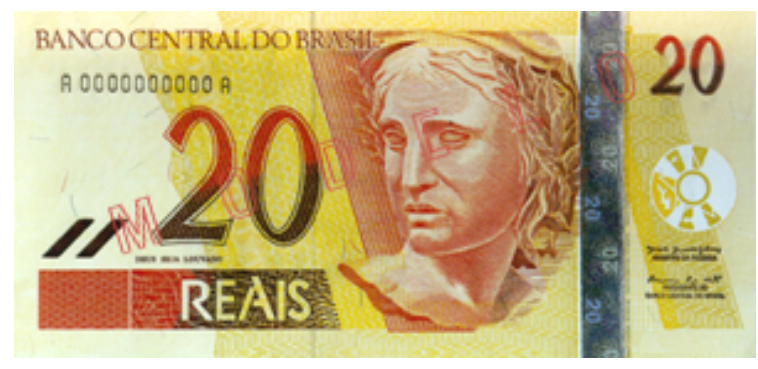

(b)

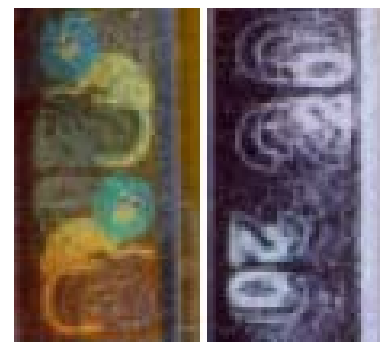

(c)

FIGURA 4- (a)Holograma rainbow convencional, (b) cédula monetária de 20 reais, emitida pelo Banco do

Brasil, utilizando um holograma rainbow como elemento de identificação; e (c) detalhe do holograma impresso na cédula de 20 reais.No holograma, são vistas duas imagens do mico-leão-dourado e da inscrição "20". 
Neste trabalho, os esforços foram centrados para o domínio da teoria, projeto e fabricação de EODs envolvidos no grupo (1): hologramas gerados por computador do tipo espaço-livre para espaço-livre, como ilustrado pela Figura 3(a) submetidos a iluminação não-coerente (luz branca por exemplo), com baixa distorção cromática e baixo custo de produção. 


\section{Capítulo 3}

\section{Introdução}

O EOD de luz branca abordado neste trabalho é um elemento óptico difrativo gerado por computador, que funciona sob iluminação parcialmente coerente em uma região localizada. Neste capítulo são apresentadas as diferenças básicas entre holografia clássica e digital. Atenção especial será dedicada aos hologramas gerados por computador.

\section{3- Holografia}

Na Holografia Clássica, as ondas de uma frente de luz são "armazenadas" em um holograma utilizando a interferência como processo de gravação. Na holografia computacional, as ondas são "armazenadas sinteticamente" no holograma utilizando cálculos computacionais. Em ambos os processos, a reconstrução óptica das ondas gravadas é obtida pela difração da luz. A Figura 5 apresenta o diagrama de blocos indicando a diferença entre os processos [41]. 
Holografia Clássica

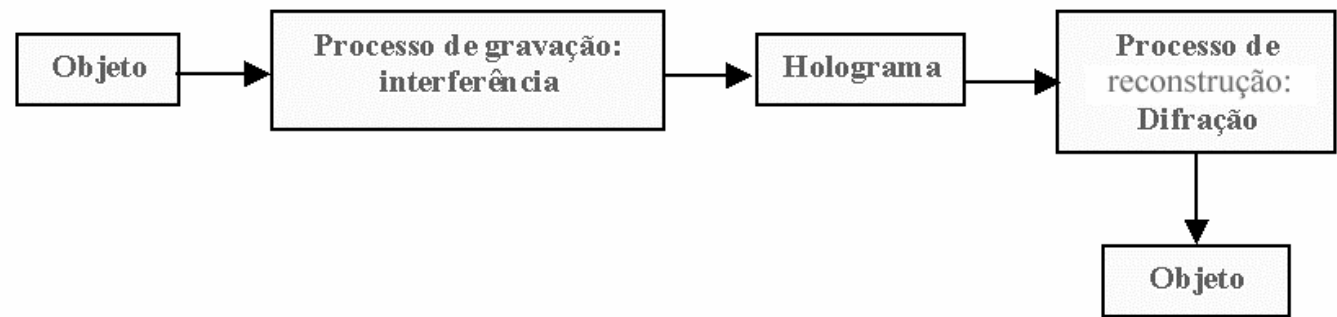

Holografia Computacional

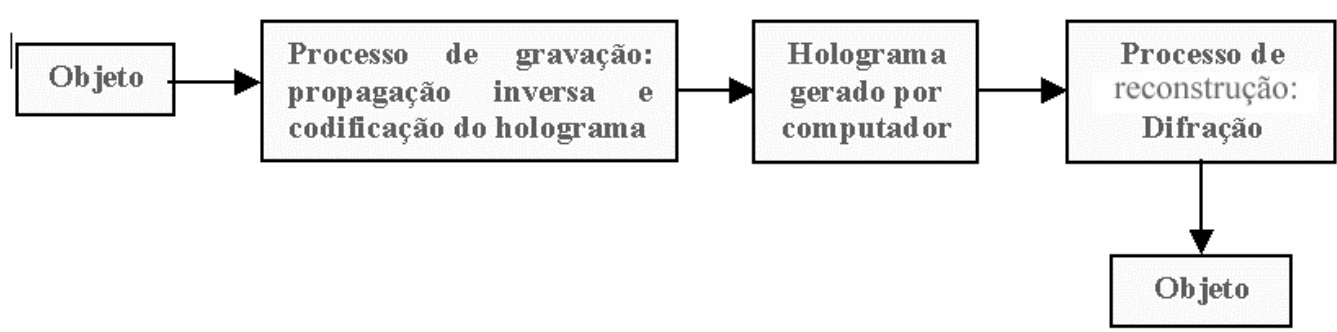

FIGURA 5- Comparação entre a Holografia Clássica e a Holografia Computacional.

Os hologramas gerados por computador são projetados por cálculo computacional considerando a difração escalar da luz [18], as características ópticas do meio em que o holograma será fabricado, que poderá ser uma distribuição de fase ou amplitude, e as características da distribuição de luz no plano de reconstrução do holograma.

É possível escolher entre o projeto de um holograma de Fourier ou de Fresnel. Um holograma de Fourier utiliza a difração de Fraunhofer para o cálculo da propagação da luz do plano do holograma ao plano de reconstrução, que também é implementada opticamente utilizando-se uma lente de Fourier para se obter a reconstrução óptica, como mostrado na Figura 6(a). Um holograma de Fresnel utiliza a difração de Fresnel ou a filtragem espacial para o cálculo da propagação da luz no espaço livre entre o plano do holograma ao plano de reconstrução óptica, como mostrado na Figura 6(b). O cálculo da difração pela filtragem espacial 
12

é realizado considerando a solução da equação de Helmholtz (vide Apêndice A) no domínio da frequência [32].

Se o holograma é iluminado por uma onda plana monocromática uniforme e coerente, com distribuição espacial de amplitudes igual a 1, logo após o holograma a distribuição de luz possui a forma: $1 \times g\left(x^{\prime}, y^{\prime}\right)=g\left(x^{\prime}, y^{\prime}\right)$. A propagação da luz da distribuição $g\left(x^{\prime}, y^{\prime}\right)$ resulta na distribuição óptica $g(x, y)$, localizada no plano de reconstrução.

No cálculo do holograma, as seguintes etapas devem ser consideradas:

a) Determinação da distribuição $g\left(x^{\prime}, y^{\prime}\right)$ que deve ser gerada no plano do holograma. $\mathrm{O}$ cálculo desta distribuição começa pelo cálculo da propagação inversa da distribuição de luz $f(x, y)$ a partir do plano de reconstrução, indo ao plano do Holograma. Pretende-se determinar uma distribuição $g\left(x^{\prime}, y^{\prime}\right)$ que gere o mais fielmente possível a reconstrução $g(x, y)$ a distribuição $f(x, y)$, com $0 \leq|f(x, y)| \leq 1$ e $0 \leq \alpha|g(x, y)| \leq 1$, onde $\alpha$ é um fator de escala real e positivo. A distribuição $f(x, y)$ precisa estar disponível de forma a permitir a manipulação computacional (geralmente valores discretos de amplitude). 

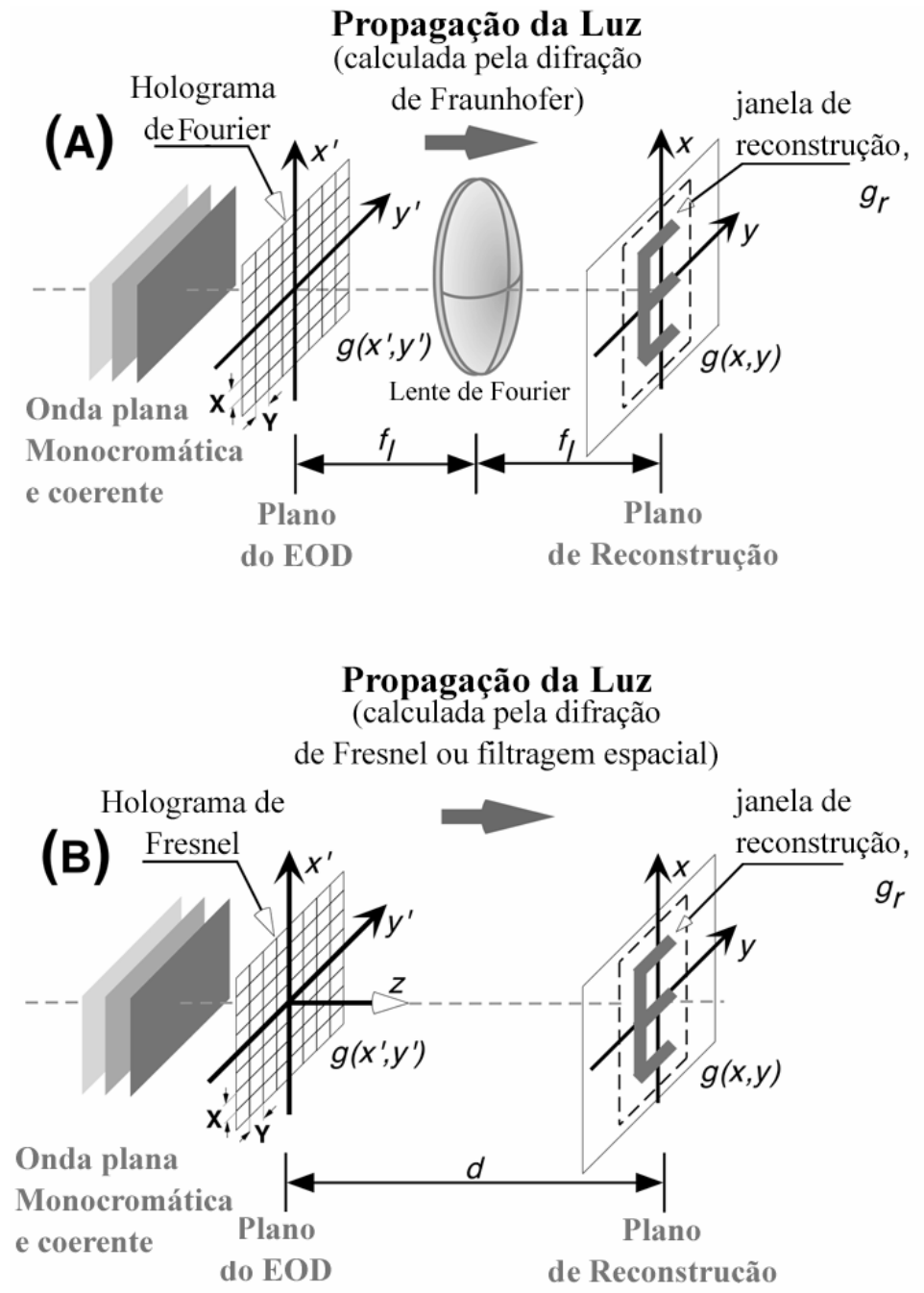

FIGURA 6- Reconstrução óptica de um EOD iluminado por uma onda plana monocromática coerente. (A) Reconstrução de um holograma de Fourier (difração de Fraunhofer) utilizando-se uma lente de Fourier; (B) Reconstrução de um holograma de Fresnel (difração de Fresnel), obtido pela propagação da luz de $g\left(x^{\prime}, y^{\prime}\right)$ pela distância $d[20]$.

b) A distribuição $f\left(x^{\prime}, y^{\prime}\right)$ resultante da propagação inversa da luz geralmente apresenta uma distribuição complexa de valores de fase e amplitude, que devem ser adaptados para as possíveis distribuições $g\left(x^{\prime}, y^{\prime}\right)$ do holograma, que neste caso é uma distribuição apenas de fase ou amplitude. As limitações físicas e práticas do meio em que será gravado o 
14

holograma irão determinar a escolha do método numérico utilizado para esta implementação.

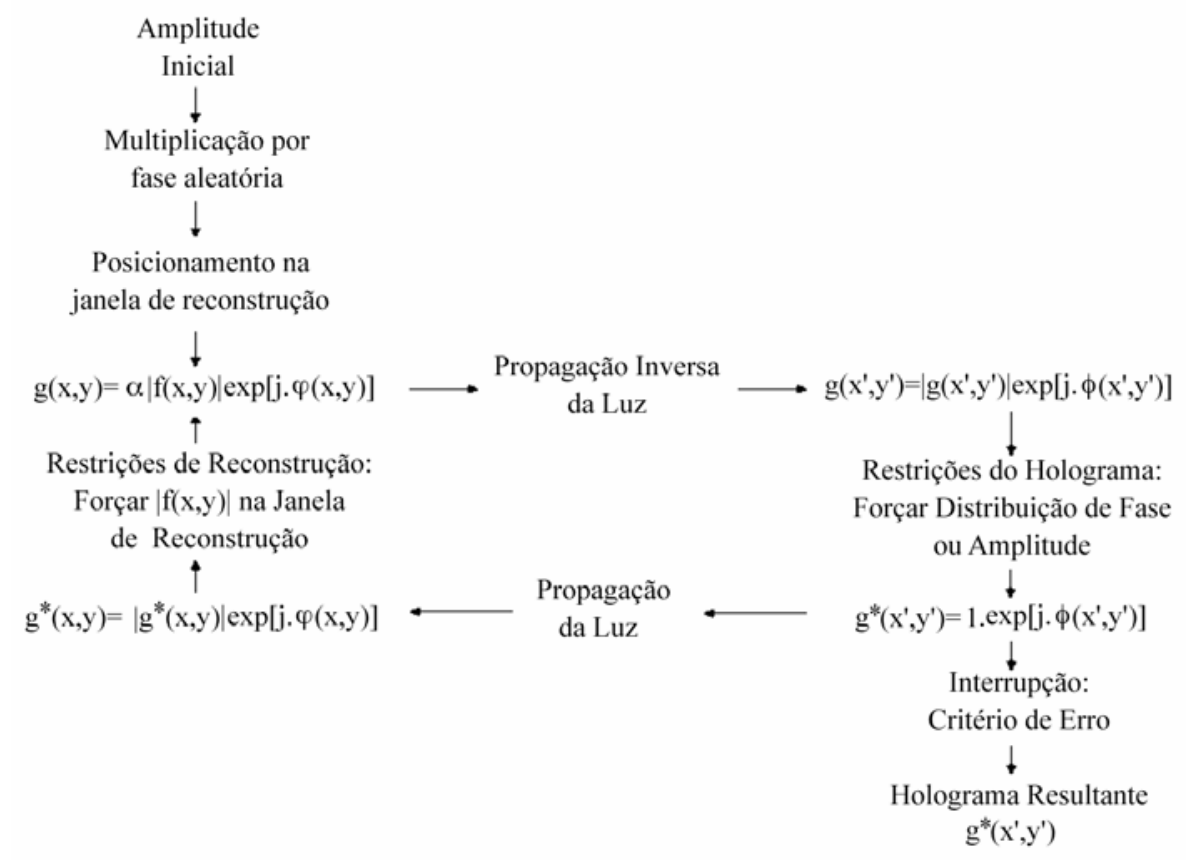

FIGURA 7-Diagrama esquemático do método iterativo da transformada de Fourier (Iterative Fourier

Transform Algorithm - IFTA) para o cálculos de hologramas em regime de modulação de fase ou de amplitude, com a reconstrução em intensidade [42].

O objetivo do cálculo do holograma é formar uma distribuição de luz no plano de reconstrução. Uma distinção é feita entre objetos de amplitude complexa (fase e amplitude determinadas) e objetos de intensidade determinada (apenas amplitude determinada). Desta maneira, para objetos de amplitude complexa tem-se:

$$
f(x, y)=|f(x, y)| \exp [i \varphi(x, y)]
$$

e para objetos de intensidade $i(x, y)$ tem-se:

$$
|f(x, y)|^{2}=i(x, y)
$$


onde os valores do argumento $\varphi(x, y)$ de $f(x, y)$ possuem total liberdade, podendo assumir quaisquer valores. Desta maneira tem-se:

$$
f(x, y)=\sqrt{i(x, y)} \exp [i \varphi(x, y)]
$$

Vários métodos foram propostos para o cálculo de hologramas por computador, entre eles o algoritmo iterativo da transformada de Fourier (Iterative Fourier Transform Algorithm - IFTA), introduzido na holografia digital por Gerchberg \& Saxton [7] e por Hirsh et al. [8].

O IFTA, descrito na Figura 7, oferece os melhores resultados práticos na codificação de hologramas gerados computador com comprimento de banda (SBP - Space Band Bandwith Product) de 256x256 ou mais células (pixels). O IFTA foi posteriormente modificado por Wyrowski [16], que implementou neste algoritmo o conceito de liberdade de fase durante as iterações para o cálculo de hologramas com modulação em níveis discretos.

No IFTA, uma iteração é realizada calculando-se a propagação inversa da luz do plano de reconstrução ao plano do holograma, onde as restrições do holograma são aplicadas (imposição de uma distribuição de fase). Na seqüência, calcula-se a propagação da luz do plano do holograma ao plano de reconstrução, onde as restrições referentes a distribuição desejada são aplicadas (determinar a intensidade da reconstrução desejada $i(x, y)$ ). Para objetos em intensidade, atribui-se uma distribuição de fase aleatória a $\varphi(x, y)$ na primeira iteração para auxiliar a convergência do algoritimo.

Infelizmente, este método numérico requer várias iterações, além de geralmente introduzir ruído do tipo speckle no plano de reconstrução. Cem ou mais iterações são necessárias dependendo da complexidade da reconstrução desejada $f(x, y)$ ou $i(x, y)$. Também é possível que não exista uma distribuição de fase ou amplitude $g\left(x^{\prime}, y^{\prime}\right)$ que satisfaça $g(x, y) \approx \alpha f(x, y)$ ou $|g(x, y)|$ $\approx \alpha[i(x, y)]^{1 / 2}$ sobre toda a região do plano de reconstrução [42]. 
16

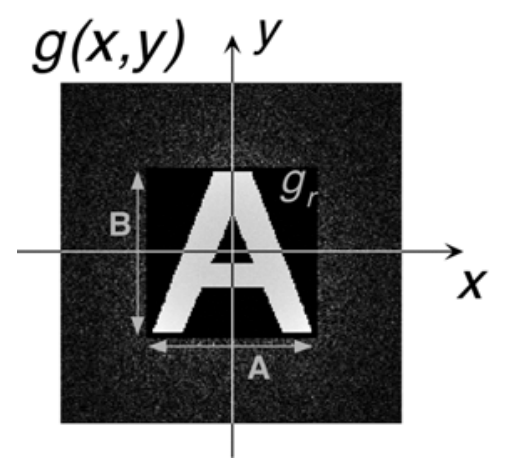

FIGURA 8-Janela de reconstrução, localizada no centro do plano de reconstrução, utilizada para melhorar a reconstrução do holograma. Fora da região $g_{r}$ de dimensões $A \times B$, a fase e a amplitude da distribuição $g(x, y)$ pode variar livremente [42].

Liberdade nos valores dos parâmetros pode ser introduzida no IFTA para auxiliar na convergência numérica, como por exemplo:

c) Liberdade de fase e amplitude para as distribuições fora da janela de reconstrução $g_{r}$, mostrada na Figura 8. Fora da região $g_{r}$, os valores de fase e amplitude de $g(x, y)$ podem variar livremente. O processo de codificação do holograma consiste em encontrar a distribuição $g\left(x^{\prime}, y^{\prime}\right)$ que satisfaça as restrições de modulação do holograma e garanta que a distribuição do objeto $f(x, y)$ está contida dentro de uma região $A \times B$ definida no plano de reconstrução $g(x, y)$, chamada de janela de reconstrução $g_{r}$.

d) Liberdade de fase na janela de reconstrução $g_{r}$ : para objetos em intensidade, a fase $\varphi(x, y)$ pode variar livremente dentro da região $g_{r}$.

e) Liberdade do fator de escala $\alpha$ : é possível variar $\alpha$ sobre a janela de reconstrução $g_{r}$ de maneira a se obter uma redução do erro dentro de $g_{r}$.

Neste trabalho, o EOD de luz branca é gerado por computador e calculado sem a necessidade métodos iterativos computacionais. 


\section{Capítulo 4}

\section{Introdução}

O EOD proposto neste trabalho funciona sob iluminação não-coerente. Neste capítulo serão apresentados alguns conceitos sobre coerência da luz.

\section{4-Coerência de uma fonte luminosa}

\section{1-O experimento de Young}

Difração é um fenômeno que ocorre quando uma frente de onda luminosa atravessa um orifício ou contorna um objeto cuja dimensão é da mesma ordem de grandeza que o seu comprimento de onda $\lambda$. Segundo Sommerfeld [32], difração é definida como "qualquer desvio da trajetória de raios de luz de caminhos retilíneos que não podem ser interpretados como reflexão ou refração". A difração é causada pelo confinamento de uma onda, quando este confinamento é comparável ao comprimento de onda da radiação incidente.

Um exemplo clássico que ilustra o fenômeno da difração é o experimento de Young $[33,43]$, no qual uma frente de onda incidente em um anteparo com duas fendas, de largura definida $a$, sofre o fenômeno de difração, e surgem então pontos de máximos e mínimos de intensidade luminosa, que podem ser observados pela formação de franjas claras e escuras, como na Figura 9. 


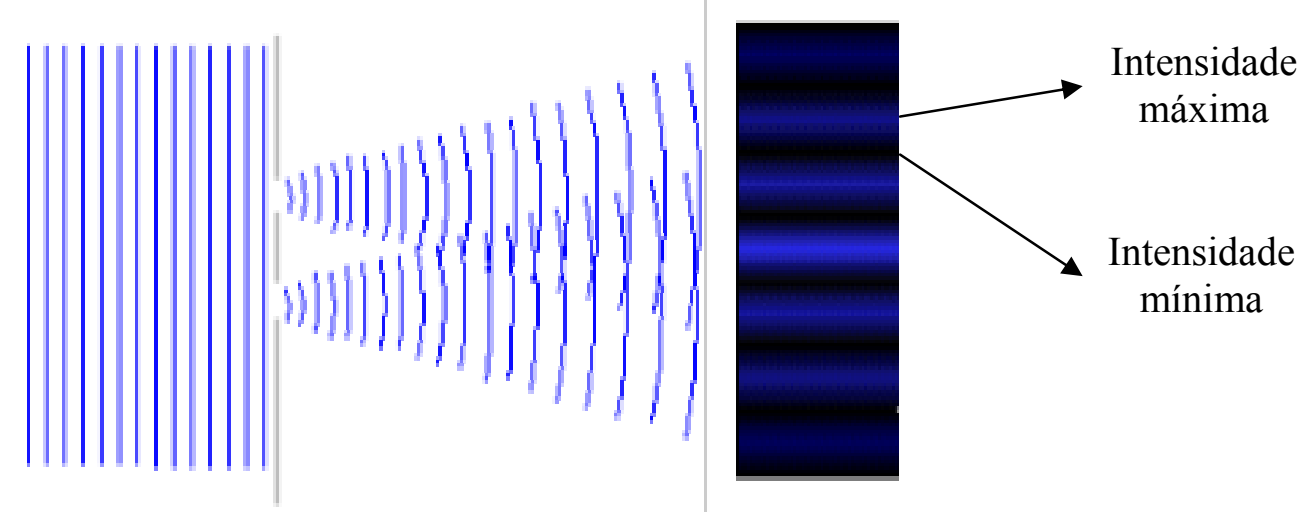

FIGURA 9-Difração da luz por duas fendas, produzindo máximos e mínimos de intensidade luminosa, observados como franjas de interferência claras e escuras.

A Figura 10 ilustra a diferença de caminhos percorridos pela onda incidente num experimento de Young. A distância entre as fendas é d e a grandeza $d \operatorname{sen} \theta$ é a diferença de percurso entre um feixe de luz que parte da extremidade superior da primeira fenda e outro que parte da extremidade inferior da segunda fenda. Considerando cada ponto na frente de onda uma fonte puntiforme de luz, a expressão geral dos pontos de intensidade nula na Figura de difração numa fenda é dada por:

$$
m \lambda \equiv 2 d \operatorname{sen} \theta
$$

onde m é um número inteiro

$\lambda$ é o comprimento de onda da luz incidente ;

d é a distância entre as fendas;

$\theta$ é o ângulo definido na Figura 10. 
Uma ilustração da diferença de caminho entre dois feixes de luz transmitidos pela parte inferior e superior da fenda pode ser vista na Figura 10.

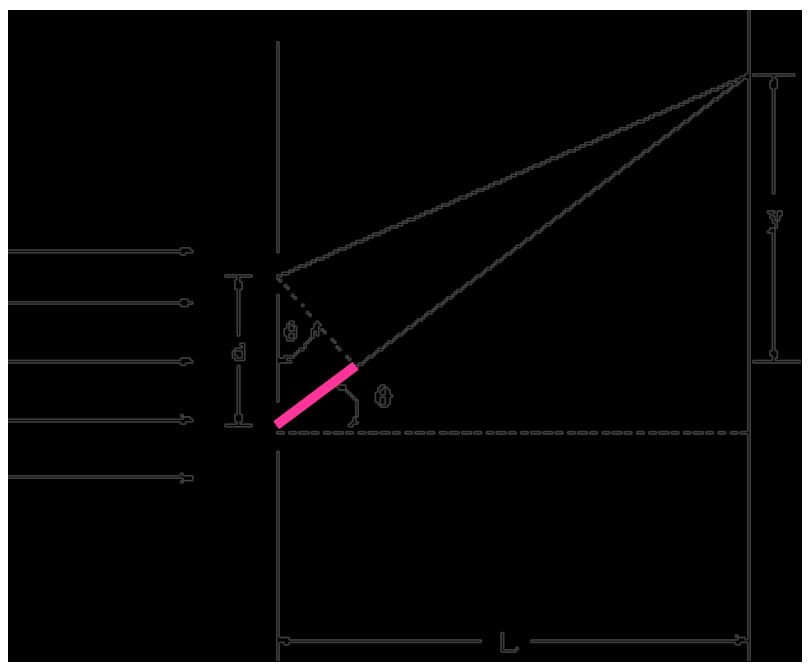

FIGURA 10-Diferença de caminhos entre dois feixes de luz que incidem na parte inferior e superior da fenda, em destaque.

Este experimento pode ser utilizado para medir o grau de coerência de uma fonte luminosa como será mostrado neste capítulo.

\section{2-Coerência temporal e espacial de uma fonte luminosa}

A coerência de uma fonte luminosa é a medida de correlação de fase entre ondas eletromagnéticas emitidas pela mesma. Existem dois tipos de coerência: coerência temporal e espacial.

A coerência temporal é a medida da correlação da fase de ondas eletromagnéticas em diferentes pontos ao longo da direção de propagação das ondas que emergem de uma fonte. Esta medida informa o quão monocromática é a fonte de iluminação. 
Já o conceito de coerência espacial, que é utilizado neste trabalho, é definido como a medida de correlação da fase das ondas eletromagnéticas em diferentes pontos na direção transversal à direção de propagação. Esta medida determina o quão uniforme é a fase da frente de onda. A medida do grau de correlação de uma fonte luminosa pode ser definida pelo coeficiente de correlação, $\gamma_{12}(t)$. A função $\gamma_{12}(t)$ é uma função periódica de $t$, que considera uma medida de correlação de um trem de ondas tomada entre um intervalo de tempo definido pelos instantes t e $t$ $+\tau$, onde $\mathrm{t}$ é o instante inicial, $\tau$ é um intervalo de tempo determinado e $\mathrm{t}+\tau$ o instante final.

Analisando o módulo do valor do grau de coerência $\gamma_{12}(t)$, podem ocorrer três situações distintas:

$$
\begin{aligned}
& \text { Se }\left|\gamma_{12}(t)\right|=1 \rightarrow \text { Coerência completa; } \\
& \text { Se } 0<\left|\gamma_{12}(t)\right|<1 \rightarrow \text { Coerência parcial; } \\
& \text { Se }\left|\gamma_{12}(t)\right|=0 \rightarrow \text { Incoerência completa. }
\end{aligned}
$$

$\mathrm{O}$ conceito de coerência espacial de uma fonte luminosa policromática com diâmetro $\rho$ e comprimento de onda de emissão médio $\bar{\lambda}$ é ilustrado na Figura 11. Sejam dois pontos consecutivos, espacialmente coerentes entre si $\mathrm{P}_{1}$ e $\mathrm{P}_{2}$, cujas distâncias em relação à fonte policromática são $\mathrm{S}_{1}$ e $\mathrm{S}_{2}$.

O grau de coerência da fonte, $\gamma$, pode ser determinado experimentalmente realizando-se o experimento da dupla fenda de Young, ilustrado na Figuras 9-10, Seção 4.1. Neste caso, o grau de coerência da fonte pode ser determinado por:

$$
\gamma \equiv \frac{I_{\max }-I_{\min }}{I_{\max }+I_{\min }}
$$

onde $\mathrm{I}_{\max }$ e $\mathrm{I}_{\min }$ correspondem às intensidades máximas e mínimas obtidas no experimento. 
A condição para que haja coerência espacial para uma iluminação policromática é, segundo o teorema de Van Cittert-Zernike [43], que se estabeleça uma relação entre a distância de dois pontos consecutivos coerentes, $d\left(P_{1}, P_{2}\right)$ de uma frente de onda que se propaga ao longo de uma distância R, emergindo de uma fonte luminosa estendida, de diâmetro $\rho$, e de comprimento de onda médio $\bar{\lambda}$, definida por (6).

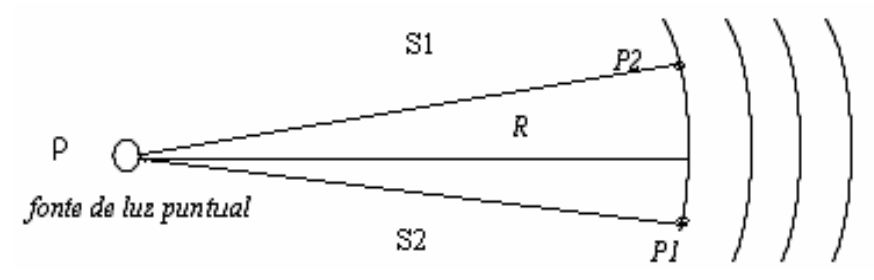

FIGURA 11-Relação entre a distância entre dois pontos espacialmente coerentes emergindo de uma fonte luminosa de diâmetro $\rho$, de comprimento de onda $\bar{\lambda}$, a uma distância $\mathrm{R}$ de propagação.

Segundo o teorema de Van Cittert-Zernike [43], para ocorrer coerência espacial da fonte luminosa ilustrada pela Figura 11 é necessário satisfazer a seguinte equação :

$$
d\left(P_{1}, P_{2}\right)=\frac{0.16 R \bar{\lambda}}{\rho}
$$

onde $\rho$ é o diâmetro da fonte de iluminação estendida; $\bar{\lambda}$ é o comprimento de onda médio da fonte luminosa ; $d\left(P_{1}, P_{2}\right)$ é a distância de dois pontos consecutivos coerentes de uma frente de onda que se propaga ao longo de uma distância $\mathrm{R}$, emergindo da fonte luminosa.

A diferença de fase $\delta$ [43] entre dois pontos coerentes da frente de onda emitida pela fonte luminosa da Figura 11 é definida por : 
22

$$
\delta \equiv \frac{2 \pi\left(S_{1}-S_{2}\right)}{\bar{\lambda}}
$$

onde $\bar{\lambda}$ é o comprimento de onda médio da fonte luminosa; $S_{1}$ e $S_{2}$ são as distâncias em relação à fonte policromática. 


\section{Capítulo 5}

\section{Introdução}

Nos capítulos anteriores foram apresentados alguns conceitos necessários para a apresentação do EOD de luz branca. Neste capítulo serão apresentados o projeto, funcionamento e o processo de fabricação deste EOD.

\section{5-O Elemento de luz branca}

\section{1-A técnica de halftoning}

O método para representação de imagens em tons de cinza utilizando pixels binários é conhecido como halftoning [44]. Esta técnica foi utilizada neste trabalho para projetar o elemento de luz branca proposto.

$\mathrm{Na}$ técnica de halftoning ou "meio-tom" imagens em níveis de cinza são codificadas por clusters de pixels brancos e pretos. Numa imagem codificada por halftoning uma pequena área que contenha pixels brancos e pretos. A uma determinada distância, da ordem de $30 \mathrm{~cm}$, o olho humano integra o conteúdo desta pequena área, de forma que o observador percebe somente a intensidade média da mesma. Esta propriedade de integração do olho humano é básica para a técnica de halftoning.

As Figuras $12(a) e(b)$ mostram, respectivamente, as imagens original e obtida através de cálculo numérico utilizando a técnica de halftoning, com 256 níveis de cinza. Um grupo de 
$n x n$ pixels binários pode produzir $n^{2}+1$ níveis de cinza. Neste caso, cada cluster da imagem em halftoning é composto por 4x4 pixels como mostrado na Figura 13.

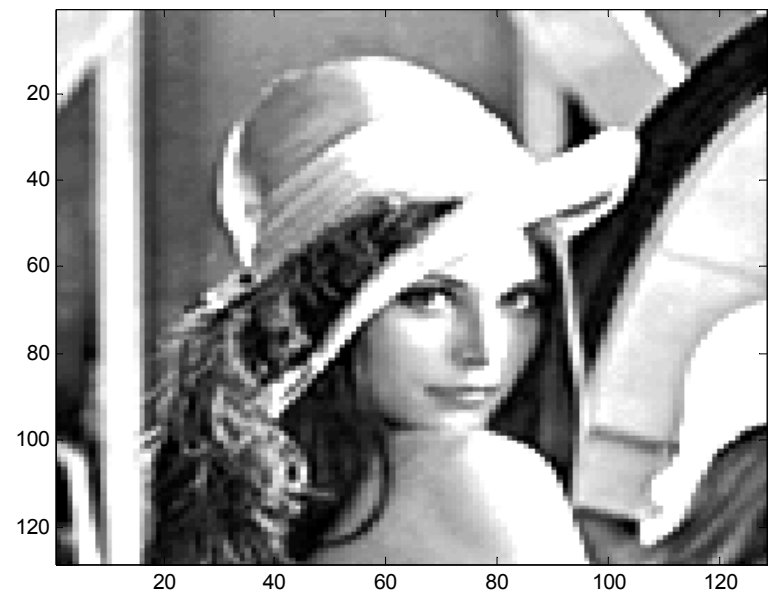

(a)

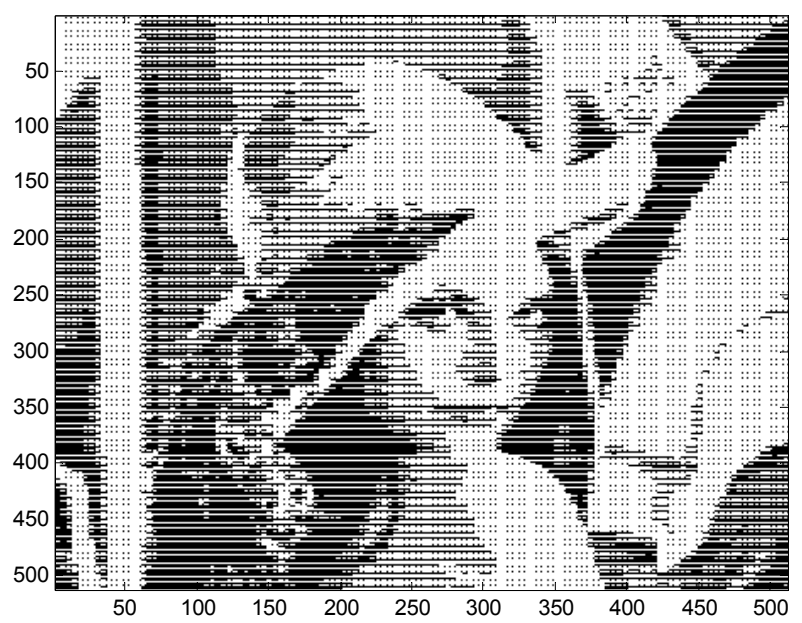

(b)

FIGURA 12(a)- Imagem original de Lenna 128x128 pixels;(b) Imagem obtida a partir da imagem original, através da técnica de halftoning. 


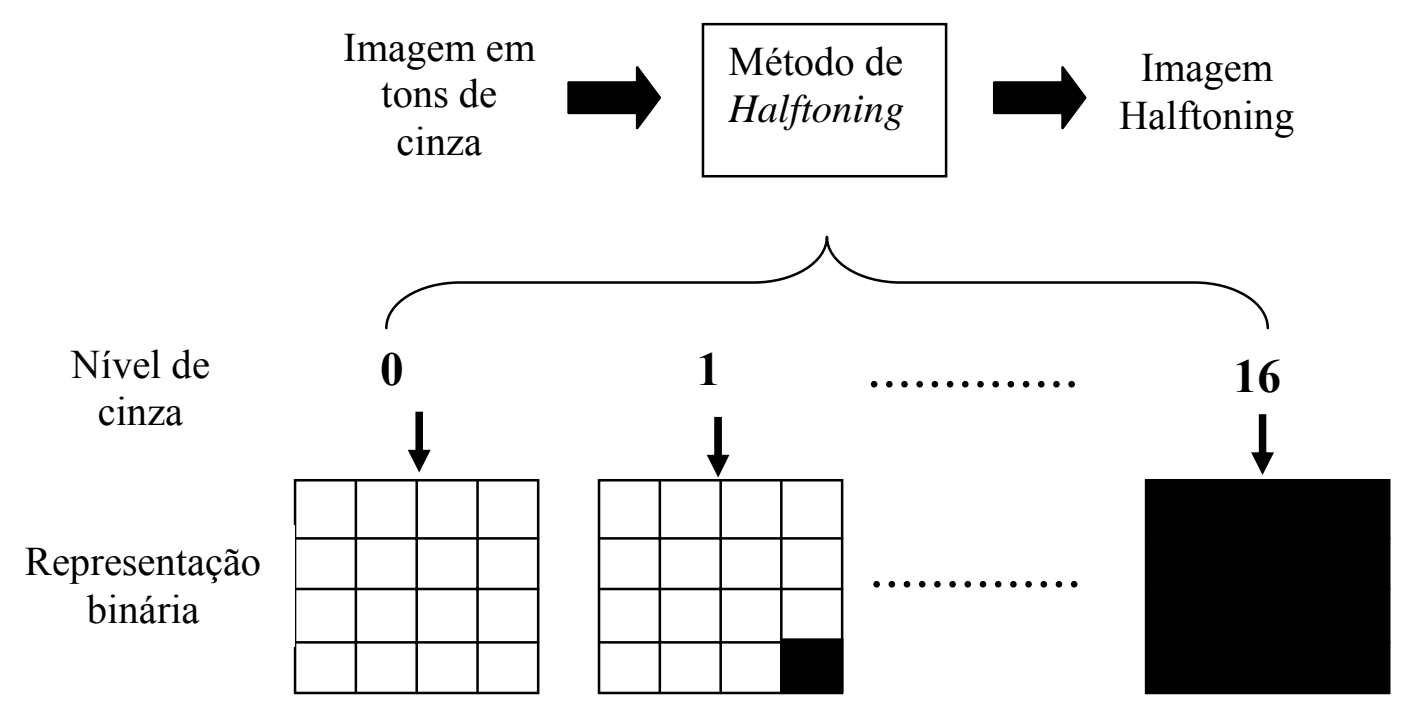

FIGURA 13- Técnica de halftoning aplicada a uma imagem com 17 níveis de cinza.

\section{2-Processo de codificação do elemento de luz branca}

O elemento de luz branca foi fabricado utilizando-se técnica de óptica binária de baixo custo. Considerando-se o custo e o tempo que estão envolvidos num processo para gerar perfis de fase contínuos, foi proposto um EOD binário com níveis de atraso de fase de 0 e $\pi$ radianos. As máscaras utilizadas no processo de fabricação destes elementos foram geradas através da técnica halftoning [44] em que cada pixel com um tom de cinza é representado por um conjunto de subpixels pretos e brancos $[21,25]$.

Os EODs de fase foram projetados para informação binária. A informação binária foi mapeada como mostrado na Figura 14: cada pixel com nível 1 é transformado em quatro pixels com valor de fase $\mathrm{e}^{\mathrm{j} 0}$, e cada pixel com nível 0 é transformado em quatro pixels ( dois pixels com valor de fase $\mathrm{e}^{\mathrm{j} 0}$ e os outros dois pixels com valor de fase $\left.\mathrm{e}^{\mathrm{j} \pi}\right)$. 


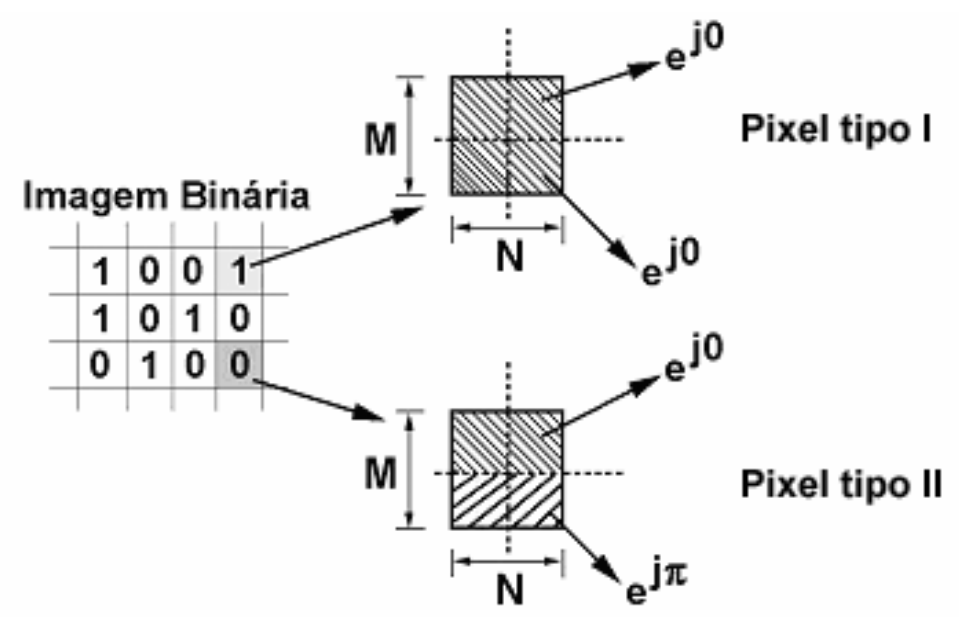

FIGURA 14-Projeto do EOD para uma informação binária

Pode-se classificar dois tipos de pixels codificados conforme ilustrado na Figura 14. Um bloco de pixels composto de 4 pixels de fases $\mathrm{e}^{\mathrm{j} 0}, \mathrm{e}^{\mathrm{j} 0}, \mathrm{e}^{\mathrm{j} 0}, \mathrm{e}^{\mathrm{j} 0}$, o qual foi denominado pixel tipo I. Outro bloco de pixels composto de 4 pixels de fases $\mathrm{e}^{\mathrm{j} 0}, \mathrm{e}^{\mathrm{j} 0}, \mathrm{e}^{\mathrm{j} \pi}, \mathrm{e}^{\mathrm{j} \pi}$, o qual foi denominado pixel tipo II. A seguir serão apresentados os padrões de intensidades luminosas geradas quando uma frente de onda atravessa os pixels tipo I e II.

\section{3-Simulação e funcionamento do elemento de luz branca}

A codificação dos elementos de luz branca foi realizada conforme a metodologia descrita na Seção 5.2. O EOD de luz branca é composto por pixels tipo I e II. Desta forma, simulou-se inicialmente o comportamento de uma frente de onda luminosa modulada por este dois tipos de pixels, segundo a propagação de Fresnel no espectro angular, dada por (8). 


$$
A\left(\frac{\alpha}{\lambda}, \frac{\beta}{\lambda}, z\right) \equiv \int_{\infty}^{\infty} U(x, y, z) \exp \left[-j 2 \pi\left(\frac{\alpha}{\lambda} x+\frac{\beta}{\lambda} y\right)\right] d x d y
$$

Onde A é a amplitude resultante da perturbação $U(x, y, z)$, e $\alpha=\lambda f_{x}$; e $\beta=\lambda f_{y}$, e $f_{x}$ e $f_{y}$ são as freqüências referentes ao plano de coordenadas xy. Assim, a função transferência do sistema é dada por (9)

$$
H\left(f_{x}, f_{y}\right)=\left\{\exp \left[j 2 \pi \frac{z}{\lambda} \sqrt{1-\left(\lambda f_{x}\right)^{2}-\left(\lambda f_{y}\right)^{2}}\right], \text { para } \sqrt{f_{x}{ }^{2}+f_{y}^{2}}<\frac{1}{\lambda}\right.
$$

O espectro de uma função de saída de um sistema, $G_{2}\left(f_{x}, f_{y}\right)$ está relacionado com o espectro de entrada $G_{1}\left(f_{x}, f_{y}\right)$ pela função transferência, de tal forma que:

$$
G_{2}\left(f_{x}, f_{y}\right) \equiv H\left(f_{x}, f_{y}\right) G_{1}\left(f_{x}, f_{y}\right)
$$

O diagrama do algoritmo para o cálculo da propagação da luz modulada pelos pixels tipos I e II é ilustrado na Figura 15.

$$
\text { Pixels tipo I e II }
$$
dos pixels tipo I e II

Propagação de Fresnel

FIGURA 15-Diagrama do algoritmo para o cálculo da propagação da luz modulada pelos

$$
\text { pixels tipos I e II }
$$


Analisando a propagação da intensidade luminosa ao longo do eixo é possível observar a formação de padrões de difração. Para uma distância de $2 \mathrm{~cm}$ foram observados os padrões de difração para os pixels tipo I e II como ilustrados nas Figuras 16-17.

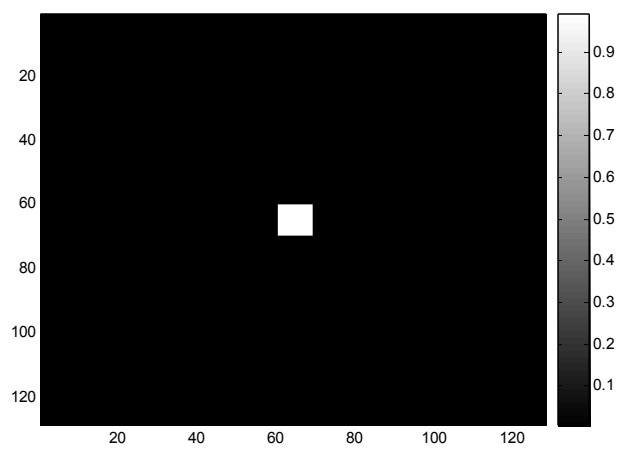

(a)

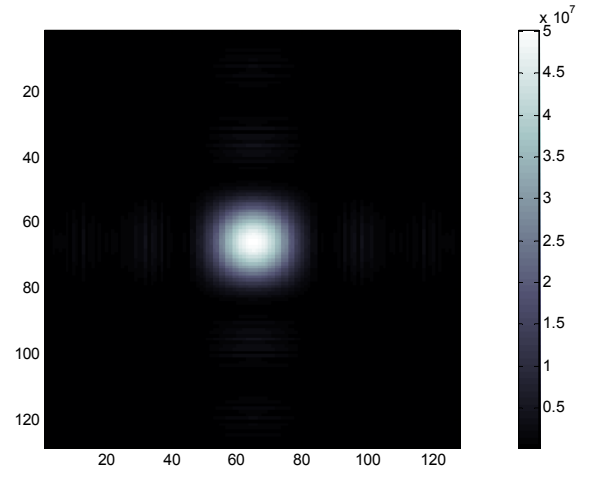

(b)

FIGURA 16-(a)pixel tipo I e (b)sua respectiva intensidade de propagação.

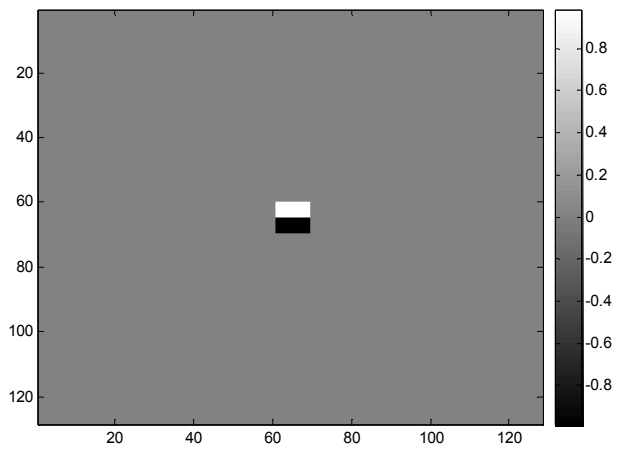

(a)

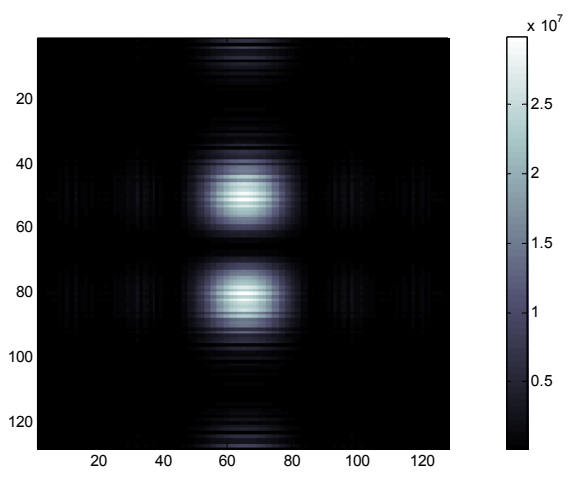

(b)

FIGURA 17- (a)Pixel tipo II e (b) intensidade de propagação do pixel tipo II. 
Estes pixels dos tipos I e II podem ser interpretados como ondas, cujas propagações podem ser calculadas pelas transformadas de Fourier já conhecidas [45]. No caso do pixel tipo I, que modula fase 0 , este se comporta como uma função $\Pi(x)$, cuja transformada de Fourier é $\sin c(s)$. Analogamente, o pixel tipo II, que apresenta fases 0 e $\pi$, tem um comportamento semelhante ao da função $-\frac{1}{2} \Pi\left(x+\frac{1}{2}\right)+\frac{1}{2} \Pi\left(x-\frac{1}{2}\right)$, cuja transformada de Fourier é $-i \sin c(s) \sin c(\pi \mathrm{s})$. As funções matemáticas dos pixels dos tipos I e II e suas transformadas de Fourier estão ilustradas nas Figuras 18 e 19. Estas figuras ilustram os padrões de difração ou transformadas de Fourier (vide Apêndice B) dos pixels tipos I e II.

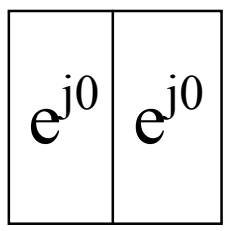

(a)

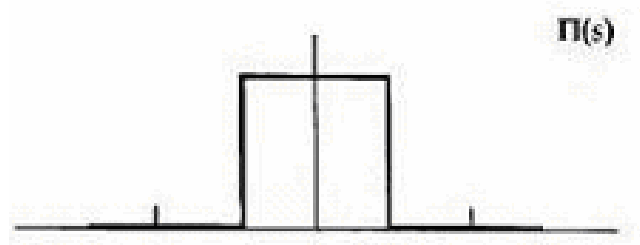

(b)

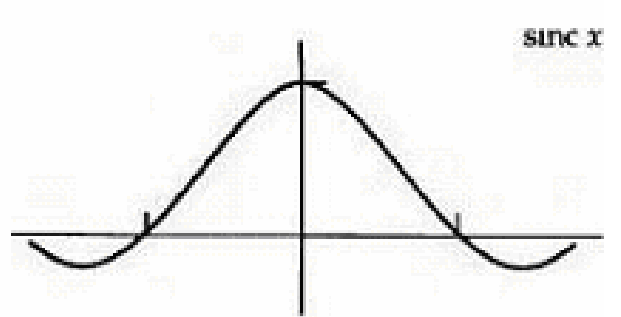

(c)

FIGURA 18-(a) Modelo proposto para o pixel tipo I ; (b) sua representação como função $r e c t(x)$ e (c) sua transformada de Fourier, $\sin c(s)$. 


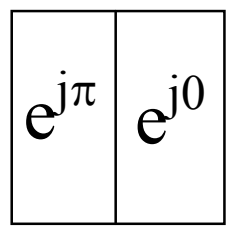

(a)

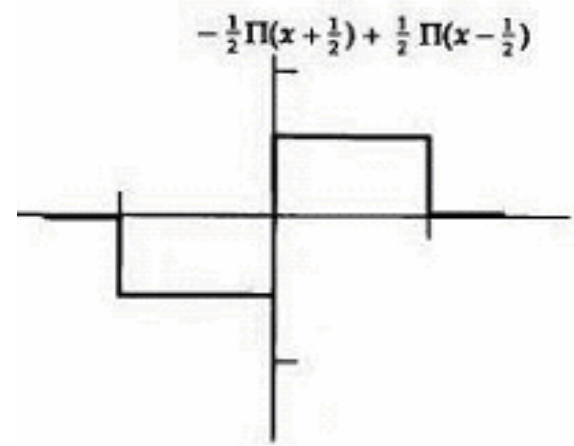

(b)

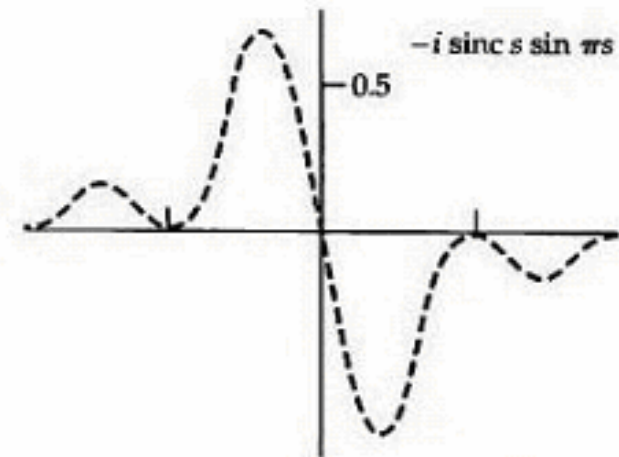

(c)

FIGURA 19- Modelo para o pixel tipo II e (b) sua representação como função $-\frac{1}{2} \prod\left(x+\frac{1}{2}\right)+\frac{1}{2} \prod\left(x-\frac{1}{2}\right) ;$ e (c)sua transformada de Fourier, $-i \sin c(s) \sin c(\pi \mathrm{s})$.

O EOD de luz branca é composto por um conjunto de pixels tipo I e II. Desta forma, é possível calcular o padrão de difração para cada tipo de pixel no plano de reconstrução para compor a imagem resultante. Cada pixel dos tipos I e II podem ser abordados como microhologramas de Fresnel. A seguir será apresentado e descrito o algoritmo para a simulação do EOD de luz branca. 


\section{4- Simulação do EOD de luz branca}

O EOD de luz branca foi projetado segundo a técnica de halftoning descrita na Seção 5.1. Uma imagem original de 128 x 128 pixels, com 256 níveis de cinza, foi transformada numa imagem halftoning de 512 x 512 pixels. Neste processo, cada nível de cinza da imagem original foi mapeado para uma matriz de 4 x 4 pixels. A partir da imagem de halfoning, foi gerado o EOD de fase conforme mostrado na Seção 5.2.

A simulação do comportamento da modulação de uma frente de onda luminosa parcialmente coerente em uma região localizada através do EOD de fase foi implementada segundo os diagramas esquemáticos dos algoritmos presentes nas Figuras 20-21. Neles foi utilizado o cálculo da propagação da luz utilizando a aproximação de Fresnel no espectro angular, mostrada em (8). O cálculo da reconstrução da imagem foi dividido em duas etapas : cálculo da propagação de Fresnel para pixels tipo I e cálculo da propagação de Fresnel para pixels tipo II. Desta forma, é obtida a função transferência (vide anexo B) para cada caso, obtida a partir de (12). Fazendo-se a operação de convolução bidimensional [32] da imagem gerada por halftoning com cada função transferência obtém-se a imagem de saída para cada tipo de pixel. Como o sistema é linear, utilizando o princípio da superposição, as imagens de saída para cada tipo de pixel podem ser somadas para a obtenção da imagem no plano de reconstrução. 
32

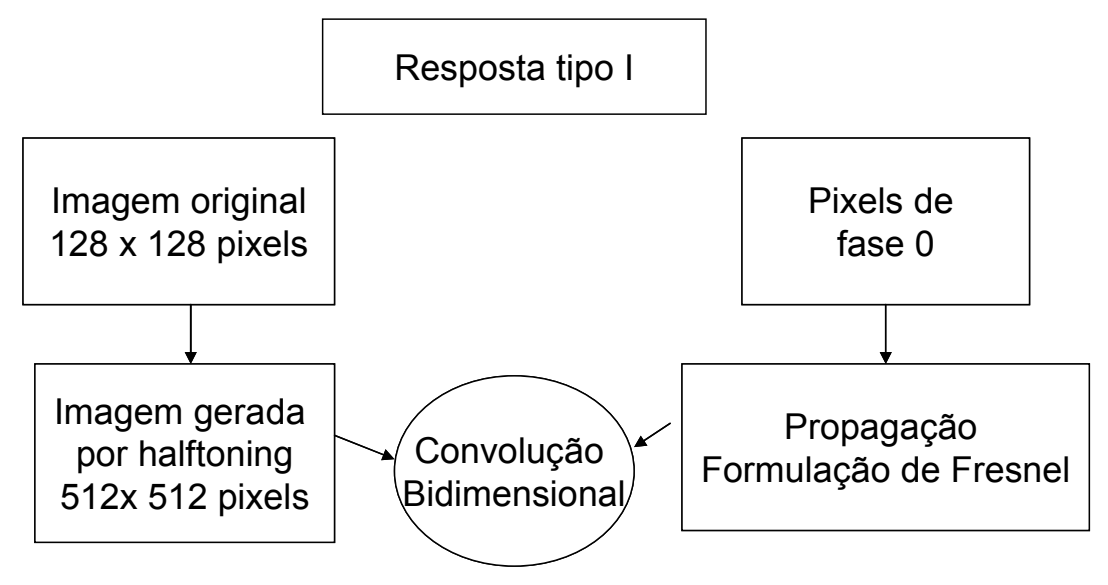

FIGURA 20- Diagrama de blocos do algoritmo para cálculo da resposta impulsional dospixels tipo I.

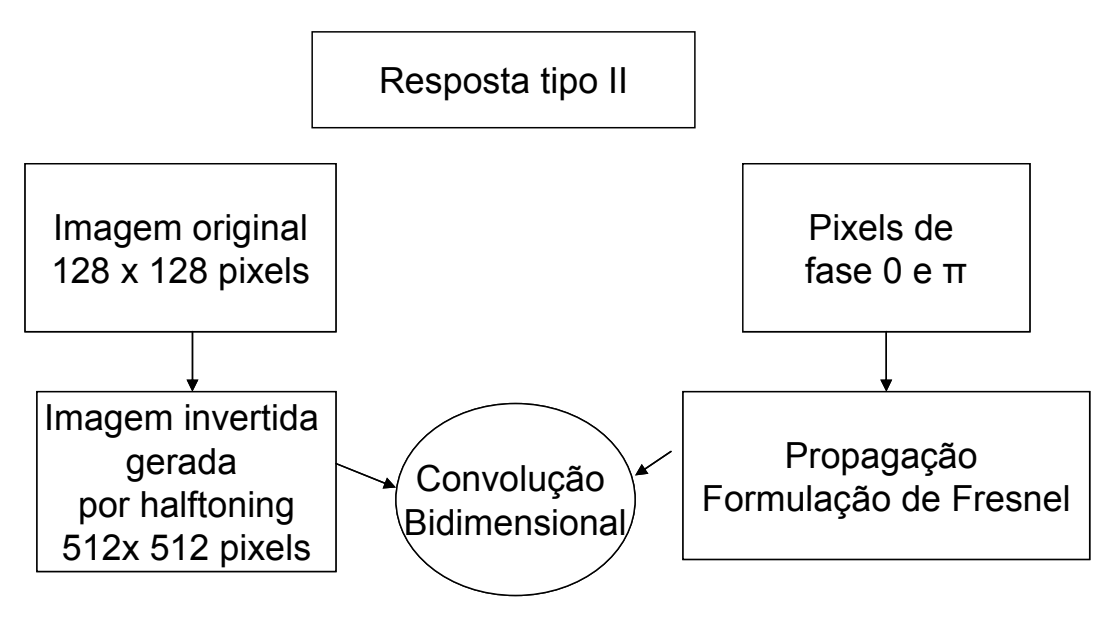

FIGURA 21- Diagrama de blocos do algoritmo para cálculo da resposta impulsional dos pixels tipo II.

Foram feitas simulações computacionais para as distâncias $(0$ e $2 \mathrm{~cm})$ entre o plano do EOD e o plano de reconstrução. Os resultados podem ser visualizados nas Figuras 22(a-b). 


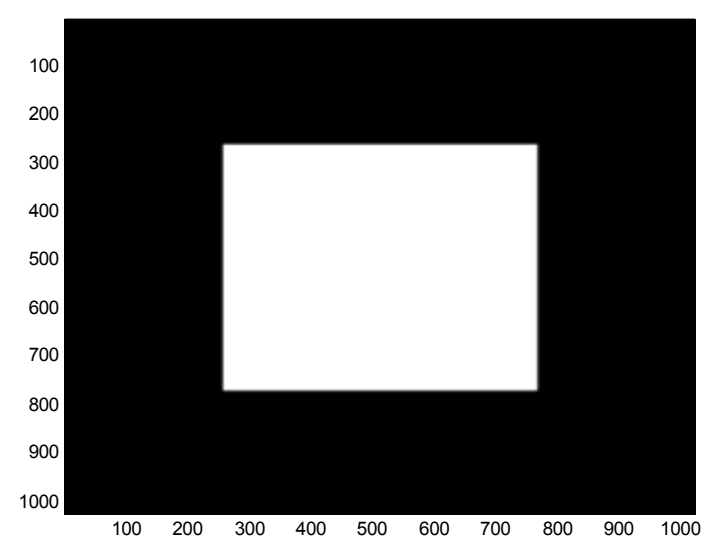

(a)

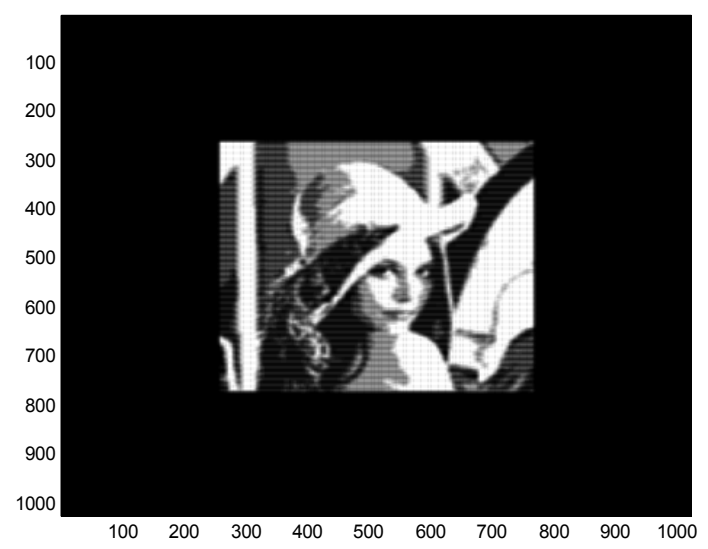

(b)

FIGURA 22- Reconstrução simulada para o EOD gerado a partir da figura Lenna para uma distância do plano do EOD ao plano de reconstrução de (a) $0 \mathrm{~cm}$ e (b) $2 \mathrm{~cm}$.

Observa-se na Figura 22 que para uma distância muito próxima entre o plano do EOD e o plano de reconstrução não há a formação de imagem. Já para uma distância de $2 \mathrm{~cm}$ entre os planos ocorre a formação de uma imagem. A Figura 22(b) ilustra o caso em que ocorre coerência local nas regiões dos pixels tipo I e II. Como conseqüência há a formação dos padrões simulados e mostrados nas Figuras 16-17 da Seção 5.3.

Para a construção de EOD de luz branca foram escolhidas quatro imagens de dimensão 128 x 128 pixels como mostrado na Figura 23. O EOD de fase foi gerado utilizando o mesmo processo aplicado anteriormente nesta seção. Na Figura 24 são mostradas as reconstruções ópticas simuladas computacionalmente para uma distância de propagação de $2 \mathrm{~cm}$. Estes resultados mostram que há uma determinada distância de propagação, neste caso $2 \mathrm{~cm}$, em que ocorre coerência espacial local nas regiões dos pixels tipo I e II. Estas regiões podem ser interpretadas como micro-hologramas de Fresnel, cuja soma das reconstruções origina a imagem de interesse. 


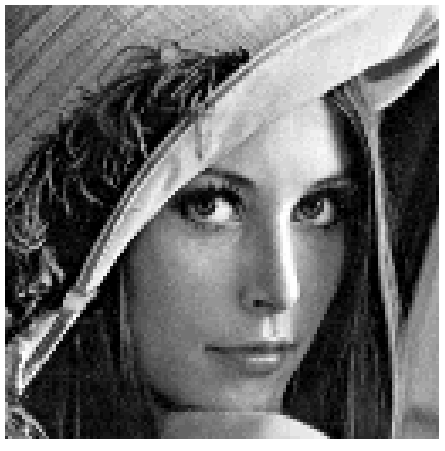

(a)

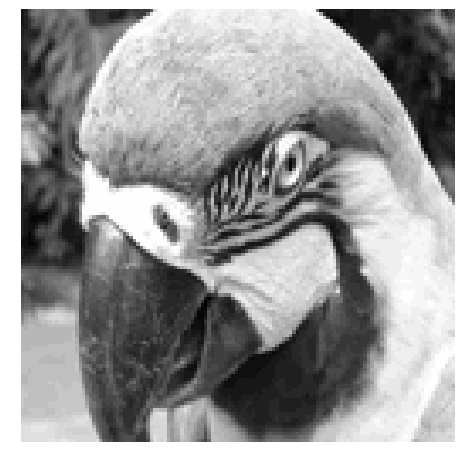

(c)

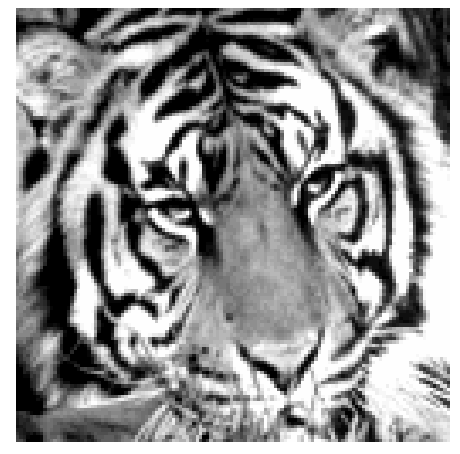

(b)

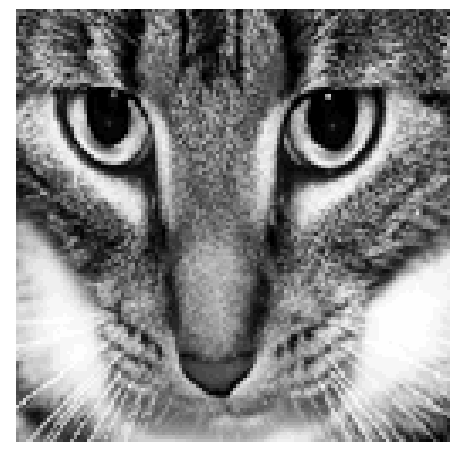

(d)

FIGURA 23- Figuras utilizadas no algoritmo para gerar o EOD de luz branca: (a) Lenna; (b) tigre, (c) periquito; (d) gato. 


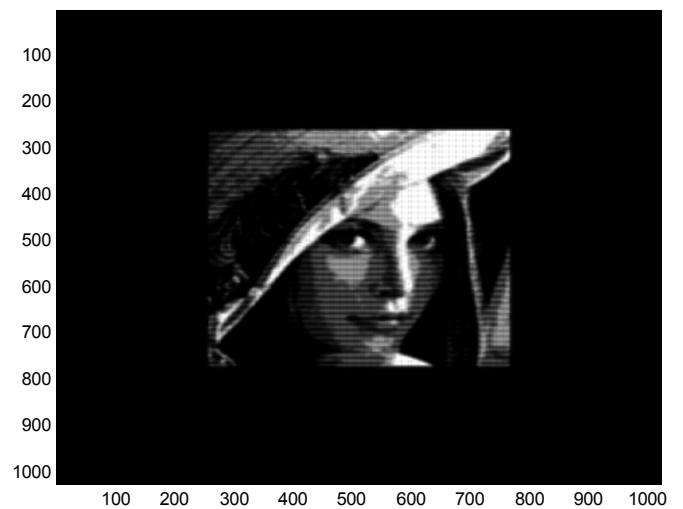

(a)

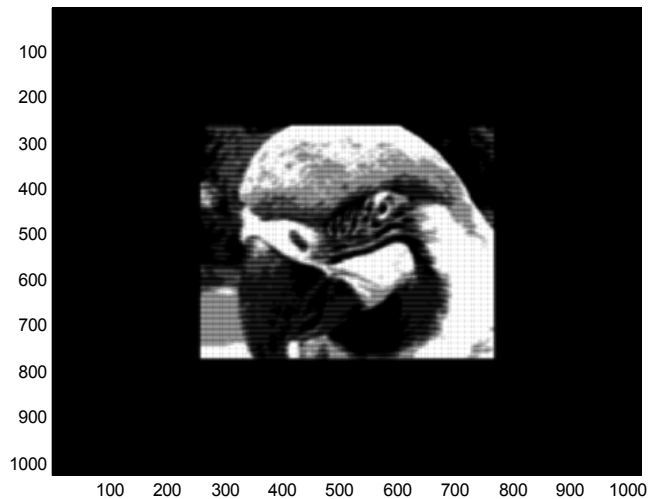

(c)

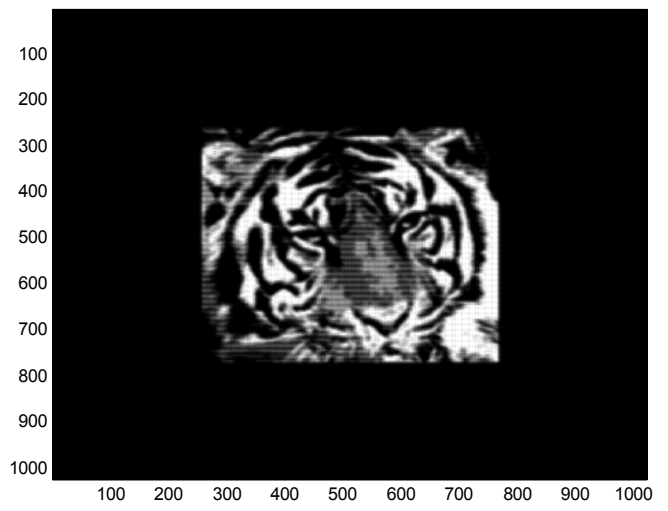

(b)

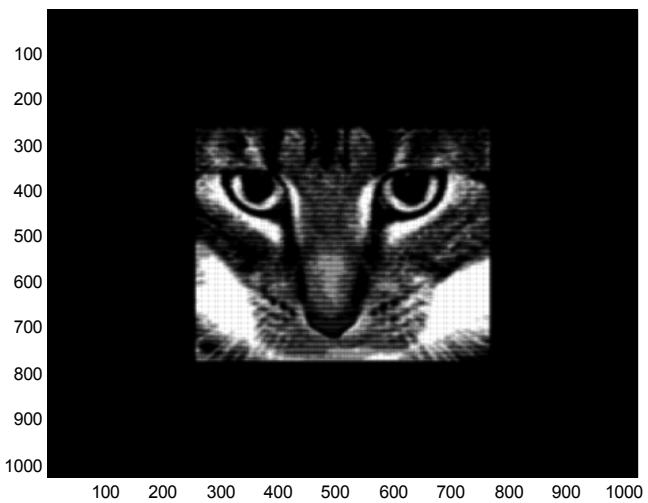

(d)

FIGURA 24- Reconstrução simulada para o EOD gerado a partir das figuras (a)Lenna, (b) tigre, (c) periquito e (d) gato, para uma distância do plano do EOD ao plano de reconstrução de $2 \mathrm{~cm}$. Estas figuras são as mesmas utilizadas para a fabricação do elemento de luz branca. 


\section{5-Construção do elemento de luz branca}

Nesta seção são descritos os processos de fabricação do elemento de luz branca, que foi fabricado com a colaboração do Laboratório de Sistemas Integráveis da Escola Politécnica - USP - Brasil.

A modulação de fase no EOD é descrita por (11) [18].

$$
\operatorname{th}(x, y)=\frac{\lambda}{2 \pi(n-1)} \phi(x, y)
$$

onde : $\phi(x, y)(0 \leq \phi(x, y) \leq 2 \pi)$ é a distribuição de fase, th $(x, y)$ é a variação de espessura necessária para gerar o padrão de difração, $\lambda$ é o comprimento de onda de operação e $n$ é o índice de refração do material da rede de fase. Visto que o EOD funciona no espectro visível foi escolhido $\lambda=633 \mathrm{~nm}$.

O EOD foi fabricado empregando óptica binária de baixo custo e a seqüência de etapas para fabricação é mostrada esquematicamente na Figura 25. Considerando o custo e o tempo deste processo, o qual gera perfis de fase contínuos, foi proposto um EOD binário com níveis de atraso de fase de 0 e $\pi$ radianos, que são gerados por etapas de fotolitografia e corrosão por plasma [20].

Um substrato de vidro de qualidade óptica com diâmetro de três polegadas foi utilizado como base para as estruturas de deslocamento de fase. Estas estruturas foram implementadas em filme fino de fotorresiste cujo índice de refração é $n_{R}=1,65$.

Substituindo $\phi(x, y)=\pi \mathrm{em}(10)$, a espessura de rede encontrada é th(x,y) $=633 /[2(1.65-$ $1)]=486,9 \mathrm{~nm}$. 
Neste trabalho, foi utilizado um processo de seis etapas, que são bem controladas e conhecidas para aplicações em micromecânica e microeletrônica. Estas etapas são apresentadas a seguir :

a) Limpeza das lâminas de vidro. O substrato de vidro utilizado apresenta diâmetro de 3 polegadas e espessura de $1,0 \mathrm{~mm}$;

b) Aplicação (spin) de álcool isopropílico, 20 seg., 2500 rpm;

c) Aplicação do promotor de aderência, 20 seg., 2500 rpm;

d) Aplicação do fotoresiste TOKYO OHKA ONPR - 800, 20 seg., $2500 \mathrm{rpm}$, a espessura do fotorresiste obtida foi de $1,1 \mu \mathrm{m}$;

e) Pré-Cura, $90 \mathrm{seg} @ 90^{\circ} \mathrm{C}$;

f) Exposição UV, $40 \mathrm{seg}$., $25 \mathrm{~mW} / \mathrm{cm}^{2}$. O fotolito utilizado para a transferência do padrão desejado foi gerado sobre um filme transparente por uma plotter (AGFA AVANTRA 30e 2400 dpi) com máxima resolução de $15 \mu \mathrm{m}$.

g) Revelação, 2 partes de revelador : 1 parte de $\mathrm{H}_{2} \mathrm{O}$-DI. O tempo de revelação foi mantido constante em 60 s. O revelador empregado foi o HPRD-402;

h) Pós cura, $30 \min @ 105^{\circ} \mathrm{C}$;

i) Medição de altura de degrau antes da corrosão. Verificação da altura de degraus do fotorresiste, antes da corrosão por plasma, via técnica de perfilometria;

j) Corrosão por plasma. Os substrato com fotorresiste foi submetido a corrosão por plasma de $\mathrm{CF}_{4}+20 \% \mathrm{H}_{2}$, durante 10 minutos; 
k) Medição de altura de degrau após a remoção do fotorresiste. Verificação das alturas de degraus após a remoção do fotorresiste remanescente da corrosão, via perfilometria.

$\mathrm{Na}$ Figura 26, pode ser visto o EOD de fase de luz branca produzido através da metodologia descrita nesta seção.

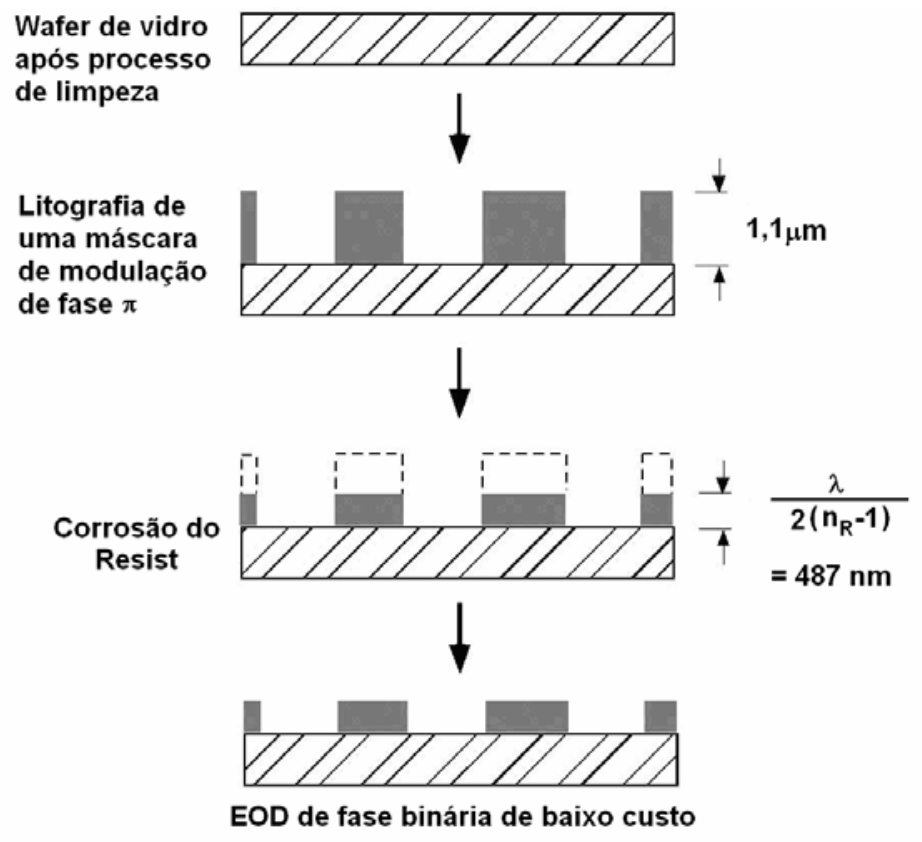

FIGURA 25- Visão esquemática da seqüência do processo de fabricação do EOD no modo transmissão.

Devido ao baixo custo de fabricação foi utilizada uma máscara que consiste de um filme transparente tipo fotolito. O padrão a ser transferido foi impresso no filme transparente por uma plotter com máxima definição $15 \mu \mathrm{m}$ ( AGFA AVANTRA 30e 2400 dpi ). Nenhuma máscara gerada por feixe de elétrons é necessária. 


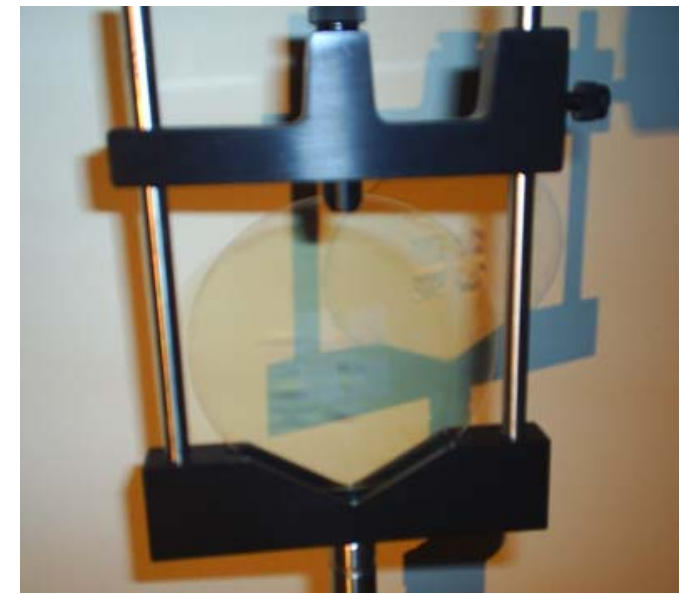

FIGURA 26- Montagem do EOD de luz branca realizada no laboratório de óptica do departamento de engenharia elétrica da EESC-USP. No plano posterior, observa-se o anteparo, onde a imagem é projetada. 
40

\section{Capítulo 6}

\section{Introdução}

No capítulo anterior foram apresentados a metodologia de projeto, funcionamento e construção do EOD de fase que opera sob iluminação parcialmente coerente em uma região localizada. Neste capítulo serão apresentados os resultados experimentais referentes às reconstruções ópticas utilizando os EODs fabricados através do método proposto.

\section{6-Resultados experimentais}

\section{1- Medida do contraste}

O EOD de fase projetado e construído é iluminado com uma fonte luminosa não-coerente. Logo, torna-se necessário avaliar o contraste obtido através da fonte luminosa utilizada.

A iluminação utilizada no processo de reconstrução óptica corresponde a uma lâmpada dicróica halógena ( $12 \mathrm{~V}, 50 \mathrm{~W}$ e comprimento de onda médio $\bar{\lambda}=633 \mathrm{~nm})$ da marca OSRAM mostrada na Figura 27. 


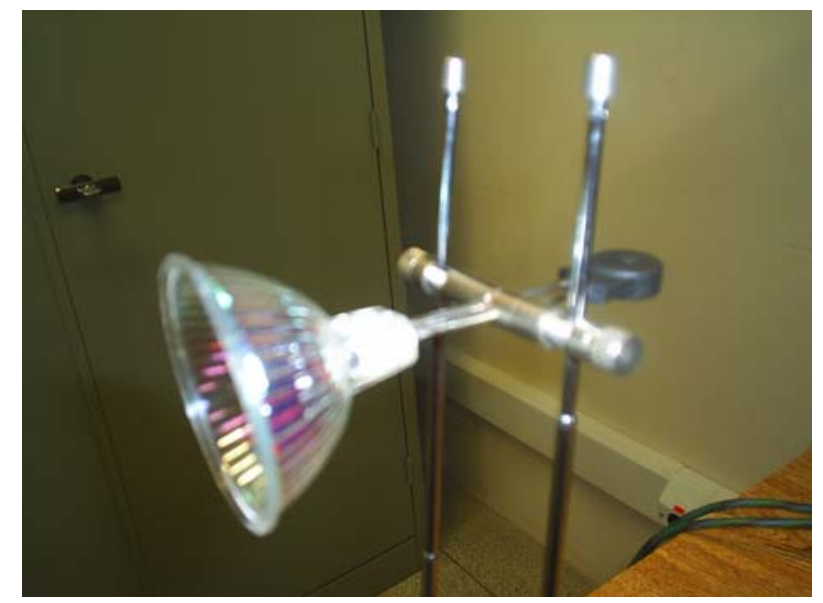

FIGURA 27- Lâmpada dicróica halógena $12 \mathrm{~V}, 50 \mathrm{~W}, \bar{\lambda}=633 \mathrm{~nm}$, da marca OSRAM, utilizada para obtenção da reconstrução óptica do elemento de luz branca.

Para a determinação do contraste da fonte luminosa utilizada para a reconstrução óptica do EOD de luz branca foram feitos três experimentos: difração da luz por uma fenda dupla (experimento de Young); difração da luz através de uma grade de difração, cujo período da rede é $10 \mu \mathrm{m}$, ou seja, da mesma ordem de grandeza da dimensão dos pixels do EOD; e difração da luz através do EOD de luz branca.

A montagem óptica utilizada nos experimentos acima está ilustrada na Figura 28. Para a reconstrução óptica do elemento de luz branca e posteriormente o cálculo do contraste da fonte luminosa empregada, foi realizada uma montagem, como visto na Figura 28, utilizandoe : suportes da marca Newport; uma lâmpada dicróica halógena $12 \mathrm{~V}, 50 \mathrm{~W}, \bar{\lambda}=633 \mathrm{~nm}$, da marca OSRAM (vide Figura 27); uma pupila Newport; uma câmera CCD Solid State COHU, acoplada a um PC; uma placa de aquisição NI-IMAQ 2.2 da National Instruments; e duas lentes, de distâncias focais $\mathrm{f}=0,15 \mathrm{~m}$ e $\mathrm{f}=0,25 \mathrm{~m}$, com o objetivo de projetar as imagens no plano do sensor da câmera CCD. 
42

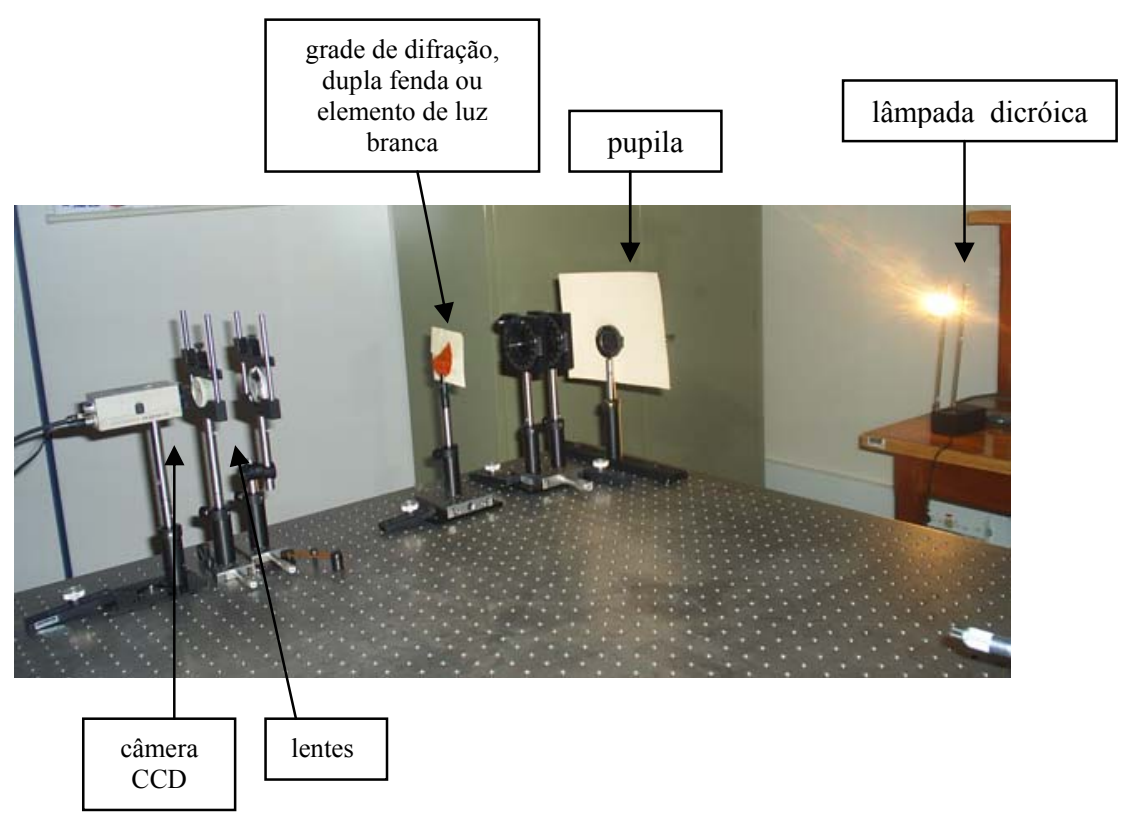

FIGURA 28-Montagem experimental para cálculo do grau de coerência realizada através de três metodologias: difração por uma fenda dupla, difração através de uma grade de difração e difração através do elemento de luz branca.

O grau de coerência da fonte luminosa foi calculado em cada experimento utilizando a formulação de (5). De acordo com (6), Seção 4.2, como a dimensão dos pixels é $20 \mu \mathrm{m}$, a distância $d\left(P_{1}, P_{2}\right)$, entre dois pontos coerentes em uma frente de onda, é a mínima distância entre dois pixels, $20 \mu \mathrm{m}$. O diâmetro do filamento da luz dicróica $\rho$ é $3 \mathrm{~mm}$, e o comprimento de onda médio $\bar{\lambda}$ é $633 \mathrm{~nm}$. O valor mínimo da distância $\mathrm{R}$ da fonte ao plano do EOD calculado para que haja coerência espacial é $0,6 \mathrm{~m}$. Tendo em vista estes resultados, a fenda dupla, a grade de difração e o elemento de luz branca foram posicionados a esta distância mínima da fonte luminosa, para que a condição de coerência fosse observada. A distância entre o plano do EOD 
de luz branca e o plano da câmera CCD foi fixada em $2 \mathrm{~cm}$, como constatado na reconstrução simulada computacionalmente.

Para cada experimento foram calculados quatro valores de contraste: um para a iluminação da lâmpada dicróica somente e outros três com a lâmpada dicróica associada separadamente com filtros (verde, vermelho e azul). Para o cálculo destes contrastes foi implementado um algoritmo simples para identificar os máximos e mínimos de intensidade nas imagens geradas em cada experimento pelos diferentes comprimentos de onda. Os resultados do cálculo dos contrastes dos experimentos são mostrados nas Tabelas I, II e III.

Tabela I. Contrastes determinados através da difração por uma grade de difração obtido com a fonte de luz branca separadamente e com filtros vermelho, verde e azul .

\begin{tabular}{|c|c|c|}
\hline \multicolumn{2}{|c|}{ 1.Grade de Difração } & Contraste \\
\hline Tipo de iluminação & $\begin{array}{c}\text { Comprimento de } \\
\text { onda } \lambda(\mathbf{n m})\end{array}$ \\
\hline Branca & 633 & 0,7899 \\
\hline Vermelha & 700 & 0,8168 \\
\hline Verde & 530 & 0,8216 \\
\hline Azul & 470 & 0,8155 \\
\hline
\end{tabular}


44

Tabela II. Contraste determinados através da difração por uma fenda dupla obtido com a fonte de luz branca separadamente e com filtros vermelho, verde e azul .

\section{Fenda de Young}

\begin{tabular}{|c|c|c|}
\hline Tipo de iluminação & $\begin{array}{c}\text { Comprimento de } \\
\text { onda } \boldsymbol{\lambda}(\mathbf{n m})\end{array}$ & Contrastes \\
\hline Branca & 633 & 0,8000 \\
\hline Vermelha & 700 & 0,8242 \\
\hline Verde & 530 & 0,7326 \\
\hline Azul & 470 & 0,7089 \\
\hline
\end{tabular}

Tabela III.(a) Contrastes determinados através da difração pelo elemento de luz branca Lenna obtidos com a fonte de luz branca separadamente e com filtros vermelho, verde e azul.

\begin{tabular}{|l|c|c|c|}
\hline \multicolumn{3}{|c|}{ 3.Elementos de luz branca } \\
\hline \multirow{4}{*}{ a) Lenna } & Tipo de iluminação & $\begin{array}{c}\text { Comprimento de } \\
\text { onda } \lambda(\mathbf{n m})\end{array}$ & Contrastes \\
\cline { 2 - 4 } & Branca & 633 & 0,7385 \\
\cline { 2 - 4 } & Vermelha & 700 & 0,8022 \\
\cline { 2 - 4 } & Verde & 530 & 0,7364 \\
\cline { 2 - 4 } & Azul & 470 & 0,7754 \\
\hline
\end{tabular}


Tabela III.(b) Contrastes determinados através da difração pelo elemento de luz branca gato obtidos com a fonte de luz branca separadamente e com filtros vermelho, verde e azul.

\begin{tabular}{|c|c|c|c|}
\hline & Tipo de iluminação & $\begin{array}{c}\text { Comprimento de } \\
\text { onda } \lambda(\mathbf{n m})\end{array}$ & Contrastes \\
\cline { 2 - 4 } & Branca & 633 & 0,7034 \\
\cline { 2 - 4 } & Vermelha & 700 & 0,7509 \\
\cline { 2 - 4 } & Verde & 530 & 0,7706 \\
\cline { 2 - 4 } & Azul & 470 & 0,7385 \\
\hline
\end{tabular}

Tabela III.(c) Contrastes determinados através da difração pelo elemento de luz branca tigre obtidos com a fonte de luz branca separadamente e com filtros vermelho, verde e azul.

\begin{tabular}{|l|c|c|c|}
\hline \multirow{4}{*}{ c)Tigre } & Tipo de iluminação & $\begin{array}{c}\text { Comprimento de } \\
\text { onda } \lambda(\mathbf{n m})\end{array}$ & Contrastes \\
\cline { 2 - 4 } & Branca & 633 & 0,7024 \\
\cline { 2 - 4 } & Vermelha & 700 & 0,7324 \\
\cline { 2 - 4 } & Verde & 530 & 0,7754 \\
\cline { 2 - 4 } & Azul & 470 & 0,7385 \\
\hline
\end{tabular}


46

Tabela III.(d) Contrastes determinados através da difração pelo elemento de luz branca periquito obtidos com a fonte de luz branca separadamente e com filtros vermelho, verde e azul.

\begin{tabular}{|c|c|c|c|}
\hline & Tipo de iluminação & $\begin{array}{c}\text { Comprimento de } \\
\text { onda } \lambda(\mathbf{n m})\end{array}$ & Contrastes \\
\cline { 2 - 4 } & Branca & 633 & 0,7376 \\
\cline { 2 - 4 } d)Periquito & Vermelha & 700 & 0,8022 \\
\cline { 2 - 4 } & Verde & 530 & 0,7501 \\
\cline { 2 - 4 } & Azul & 470 & 0,7698 \\
\hline
\end{tabular}

Os resultados dos experimentos com a fenda dupla, a grade de difração e o elemento de luz branca mostrados nas Tabelas I, II e III indicam contrastes para a luz branca e para os comprimentos de onda verde, vermelho e azul. Nota-se que o contraste obtido através da fonte de luz branca e de suas componentes estão muito próximos. Estão ilustradas nas Figuras 29-32 as reconstruções ópticas do EOD de luz branca para os seguintes casos: lâmpada dicróica somente e lâmpada dicróica associada com filtros isolados (vermelho, verde e azul). 


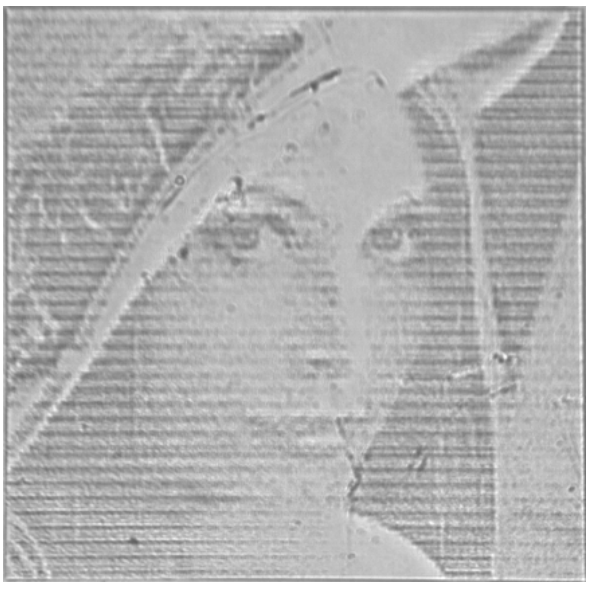

(a)

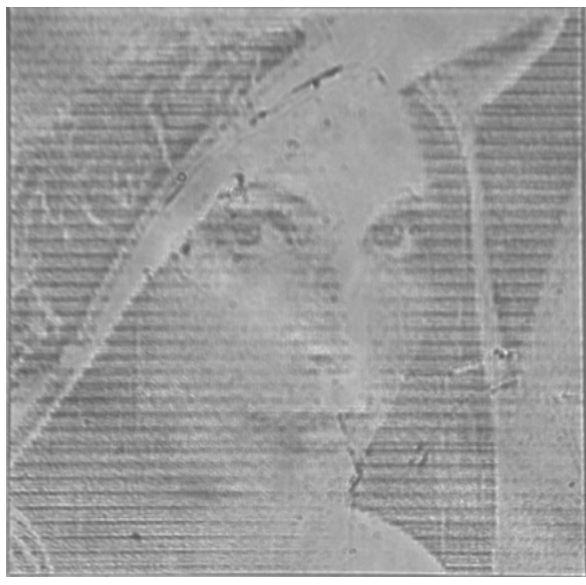

(c)

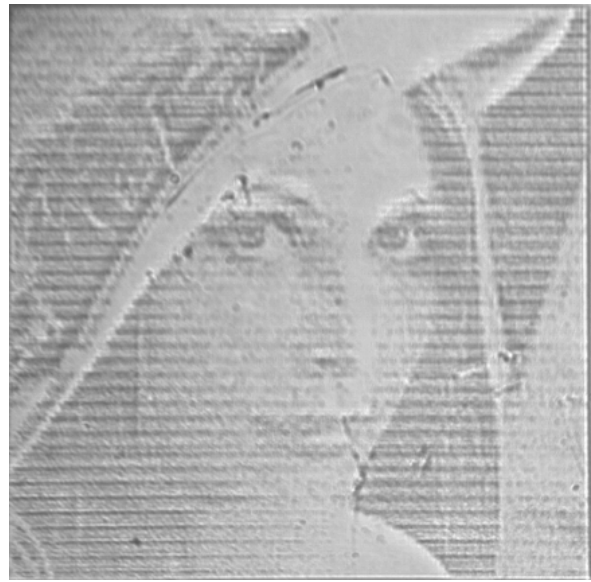

(b)

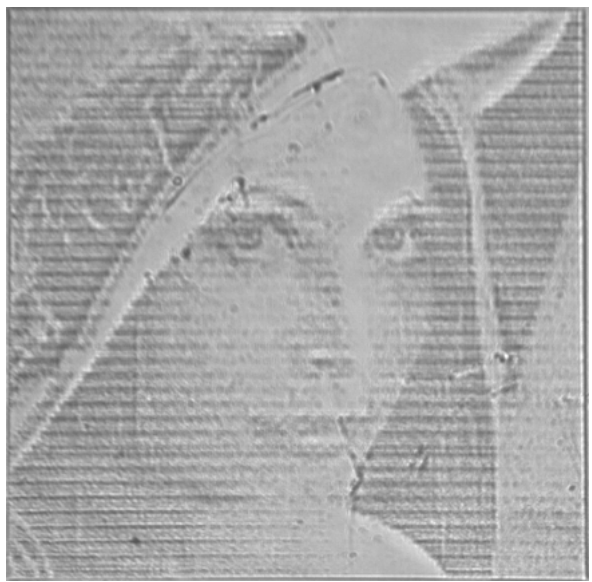

(d)

FIGURA 29- Reconstruções ópticas geradas a partir do elemento de luz branca "Lenna" utilizando: (a)

lâmpada dicróica somente; e lâmpada dicróica com filtros (b) vermelho; (c) verde e (d) azul. 


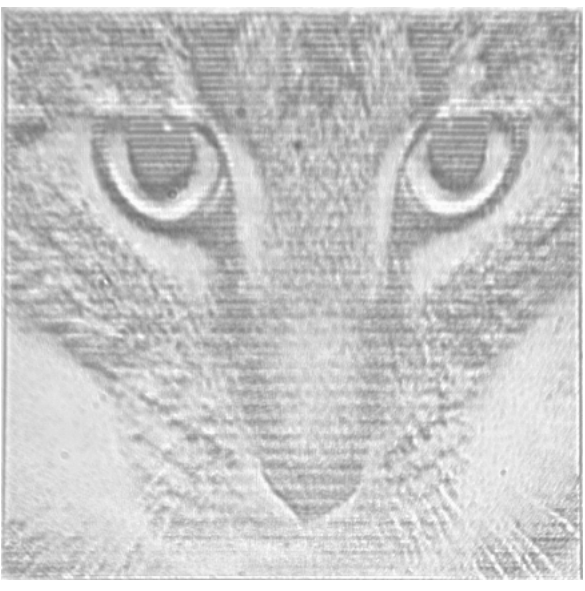

(a)

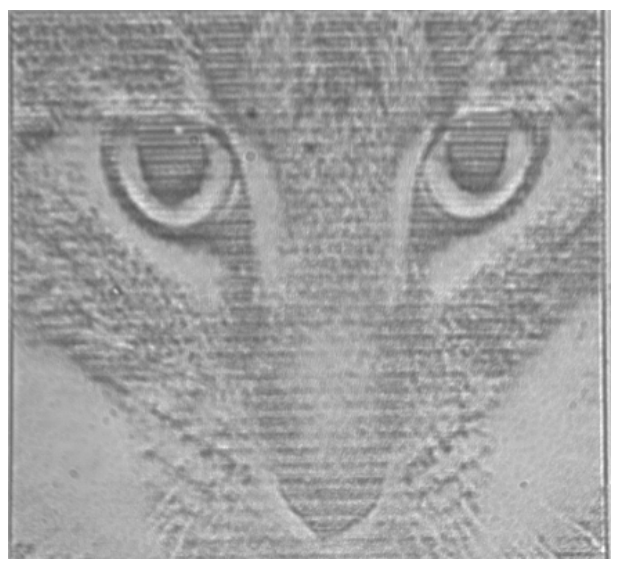

(c)

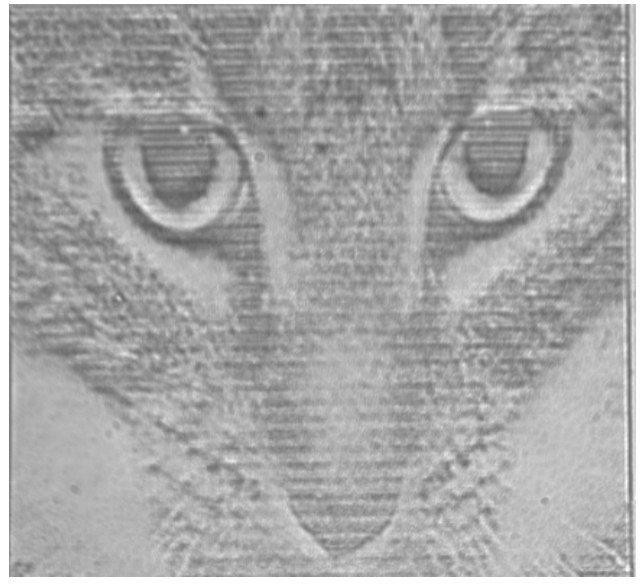

(b)

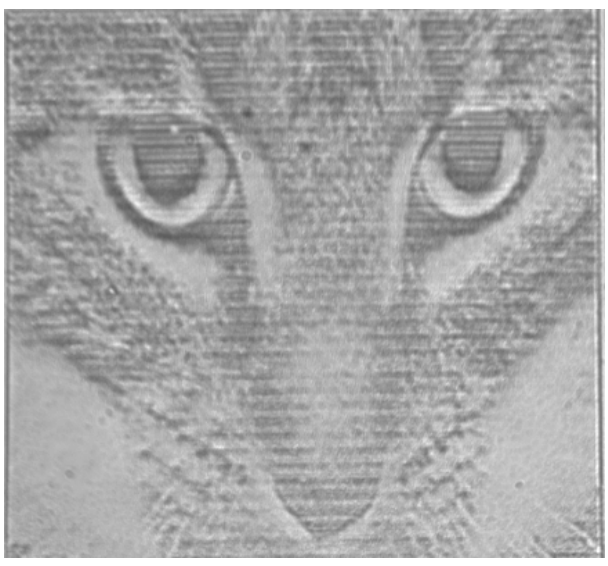

(d)

FIGURA 30- Reconstruções ópticas geradas a partir do elemento de luz branca "gato" utilizando: (a) lâmpada dicróica somente; e lâmpada dicróica com filtros (b) vermelho; (c) verde e (d) azul. 


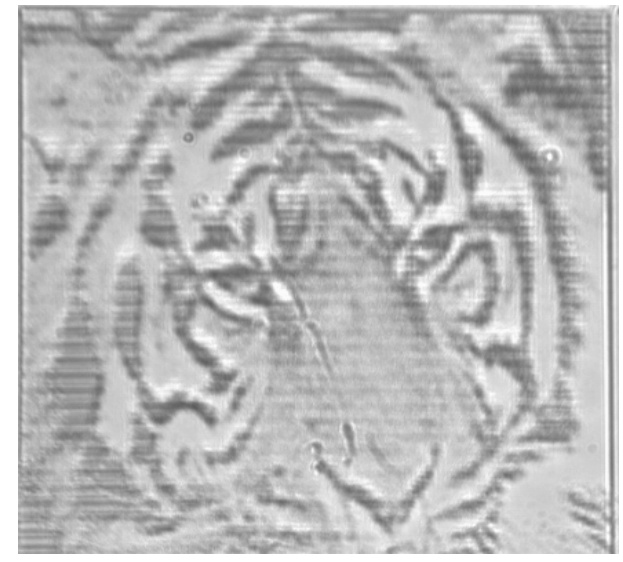

(a)

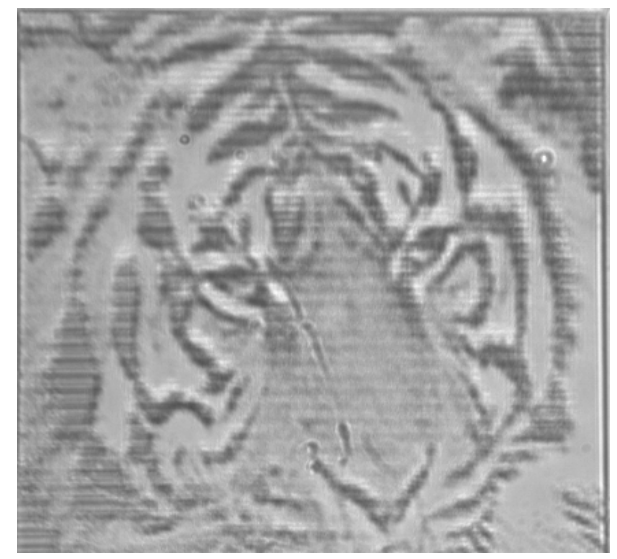

(c)

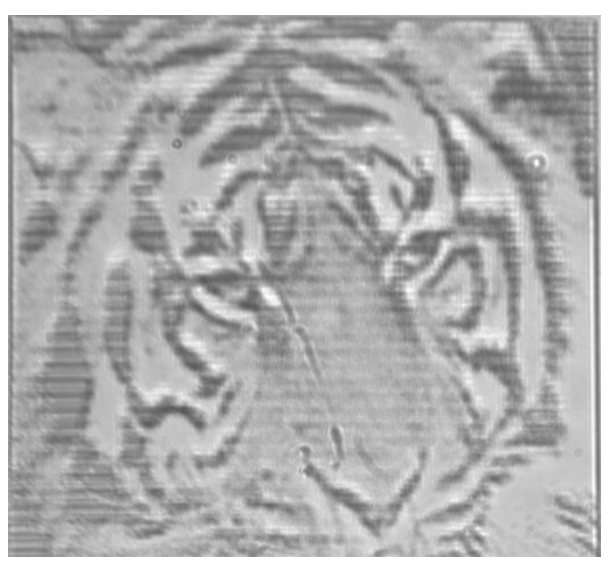

(b)

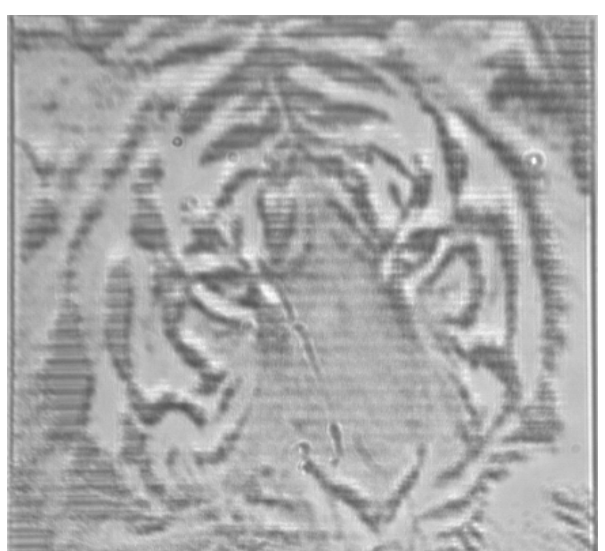

(d)

FIGURA 31- Reconstruções ópticas geradas a partir do elemento de luz branca "tigre" utilizando: (a)

lâmpada dicróica somente; e lâmpada dicróica com filtros (b) vermelho; (c) verde e (d) azul. 


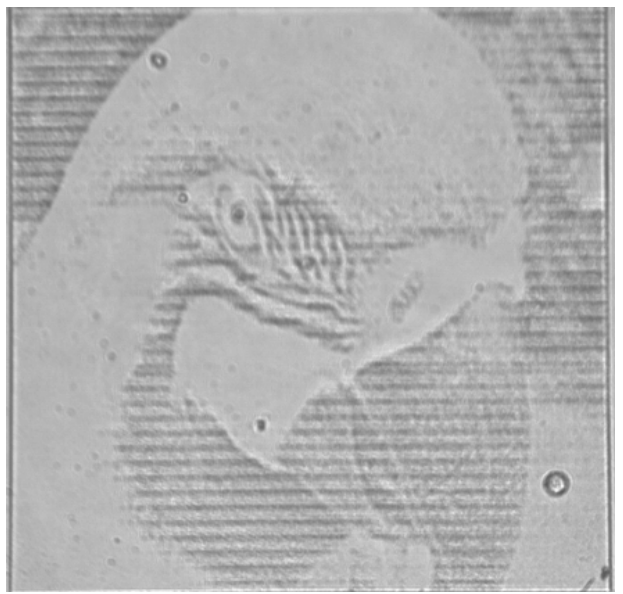

(a)

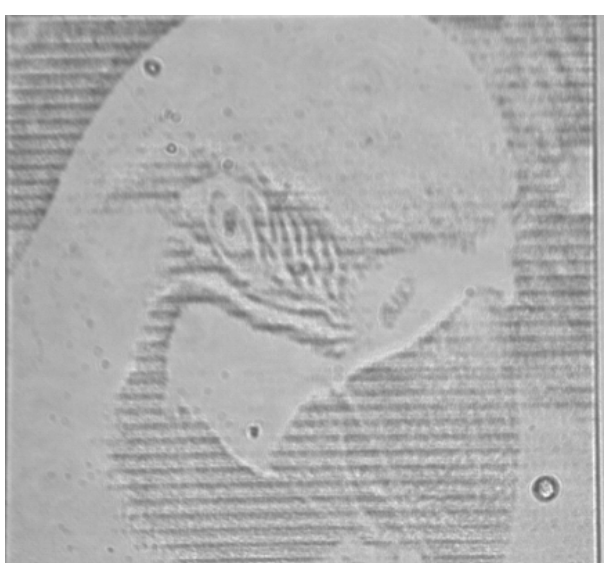

(c)

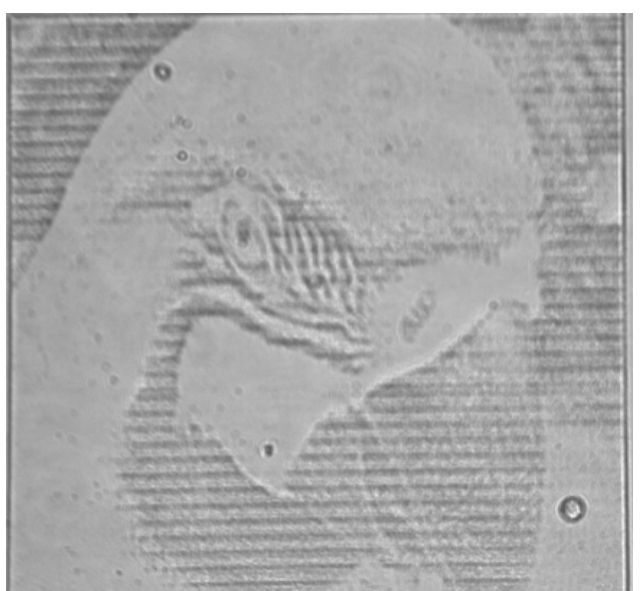

(b)

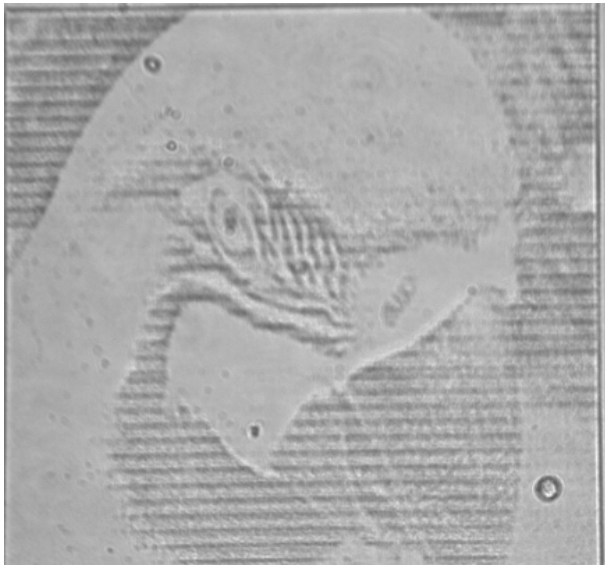

(d)

FIGURA 32- Reconstruções ópticas geradas a partir do elemento de luz branca "periquito" utilizando: (a)

lâmpada dicróica somente; e lâmpada dicróica com filtros (b) vermelho; (c) verde e (d) azul. 
Como pode ser visto nas Figuras 29(a), 30(a), 31(a) e 32(a), as reconstruções ópticas geradas pelos elementos ópticos difrativos de luz branca apresentam boa nitidez e resultados satisfatórios. Não foi observada distorção cromática considerável, como o efeito rainbow constatado em outros hologramas de luz branca convencionais. As reconstruções ópticas do EOD de luz branca obtidas com luz branca somente, e com suas componentes vermelha, verde e azul são muito semelhantes. Segundo o conceito de amostragem (vide Apêndice C), os intervalos de amostragem são proporcionais ao comprimento de onda $\lambda$. Entretanto, a diferença de tamanho dos pixels das imagens de reconstrução geradas pelos três comprimentos de onda não é perceptível ao olho humano e, segundo o princípio da superposição, descrito no Apêndice $B$, cada pixel da imagem resultante gerada a partir do elemento de luz branca iluminado com a lâmpada dicróica é a soma de todos os pixels de cada imagem gerada pelos diferentes comprimentos de onda que a compõem. Os pixels se sobrepõem e o olho humano integra a imagem, de tal forma que distorções cromáticas não são observadas. 
52

\section{Capítulo 7}

\section{Introdução}

No capítulo anterior foram apresentados resultados experimentais referentes as reconstruções ópticas utilizando os EODs construídos. Neste capítulo serão destacadas algumas conclusões e considerações em relação ao EOD de luz branca proposto.

\section{7-Conclusões}

O cálculo e simulação do elemento de luz branca foram propostos a partir de um algoritmo que utiliza a transformada de Fourier como ferramenta para o cálculo da propagação de luz através do elemento binário, construído utilizando uma imagem gerada pela técnica de halftoning, obtida rearranjando-se regiões de pixels que apresentam coerência espacial local. Esta proposta de fabricação utiliza óptica binária de baixo custo, uma vez que foi introduzida uma modulação de fases 0 e $\pi$.

Uma das vantagens da utilização deste algoritmo é a eliminação de métodos iterativos, utilizados na maioria dos hologramas gerados por computador. Utilizando conceitos da técnica de halftoning no algoritmo proposto, pode-se gerar uma máscara para produzir o elemento de luz branca facilmente, utilizando uma impressora de alta resolução e técnicas de fabricação de circuito impresso.

Uma outra vantagem deste EOD de fase de luz branca é que os resultados da reconstrução óptica mostram mínima distorção cromática, imperceptível ao olho humano, ao contrário do 
observado em hologramas de luz branca convencionais. Outras vantagens importantes são o baixo custo e o tempo envolvidos no processo de fabricação do EOD de luz branca proposto, já que este utiliza técnicas simples de fabricação de circuitos impressos.

Os resultados obtidos a partir da reconstrução óptica e simulada do EOD de fase de luz branca apresentam semelhança entre si, o que indica que o algoritmo proposto neste trabalho foi capaz de reproduzir este comportamento óptico do elemento, de forma simples e sem necessidade de métodos complexos ou iterativos.

O EOD de luz branca poderia ser utilizado em diversas aplicações: processamento óptico não-corente (correlatores ópticos), sistemas de segurança para autenticação de informações (documentos, cartões de crédito) e projeção de imagens holográficas como arte. 
54

\section{Capítulo 8}

\section{8-Referências Bibliográficas}

[1]GABOR, D.(1948). “A new microscope principle”. Nature, vol. 161, pp.777.

[2] DENISYUK, Y. N.(1997). "From Lippmann photography to selectograms via white light holography”. Journal of imaging science and tecnology. vol 41(3), pp.205-210, mai/jun.

[3] BENTON, S. A.(1969). "On a method for reducing the information content of holograms .Journal of Optical Society of America, vol.59, pp.1969.

[4] SIEBERT, L. D.(1967). "Front-lighted pulse laser holography". Applied Physics Letters, vol. 11(10), pp.326.

[5] MOLLENST, G. ; WAHL, H.(1968). "Electron holography and reconstruction with laser light”.Naturwissenschaften, vol.55(7), pp. 340.

[6] TANNER, L.H. (1968). “A study of fringe clarity in laser interferometry and holography. Journal of Physics e Scientific Instruments, vol.1(5), pp. 517.

[7] GERCHBERG, R. W ; SAXTON, W.O. (1972). Optik vol.35, pp. 237.

[8] HIRSCH, P.M.; JORDAN, J.A.; LESEM, L.B. (1971). US Patent Nº 3.619.022.

[9] BROWN, B. R.; LOHMANN, A.W.(1969). IBM J. Res. \& Dev. vol. 13, pp160.

[10] LOHMANN, A.W; PARIS, D.P. (1967). Applied Optics vol.6, pp.1739.

[11] BROWN, B. R.; LOHMANN, A.W.(1969). IBM J. Res. \& Dev. vol. 14, pp. 380

[12] LEE, W. H.(1974). Binary Synthetic Holograms. Applied Optics vol. 13, 1677-1682.

[13] SELDOWITZ, M. A.; ALLEBACH, J. P.; SWEENEY, D. W.(1987).Synthesis of digital holograms by direct binary search. Applied Optics, vol. 26, nº 14, pp. 2788-2797. 
[14] HAUCK, R.; BRYNGDAHL, O.(1984). Computer-Generated Holograms with PulseDensity Journal of Optical Society of America A1, 5-10.

[15] WYROWSKI, F.(1989). Iterative quantization of digital amplitude holograms. Applied Optics, vol. 28, nº18, pp.3864-3870.

[16] WYROWSKI, F.(1989). Diffractive optical elements: iterative calculation of quantized, blase phase structures. Journal of Optical Society of America A, vol.7, nº, pp.961-969.

[17] TURUNEN, J. ; WYROWSKI, F. (1997) - In : Diffractive Optics for Industrial and Commercial Applications (Akademie Verlag, Alemanha).

[18] Y. FU et al.Temporal wavelet analysis for deformation and velocity measurement in speckle interferometry. In: SPIE Optical Engineering Press, ISSN 0091-3286,1994.

[19] ARSENAULT H.; SHENG Y. An Introduction to Optics in Computers. In: SPIE Optical Engineering Press, ISBN 0-8194-0825-5, 1992.

[20] NETO; L. G. et al (2003). Design, fabrication and characterization of a full complexamplitude modulation difractive optical element. Journal of Microlithography Microsystems and Microfabrication, vol.2, n², pp. 96-104.

[21] PIZOLATO JUNIOR; J. C. Novas Técnicas de contraste de fase para a verificação de padrões cifrados, [Tese], Escola de Engenharia de São Carlos, Universidade de São Paulo, 2006.

[22] ICHIOKA, Y.; IZUMI, M.; SUZUKI, T.(1971). Scanning halftone plotter and computergenerated continuous-tone hologram. Applied Optics vol. 10(2), pp. 403.

[23] CAULFIELD, H. J.; MUELLER P. et al (1983). Continuous tone holograms by halftoning. In: PROCEEDINGS OF SPIE, vol. 437.

[24] PINHASI, Y.; PERI, D.(1993). “A generalized analysis of binary half-tone representation of images".Optics Communications, vol. 101(3-4), pp. 277-285. 
[25] PIZOLATO JUNIOR, J. C.; et al.(2007). Zeroth-order phase-contrast technique, Applied Optics, vol. 10. No prelo.

[26] MERZLYAKOV, N. S.; MOZEROV, M. G. (1998). “Computer-generated True-color Rainbow Holograms”.Optics and Lasers in Engineering, vol. 29, pp.369-376.

[27] SANDO, Y.; ITOH, M.; YATAGAI, T.(2004). “Color computer-generated hologram from projection images”. Optical Society of America, vol. 12(11), pp.2487-2493.

[28]GONÇALVES, C.; et al. White light computer-generated element based on halftoning. In: XXX Encontro Nacional de Física da Matéria Condensada, 2007, São Lourenço.

[29] GONÇALVES, C. et al. White light computer-generated element based on halftoning. In: OSA Topical meetings, 2007,Vancouver, Canadá.

[30] VELDKAMP, W. B.; MCHUGH, T. J. (1992).“Binary Optics”, Scientific American, maio, pp.92-97.

[31] Consulte artigos em “Applied Optics - Diffractive Optics”. vol. 34, n¹4.

[32]GOODMAN, J.W. Foundations of Scalar Diffraction Theory. In: "Introduction to Fourier Optics”. McGraw-Hill Publishing Company, 1988.

[33] HECHT, E. “Optics”, Addison-Wesley Publishing Company, Inc,1984.

[34] LI, M.; et al.(1996). “Optical Waveguide Fan out Elements Using Dislocated Gratings for Both Outcoupling and Phase Shifting”, IEEE Photonics Technology Letters, vol. 8, $\mathrm{n}^{\circ} 9$.

[35]VELDKAMP, W. B. "Wireless Focal Planes: On the Road to Amacronic Sensors", IEEE Journal of Quantum Electronics, vol.29, nº. 2, February 1993, p.801-813.

[36] AGRAWAL, G. P. “Fiber-Optics Comunication Systems”, John Wiley \& Sons, Inc, 1992, p.282.

[37] SHENG.,Y; ROBERGE, D., NETO,L.G; L. SHEN e PAUL-HUS G, “Programmable phasemostly holograms and correlation filters", Laser and Opt. Tech., vol. 28, nº.2, pp.129-143, 1996 
[38] SHENG.,Y et al. (1996). “Optoelectronic Devices and Systems for Processing”,A. Critical Reviews Series, SPIE Optical Engineering Press, pp.103-127.

[39] BULLA, D.A.P; et al. (2002)“Design and Fabrication of $\mathrm{SiO}_{2} / \mathrm{Si}_{3} \mathrm{~N}_{4}$ Integrated-Optics Waveguides with Application to Free-Space Optical Interconnects", IEEE Transactions on Microwave Theory and Techniques - Special Issue on Selected Papers of the International Microwave and Optoelectronics Conference - IMOC'99.

[40] VAN RENESSE, R.L. In: “Optical document security”, $2^{\text {nd }}$ Edition, Artech House Optoelectronics Library,1997.

[41] BRYNGDAHL, O.; WYROWSKI, F.(1990). Digital Holography - Computer-Generated Holograms. E. Wolf, Progress in Optics XXVIII, Elsevier Science Publishers B.V.

[42] ROBERTO, L. B. Algoritmos para o Cálculo de Hologramas Gerados por Computador. [Dissertação], Escola de Engenharia de São Carlos, Universidade de São Paulo, 2000.

[43] BORN, M.; WOLF, E. "Principles of Optis-Eletromagnetic Theory of Propagation Interference and Difraction of Light", Editora Pergamon, 1980.

[44] GONZALEZ, R. C ; WOODS, R. E. In:“Digital Image Processing”, $2^{\text {nd }}$ Edition, Prentice Hall, 2002.

[45] BRACEWELL, R. N. In: “The Fourier Transform \& Its Applications”, $3{ }^{\text {rd }}$ Edition, McGraw-Hill Science/Engineering/Math ,1999. 
Apêndice A

\section{A-Transformada de Fourier}

$$
F\{g\} \equiv \iint_{-\infty}^{\infty} g(x, y) \exp \left[-j 2 \pi\left(f_{x} x+f_{y} y\right)\right] d x d y
$$

Onde $f_{x}$ e $f_{y}$ são as freqüências relativas às coordenadas do plano xy.

\section{B-Equação de Helmholtz}

$$
A\left(\frac{\alpha}{\lambda}, \frac{\beta}{\lambda}, z\right) \equiv \int_{-\infty}^{\infty} U(x, y, z) \exp \left[-j 2 \pi\left(\frac{\alpha}{\lambda} x+\frac{\beta}{\lambda} y\right)\right] d x d y
$$

Onde A é o espectro angular de uma perturbação $U$, e $\alpha=\lambda f_{x} ; \beta=\lambda f_{y}$. 


\section{Apêndice B}

\section{Resposta impulsional, função transferência, e sistemas lineares invariantes}

Muitos fenômenos físicos apresentam uma resposta a vários estímulos como sendo identicamente iguais à soma de suas várias respostas contabilizadas individualmente. Quando isto ocorre, o sistema é chamado linear. Exemplos destes são redes elétricas compostas de resistores, capacitores e resistores, que são lineares para várias entradas. Analogamente, a equação de onda descrita pela propagação da luz ao longo de muitos meios permite a análise de operações de imagem como um mapeamento linear de distribuições luminosas de um objeto em distribuições luminosas de uma imagem.

Analisar a formação de imagens utilizando-se a propriedade de linearidade é uma vasta simplificação matemática, a qual recorre-se à teoria de sistemas lineares. A vantagem de se utilizar esta teoria é a habilidade de expressar a resposta (seja corrente, tensão, amplitude da luz ou intensidade luminosa) em termos de respostas a estímulos elementares. Quando um estímulo é decomposto em uma combinação linear de pequenos estímulos, cada um destes produz uma resposta, e a resposta total é calculada como a soma de todas as respostas aos estímulos elementares.

Se a iluminação utilizada em um sistema óptico apresenta coerência espacial local, a luz pode ser descrita como um campo de valores complexos de amplitude, e é interessante descrevêla como uma distribuição de valores reais de intensidade. Para sistemas lineares invariantes no tempo, como o caso de um sistema óptico com iluminação parcialmente coerente, a análise de 
60

Fourier é uma ferramenta útil para simplificar os cálculos de funções de saída do sistema, no caso, as imagens reproduzidas.

A transformada de Fourier de uma função $g(x, y)$ é representada por $F\{g\}$ e é definida por:

$$
F\{g\} \equiv \int_{-\infty}^{\infty} g(x, y) \exp \left[-j 2 \pi\left(f_{x} x+f_{y} y\right) d x d y\right]
$$

onde $\mathrm{g}(\mathrm{x}, \mathrm{y})$ é a função de entrada, $\mathrm{f}_{\mathrm{x}}$ e $\mathrm{f}_{\mathrm{y}}$ são freqüências no plano de coordenadas.

Da mesma forma, a transformada de Fourier inversa é definida por:

$$
F\{G\} \equiv \iint_{-\infty}^{\infty} G\left(f_{x}, f_{y}\right) \exp \left[j 2 \pi\left(f_{x} x+f_{y} y\right) d f_{x} d f_{y}\right]
$$

Considerando que a fonte luminosa esteja a uma distância considerável, de forma que seja vista como puntual, esta fonte pode ser representada por uma função delta de Dirac, definida por:

$$
\delta(x, y) \equiv \lim _{N \rightarrow \infty} N^{2} \exp \left[\left(-N^{2} \pi\left(x^{2}+y^{2}\right)\right)\right]
$$

onde $\mathrm{N}$ é um valor arbitrário. A transformada de Fourier para a função $\delta$ é então:

$$
F\{\delta(x, y)\} \equiv \lim _{N \rightarrow \infty}\left\{\exp \left[-\frac{\pi\left(f_{x}^{2}+f_{y}^{2}\right)}{N^{2}}\right]\right\} \equiv 1
$$

O espectro da função delta se estende ao longo do domínio das freqüências.

Segundo o teorema da convolução, sejam $F[g(x, y)] \equiv G\left(f_{x}, f_{y}\right)$ e $F[h(x, y)] \equiv H\left(f_{x}, f_{y}\right)$, tem-se:

$$
F\left\{\iint_{-\infty}^{\infty} g\left(x^{\prime}, y^{\prime}\right) h\left(x-x^{\prime}, y-y^{\prime}\right) d x^{\prime} d y^{\prime}\right\} \equiv G\left(f_{x}, f_{y}\right) H\left(f_{x}, f_{y}\right)
$$

onde x' e y' são coordenadas do plano xy.

Outra função de interesse em sistemas lineares invariantes, como um sistema óptico com iluminação parcialmente coerente, é a função transferência. No caso do holograma de Fresnel, sejam z a distância de um plano onde situa-se o holograma e o plano de reconstrução de sua 
imagem e $\lambda$ o comprimento de onda da fonte luminosa empregada no sistema óptico, a função transferência $H\left(f_{x}, f_{y}\right)$ é definida por:

$$
H\left(f_{x}, f_{y}\right)=\left\{\exp \left[j 2 \pi \frac{z}{\lambda} \sqrt{1-\left(\lambda f_{x}\right)^{2}-\left(\lambda f_{y}\right)^{2}}\right], \text { para } \sqrt{f_{x}{ }^{2}+f_{y}^{2}}<\frac{1}{\lambda}\right.
$$

O espectro de uma função de saída de um sistema, $G_{2}\left(f_{x}, f_{y}\right)$ está relacionado com o espectro de entrada $G_{1}\left(f_{x}, f_{y}\right)$ pela função transferência, de tal forma que:

$$
G_{2}\left(f_{x}, f_{y}\right) \equiv H\left(f_{x}, f_{y}\right) G_{1}\left(f_{x}, f_{y}\right)
$$

Para calcular a imagem de reconstrução, calcula-se a função transferência do sistema e, posteriormente, faz-se uma operação de convolução com a imagem de interesse, a fim de se obter a sua reconstrução. 
62

\section{Apêndice C}

\section{Amostragem no plano de freqüências}

O processo de holografia, tanto analógico como digital, envolve invariavelmente a criação de um campo complexo no plano do holograma, um campo que deve ser regenerado com o processo de reconstrução da frente de onda. Para hologramas gerados por computador, este campo é calculado utilizando um computador, e deve ser amostrados e os valores complexos são computados em cada ponto de amostra. Para saber quantas amostras do campo devem ser computadas, deve-se considerar que o objetivo é criar um campo do holograma que seja a transformada de Fourier do campo do objeto que deseja-se reproduzir. Considerando o caso do holograma de Fresnel, a relação entre a largura de banda do campo do holograma e o tamanho do objeto pode ser aproximada por uma função. Um objeto no caso é visto como uma função $U_{0}(x, y) \exp \left[j \frac{\pi}{\lambda z}\left(x^{2}+y^{2}\right)\right]$, onde $\mathrm{U}_{0}$ é a amplitude da intensidade luminosa, $\mathrm{x}$ e y são coordenadas espaciais, $\lambda$ é o comprimento de onda da iluminação e z é a distância entre o plano do holograma e o plano de reconstrução, como visto na Figura A1. A presença de uma distribuição de fase ao longo do objeto não afeta a distribuição de intensidade, que é a quantidade que deseja-se recriar através do campo do holograma. As larguras de banda do holograma podem ser obtidas, de acordo com Goodman[32] como :

$$
2 B_{x}=\frac{L_{x^{\prime}}+L_{x}}{\lambda z}
$$




$$
2 B_{y}=\frac{L_{y^{\prime}}+L_{y}}{\lambda z}
$$

onde $L_{x^{\prime}}, L_{x}, L_{y^{\prime}}, L_{y}$ são freqüências espaciais locais e $\mathrm{B}_{\mathrm{x}} \mathrm{e} \mathrm{B}_{\mathrm{y}}$ são as larguras de banda nas direções dos eixos $\mathrm{x}$ e y respectivamente.

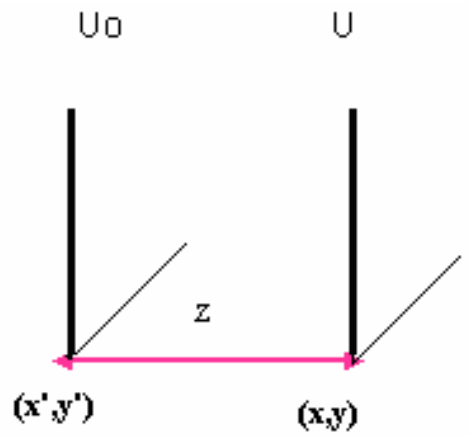

FIGURA A1-Ilustração do holograma de Fresnel; $(x, y)$ são as coordenadas do plano do holograma e $\left(x^{\prime}, y^{\prime}\right)$ as coordenadas do plano de reconstrução.

A largura de banda depende da extensão do campo de um objeto e do campo do holograma. Os intervalos de amostragem nos eixos x e y neste caso são definidos como:

$$
\begin{gathered}
\Delta x=\frac{\lambda z}{L_{x^{\prime}}+L_{x}} \\
\Delta y=\frac{\lambda z}{L_{y^{\prime}}+L_{y}}
\end{gathered}
$$

Sendo assim, o número total de amostras em x e y, necessárias para reconstruir o objeto através do holograma é:

$$
N_{x}=\frac{L_{x}}{\Delta_{x}}
$$


64

$$
N_{y}=\frac{L_{y}}{\Delta_{y}}
$$

De acordo com as equações 1 a 6 , observa-se que para cada comprimento de onda há um determinado número de amostras requeridas e um intervalo de amostragem. Todas as contribuições provenientes da luz branca, ou seja, vários comprimentos de onda são somados a fim de se obter a imagem de reconstrução resultante, segundo o princípio da superposição. Estes valores podem ser alterados conforme o comprimento de onda da iluminação utilizada. Considerando que neste trabalho foi utilizada luz branca, cujo comprimento de onda médio $\bar{\lambda}$ é da ordem de $633 \mathrm{~nm}$, a soma de várias contribuições relativas a vários comprimentos de onda vai gerar a imagem de reconstrução. 


\section{Anexo A}

XXX Encontro Nacional de Física da Matéria Condensada / ID: 1185-1

White light computer-generated element based on haftoning

Cristhiane Gonçalves, José Carlos Pizolato Júnio, Luiz Gonçalves Neto

Universidade de São Paulo

Giuseppe Antônio Cirino

Grupo Holovision

White light holograms are used in several applications, such as security, to assure the authenticity of credit cards and other documents. These holograms usually uses the reflection of light and in some cases presents a undesirable effects like chromatic distortions called as Rajnbow effect. They are produced using traditional holography techniques. Holograms or can be also generated by computer, like the CGHs (Computer generated holograms). There are many algorithms which are regularly used to generate holograms, like the IFTA (Iterative Fourier Transform Algorithm), introduced in digital holography digital by Gerchberg\& Saxton. This work presents a method to generate white light phase elements using half toning techniques and binary optics. Some advantages are the low cost production and low chromatic aberration. No iterative algorithms are used for the calculation of the element. The phase devices were manufactured by employing well-established, low-cost integrated circuits fabrication steps. Optical verifications of the intensity distribution retrieved from the phase information encoded are shown. 
Anexo B 